



\section{Northern Lights on PISA 2006}

Differences and similarities in the Nordic countries

Tomas Matti (Eds.) 


\section{Northern Lights on PISA 2006}

Differences and similarities in the Nordic countries

TemaNord 2009:547

(C) Nordic Council of Ministers, Copenhagen 2009

ISBN 978-92-893-1881-5

Print: Scanprint as

Cover: Jette Koefoed, Publication Unit

Layout: Publication Unit

Copies: 2,000

Printed on environmentally friendly paper

This publication can be ordered on www.norden.org/order. Other Nordic publications are available at www.norden.org/publications

Printed in Denmark

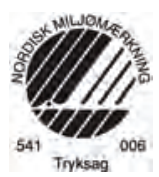

Nordic Council of Ministers

Store Strandstræde 18

DK-1255 Copenhagen K

Phone (+45) 33960200

Fax (+45) 33960202

\section{Nordic Council}

Store Strandstræde 18

DK-1255 Copenhagen K

Phone (+45) 33960400

Fax (+45) 33111870

www.norden.org

\section{Nordic co-operation}

Northern Lights on PISA 2006Nordic cooperation is one of the world's most extensive forms of regional collaboration, involving Denmark, Finland, Iceland, Norway, Sweden, and three autonomous areas: the Faroe Islands, Greenland, and Åland.

Nordic cooperation has firm traditions in politics, the economy, and culture. It plays an important role in European and international collaboration, and aims at creating a strong Nordic community in a strong Europe.

Nordic cooperation seeks to safeguard Nordic and regional interests and principles in the global community. Common Nordic values help the region solidify its position as one of the world's most innovative and competitive. 


\section{Content}

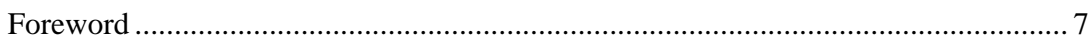

1. The Nordic countries

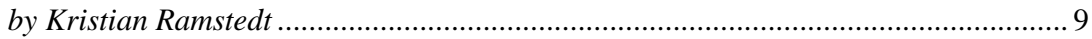

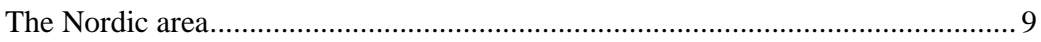

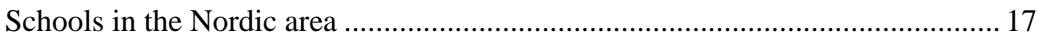

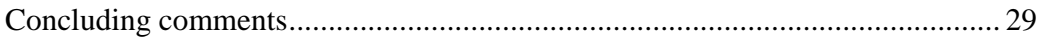

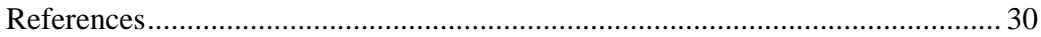

2.1 Science education, the science curriculum and PISA 2006

by Jari Lavonen, Svein Lie, Allyson Macdonald, Magnus Oscarsson,

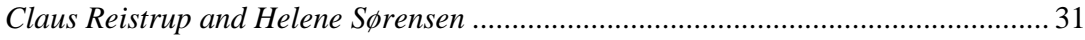

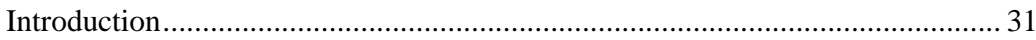

The education system in Nordic countries ........................................................ 33

Goals and content of science described in national level science curricula........... 42

Assessment in science education in Nordic countries ........................................... 49

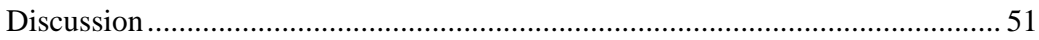

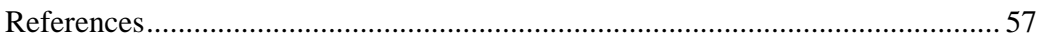

2.2 What do principals and students say about schooling and science education?

- Comparing views in Nordic countries

by Jarkko Hautamäki, Jorma Kuusela \& Sirkku Kupiainen ...................................... 59

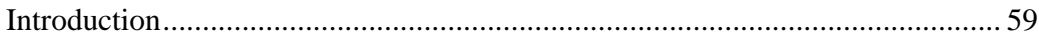

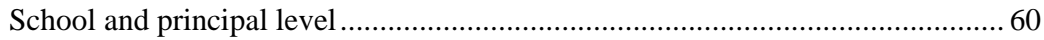

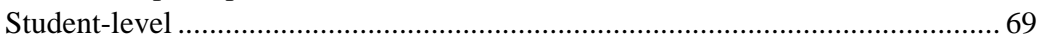

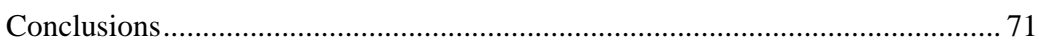

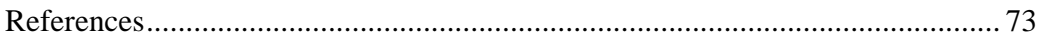

3.1 Science Performance: The Nordic Countries from an International Perspective

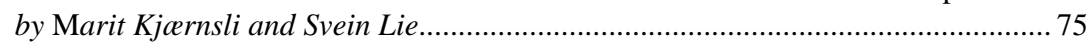

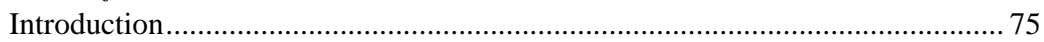

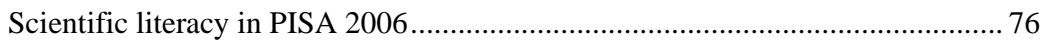

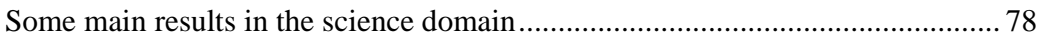

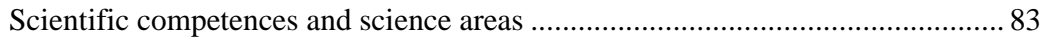

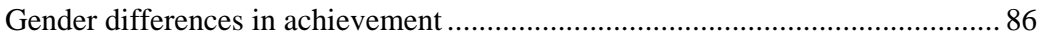

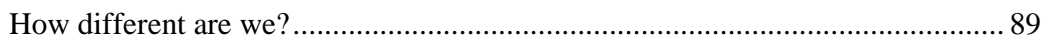

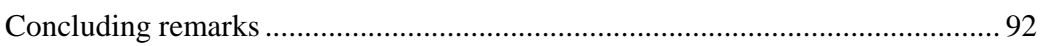

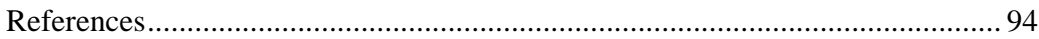


3.2 Are Icelandic boys really better on computerised tests?

by Almar M. Halldórsson, Pippa McKelvie and Júlíus K. Björnsson......................... 97

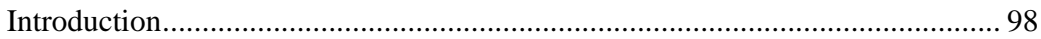

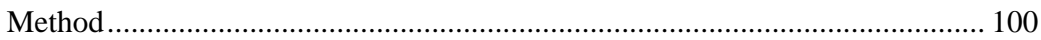

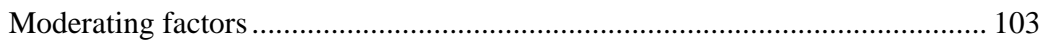

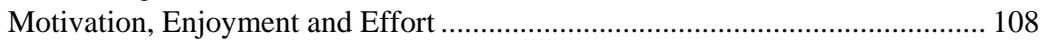

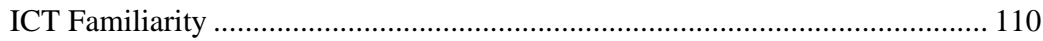

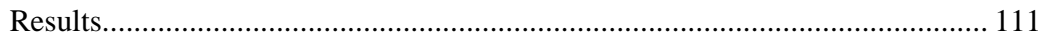



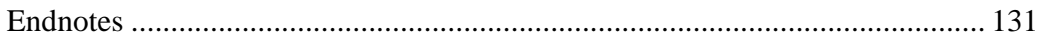

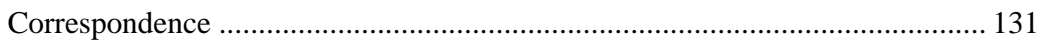

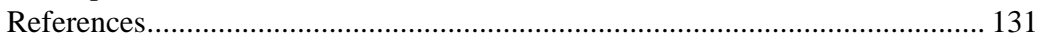

3.3. Norwegian and Swedish students' reading engagement in 2000 and

2006 from a gender perspective

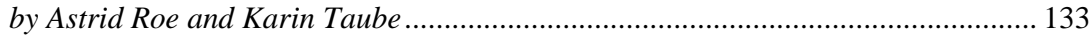

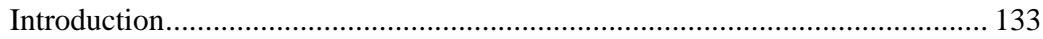

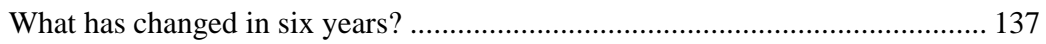

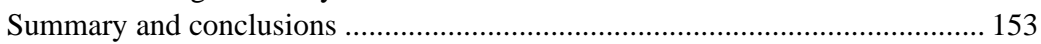

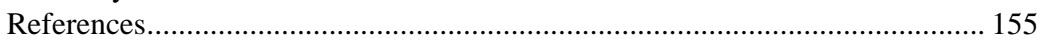

4.1. Educational Equity Account in Nordic Countries

by Jarkko Hautamäki, Airi Hautamäki \& Sirkku Kupiainen .................................... 157

The Educational Equity Account ................................................................... 157

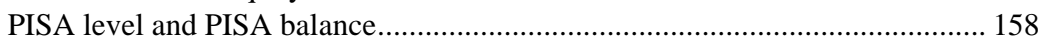

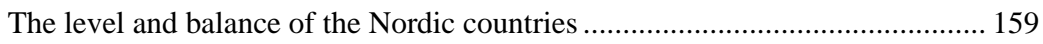

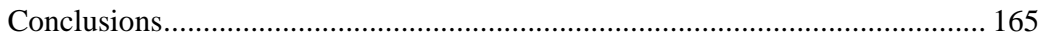



4.2. The influence from individual social background and school social background in the Nordic countries

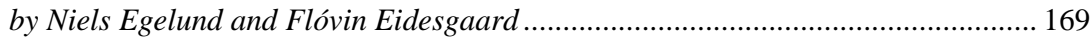



Method and material ................................................................................... 170

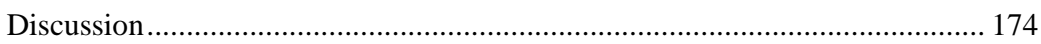

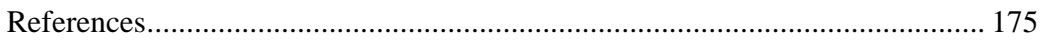

4.3. Reading and Socio-Economic Factors: A cross-sectional Nordic study

of the 2000, 2003 and 2006 PISA-results

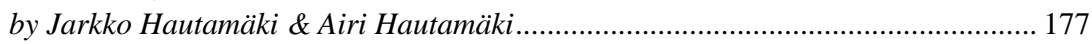

Reading and socio-economic factors............................................................ 177

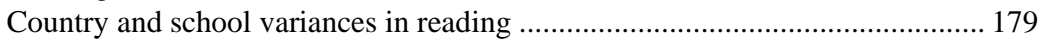

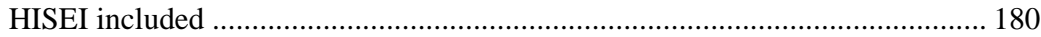

Reading and HISEI by countries in 2000, 2003 and 2006 .............................. 181

HISEI-coefficients as a summative index ...................................................... 183

HISEI coefficients by PISA cycles and by countries ......................................... 184

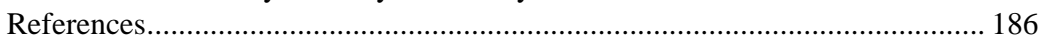

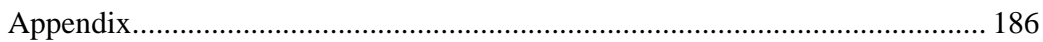

5. Summary and comments

by Tomas Matti, Kerstin Mattsson, Kristian Ramstedt \& Anita Wester .................... 187 


\section{Foreword}

This publication is the third edition of Northern Lights on PISA. The first editions were based on PISA 2000 and PISA 2003 whilst the current edition is based on PISA 2006. As with former editions, this one has received financial support from the Nordic Council of Ministers.

The structure of the publication has been developed by a working group with representatives, appointed by the ministries from the Nordic countries including the Faroe Islands: Claus Reistrup, Grethe Hovland, Jarkko Hautamäki, Jorma Kuusela, Júliús Björnsson, K-G Karlsson, Niels Egelund, Marit Kjærnsli, Astrid Roe, Anita Wester and Kerstin Mattsson. At a later stage Charlotte Rotböll and Magnus Oscarsson joined the working group.

Attached to the working group there have been two other persons from the Swedish National Agency for Education. Tomas Matti has been the editor of the report. Kristian Ramstedt, has also played an active role during the production process. Together with Anita Wester, these two have taken ultimate responsibility for making the publication ready for printing. Even though these three persons have been very important and deserve special acknowledgement, the whole working group has been of invaluable help in reading and discussing the various drafts. Finally as the chair of the working group, I would particularly like to thank all those who have contributed articles for the publication, and Brian Turner who has translated one article and transformed the text as a whole into comprehensible English.

Stockholm in May 2009

Kerstin Mattsson 



\section{The Nordic countries}

Kristian Ramstedt

\section{The Nordic area}

The Nordic countries are located in the north-western corner of Europe and consist of Denmark, Finland, Iceland, Norway and Sweden. The Nordic area also includes the autonomous areas of the Faroe Islands and Greenland under Denmark, and also Åland which belongs to Finland but has some degree of autonomy. However, in this publication the last mentioned areas will not be specifically treated except for the Faroe Islands.

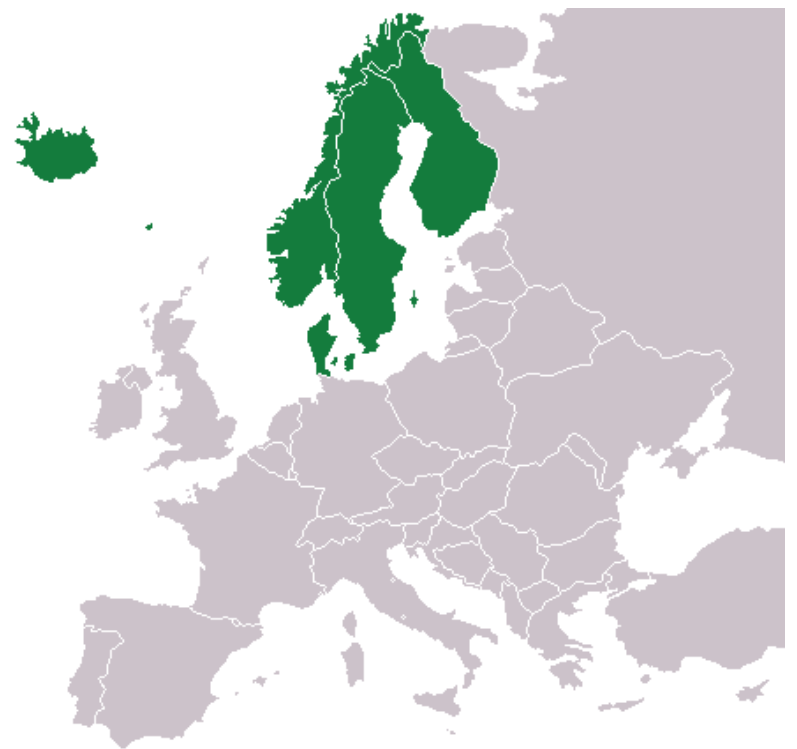


The Nordic countries have much in common, but at the same there are also some substantial differences. This chapter provides an overall picture of the Nordic countries, their historical development, their most important industries, some special features of the organisation and development of their school systems, as well as a summary of the results from the three Pisa studies carried out so far.

Some data

Table 1.1. Some comparative data for the Nordic countries

\begin{tabular}{|c|c|c|c|c|c|c|}
\hline Category & Denmark. & Finland & $\begin{array}{r}\text { Faroe } \\
\text { Islands }\end{array}$ & Iceland & Norway & Sweden \\
\hline Area (km2) & 43561 & 338419 & 1399 & 103300 & 323782 & 450295 \\
\hline Population & 5475791 & 5300484 & 48778 & 313376 & 4737171 & 9182927 \\
\hline \multicolumn{7}{|l|}{$\begin{array}{l}\text { Average life } \\
\text { expectancy (2007) }\end{array}$} \\
\hline Men & 76.0 & 75.8 & 76,6 & 79.4 & 78.2 & 78.9 \\
\hline Women & 80.5 & 82.9 & 82,0 & 82.9 & 82.7 & 83 \\
\hline $\begin{array}{l}\text { Asylum applications } \\
\text { (2007) }\end{array}$ & 1028 & 1512 & 0 & 42 & 6258 & 36207 \\
\hline Access to PC 2006 & & & & & & \\
\hline$(\%)$ & 85 & 74 & N/A & 89 & N/A & 82 \\
\hline Internet (\%) & 78 & 69 & N/A & 84 & 78 & 79 \\
\hline $\begin{array}{l}\text { Children }(5 \mathrm{yrs}) \\
\text { in care }(\%)\end{array}$ & 95,6 & 76.1 & 70 & 91.3 & 94.9 & 100.0 \\
\hline \multicolumn{7}{|l|}{$\begin{array}{l}\text { Parental allowance } \\
(2007)\end{array}$} \\
\hline Used by men (\%) & 6.2 & 6.1 & 30,1 & 32.6 & 11.4 & 21.2 \\
\hline
\end{tabular}

Nordic Council of Ministers (2008). Nordic area in figures 2008

Claus Reistrup for the Faroe Islands

Table 1.1 shows that Sweden is 10 times larger in terms of area than Denmark, the Nordic area's second largest country in terms of population. Norway and Finland have approximately just as large a population and land areas, whilst Iceland with the smallest population is twice as large as Denmark when it comes to area.

Statistics from the Nordic Council reveal a number of other interesting aspects. That women live longer than men is a well known fact. But in 
Iceland men live the longest and almost as long as the average Danish woman. The Danish lifestyle appears to lead to somewhat shorter life expectancy than in the rest of the Nordic area, with the exception of Finnish males. However, if we look at the Second European Quality of Life Survey (Eurofond), it can be seen that the Nordic countries lead the field in the EU and EEA as measured by the life satisfaction and happiness index, and at the very top we have Denmark despite its shorter life expectancy. In other words the Nordic people appear to be the most satisfied and happy in Europe.

The Faroe Islands demographically differ from the rest of the Nordic area by having a surplus of males.

Table 1 shows some other relationships. For example, in 2007 Sweden took in more than 36,000 asylum applicants, a figure four times as large as for the rest of the Nordic area put together. It can also be seen that access to personal computers is high, and that close to 80 percent of households have access to the Internet.

A large majority of five year-olds in the Nordic area have access to childcare. In all the Nordic countries, parents receive allowances during pregnancy, childbirth and adoption. Of the fathers, it is mainly those from Iceland and the Faroe Islands who appear to make use of this opportunity: One third of all parental allowance days are used by men. Sweden ranks third, where one in every five parent days are used by men, in Norway the figure is one in every nine, whilst Danish and Finnish fathers do not appear to be particularly interested in using their parental allowance, since only one in every 16 fathers do so.

The overall picture of the Nordic countries is that their populations live under good conditions and they are satisfied with their position at least that is what they stated in 2007. Since then the Nordic area just like other parts of the world has been affected by changing conditions on the global financial market, the labour market, the housing market etc, and today the picture might perhaps not be as positive.

\section{Historical development}

The Nordic area has been regarded as an area with common roots for more than a 1,000 years. An important unifying factor is language. The Danes, Swedes and Norwegians understand each other's languages, al- 
though sometimes only with difficulty. Icelandic and Faroese belong to the same language family, but today can hardly be understood by other Nordic inhabitants. In Finland a shrinking minority (6\%) of the population have Swedish as their mother tongue. Finnish and Sami are two Nordic languages that are not understood by other people in the Nordic area as they belong to other language families. Apart from these old languages, there are a whole range of other languages spoken by recently arriving immigrants.

Today there is a large measure of unity and co-operation between the Nordic countries. However, this has not always been the case. Over many centuries, relationships particularly between Denmark and Sweden have been disturbed by recurring wars. During certain periods, the countries have also entered into different unions. Between 1397 and 1523 Denmark, Sweden and Norway were members of the Kalmar Union. After its dissolution, the Union between Denmark and Norway continued until 1814. At the time of the Kalmar Union, Sweden consisted of what is Sweden today except for the southern and south western area which was a part of Denmark. Finnish coastal settlements were for a long time colonised by the Swedes, and in 1249 Finland was a part of Sweden. And until 1809 Finland was an integral part of Sweden.

After the break-up of the Kalmar Union there were a number of wars between Sweden and Denmark/Norway. During the 17th century Sweden as a result of its successes in Thirty Years' War developed into a major military power in Northern Europe and dominated the Baltic Sea area. Denmark was defeated on a number of occasions, and after subsequent peace agreements, Sweden finally came to consist of those parts that make up Sweden today, with Denmark losing the south and south-west areas. Denmark's, Union partner, Norway, lost a part of its former territory to Sweden before the Nordic wars ceased.

Sweden also subsequently lost land areas around the Baltic Sea it had taken over at the height of its powers with the loss of Finland in 1809 as the culminating point. Sweden's current borders were established at that time.

The Union between Denmark and Norway was dissolved in 1814 as Norway had more or less reluctantly entered into a union with Sweden. The union lasted until 1905, and since then Norway has been an independent nation. 
Iceland and the Faroe Islands became a part of Denmark in connection with the Kalmar Union until 1944 when Iceland became an independent nation for the first time in more than 650 years. The Faroe Islands as a part of Norway became a part of the Kalmar Union and remained principally a part of Norway until 1814 when the Faroe Islands together with Iceland and Greenland became a part of the Kingdom of Denmark.

As a result of the break-up of the different unions, Denmark's sphere of power decreased and today only the Faroe Islands and Greenland remain as autonomous parts.

Sweden participated, hopefully for the last time, in a war 200 years ago, the 1808-1809 war with Russia. Sweden was defeated and lost the eastern part of her kingdom, namely Finland. In 1809 Finland became a Grand Duchy with a relatively large degree of autonomy under the Russian Empire. Even though Finland came under the Russian Empire, it was from this position as a part of the Russian Empire that the foundations of Finland as a nation were established.

However, full independence was not obtained until December 1917. After the Bolsheviks seized power in the Russian Revolution, the Finnish Senate and Diet issued a Declaration of Independence, which was accepted by Lenin on 31/12 1917. As a result Finland became for the first time in her history a fully independent nation. The newly gained freedom, however, was not a happy time. Soon after independence, civil war broke out between red and white sympathisers. The war was short but traumatic, and left scars that would take many decades to heal. After its liberation from Russia, Finland became, just like Iceland later on, a republic with a president as head of state, whilst the other Nordic countries retained their monarchies.

As mentioned Sweden has succeeded in living in peace for the last 200 years. The other Nordic countries have not been equally successful. Denmark and Norway were occupied by German troops in April 1940. In November 1939 Finland had been attacked by the Soviet Union which led to the Winter War. Finland lost the war and was forced to concede territory in the north and east. A year later this war was followed by the Continuation War where Finland assisted the German side in an attempt to regain lost territory. This war was also lost. In addition to heavy losses and many wounded, towns bombed and destroyed, Finland was also forced to pay substantial war reparations to the Soviet Union. However, 
she was able to retain her status as an independent nation in contrast to many other countries neighbouring the Soviet Union, which were either annexed into the Soviet Union or ended up behind the Iron Curtain.

Initially Iceland declared her neutrality, but after the German invasion of Denmark and Norway, Iceland was invaded by the United Kingdom in May 1940, and for the rest of the war was on the Allied side. This laid the foundations for Iceland's independence in 1944. The Faroe Islands were also occupied during the Second World War by the British, and this reinforced nationalist sentiments, and after a referendum and election, the Faroe Islands gained far-reaching autonomy in 1948.

The idea of a Nordic area grew strongly during the war years. Swedish, Danish and Norwegian volunteers participated on the side of Finland in the Winter War, and during the occupation of Denmark and Norway, Sweden was a free zone for all the resistance movements. Many Finnish refugee children also came to Sweden.

The Nordic Council, which is a cooperative body for the Nordic Parliaments, was formed in 1952 (Finland joined in 1955) for the purpose of providing a platform for joint discussions between parliamentarians and government members of the five Nordic countries and the three autonomous areas.

A common Nordic labour market was created in 1954 and this was subsequently followed by the Nordic Passport Union which meant that passports were no longer needed when travelling between the Nordic countries. In 1971 the Nordic Council of Ministers was formed as a cooperating body for the governments of the Nordic countries. Today there is close cooperation between the Nordic countries, and a highly developed feeling of community amongst the inhabitants of the different countries. This is evident in voting during the Eurovision Song Contest.

\section{Nature and industry}

Nature in the Nordic area is highly diversified; from fertile Danish fields to Swedish and Finnish forests, Norwegian mountain areas and fjords, via grass-covered and windswept mountains in the Faroes to the desolate lava plains of Iceland. Differences in natural conditions have provided the foundation for industrial development, even though development has evolved very differently from what nature originally endowed them with. 
From having been during the 19th century a virtually under developed corner of Europe where most people were working in agriculture, the Nordic countries have undergone rapid development into modern democracies and welfare states with all that this entails, in terms of high taxes and a large public sector for healthcare, schooling and care of the elderly. Today only a very small percentage of the population works in agriculture. The proportion employed in industry is decreasing, and productivity is increasing. It is primarily services of different kinds that are growing. Denmark, Finland and Sweden are currently members of the EU, whilst Iceland and Norway are part of the EEA. .

Denmark, in particular, has been dominated over a long period by agriculture and agricultural products, but has subsequently developed diversified industry covering a wide range of areas such as production of beer, international maritime transport, and the manufacture of wind power stations. Gas and oil deposits in the North Sea have also contributed to prosperity. And naturally agriculture still plays an important role.

Nature in Sweden is more varied than in Denmark. In Sweden agriculture has also been important, particularly in the southern parts, but forests and iron ore have also been important resources. This has led to the forestry industry and paper production becoming important industries. Processing of iron ore and other minerals has a long tradition, and over time has led to a substantial engineering industry with i.a. manufacturing of cars and lorries. In areas such as pharmacology and telephony, Swedish companies have established leading positions on a global scale.

In Finland dependence on forestry has been still greater, even though different kinds of industries have also developed there. Strangest of all perhaps is the development of a more or less anonymous forest and rubber company over a period of three decades as a result of an early farsighted investment in mobile telephones. Today Nokia is the world leader in this area.

In Norway, the long coastline has left its imprint, so that fishing and shipping have been dominant industries, whilst forestry and minerals have also provided important resources. Over the last 30 years the feasibility of extracting oil and gas from the seabed have provided a funda- 
mental economic stimulus which has taken Norway to one of the top positions in the world as measured by per capita GDP. ${ }^{2}$

In Iceland, with its closeness to the sea, whaling and fishing have been an important means of support. Whaling has now ceased but fishing is still important, and this applies even more to the Faroe Islands. Iceland in contrast to the other Nordic countries has access to few natural resources, apart from hydropower and geothermal electricity production. Access to electricity has been the foundation for substantial industrial development where cheap electricity is essential, as in the production of aluminium. Compared with other parts of the Nordic area, Iceland underwent industrialisation late, but in recent years has developed an important financial sector. This sector, however, has been severely affected by the financial turbulence that swept across the world in autumn 2008 with far-reaching effects on the country's economic position. However at the time when PISA was carried out at, all the indicators were at the very top.

Over 150 years the Nordic countries have undergone a transformation from being poor, undeveloped societies based on agriculture, fishing, shipping and exports of raw materials into highly industrialised countries, dependent on exports with high value-added for their prosperity. Possibly with some exceptions for Norway, which is largely dependent on exports of oil and gas, these are finite resources which over the next few decades must be replaced by other sources of income. For Iceland, this is a question of how the country can rebuild its financial centre, or find new niches and industries to develop.

Irrespective of the solution, it can be stated that in all Nordic countries human capital in the form of a well educated labour force plays a crucial role in maintaining and developing Nordic prosperity. Today education is regarded as one of the most important factors in a country's economic development. This is the reason that an organisation such as the OECD is interested in the quality of education systems in different countries, and has initiated PISA as an indicator of this quality.

Despite their similarities and differences, there are good reasons to try to examine how the results of different Nordic countries vary, and if these 
variations can be explained by differences in attitudes, teaching and school organisation or if there are other factors of importance in determining educational outcomes.

For instance, why do Finnish pupils perform so well compared to Nordic pupils? Is this purely dependent on teaching being such a popular profession in Finland, or are there other explanations as well? How important are reading skills, and interest in reading? What is the importance of the changing media society which we see in an increasingly digitalised world, and what is its impact on results? Do the instruments we currently have at our disposal assess today's knowledge and skill requirements, or do they need to be redesigned to assess both pupils' and society's current and future need for knowledge? These are examples of the questions being raised and which this anthology is partly at least trying to address.

For the Nordic countries with important sectors in mechanical engineering, paper, chemistry, pharmacology, electrical engineering, telephony etc., mathematics and the natural sciences are, of course, important basic knowledge for education in the technical competence industry needs, which does not exclude the crucial importance of good reading skills. In the two previous anthologies, the focus was on reading comprehension (2000) and mathematics (2003). In this publication, the ambition is to look more closely at results in scientific subjects and use these as a basis for different analyses.

But before we leave this broad view of Nordic background, let us have a brief look at the school systems.

\section{Schools in the Nordic area}

As in many other respects, there are major similarities between the school systems in the Nordic countries, but there are also some significant differences.

In this section we provide an overall description of some similarities and differences between the education systems of the Nordic countries for younger pupils. 


\section{Organisation and development}

Seven year compulsory school was introduced in Denmark in 1814 and a system of municipal education authorities was built up. Over a long period there have been different regulatory systems for rural municipalities and towns which underwent changes at different times. In 1971 the school was extended into a public nine-year elementary school. (Eurydice, Denmark). Denmark and the Faroe Islands have like Finland compulsory learning whilst Iceland, Norway and Sweden have compulsory schooling. Compulsory schooling means that a pupil is obliged to attend school. Compulsory learning, however, means that the municipality is obliged to ensure that pupils acquire the knowledge laid down in the curriculum, but this can be achieved in a variety of ways such as parents teaching their children.

In Sweden compulsory schooling was introduced in 1842 whilst in Finland legislation on compulsory learning was established in 1921 (Geber, 2003). In practice, this does not necessarily mean very much since elementary schools (folkskolor) already existed on a broad scale, the laws were merely a recognition of what already existed in practice. In Sweden the school system was also more or less already developed before 1842, particularly in the towns (Ödman, 2006).

Compulsory schooling in Sweden since 1972 means that schooling is obligatory for all children between the ages of 7 and 16, even though the nine-year compulsory school itself had already been introduced in 1962.

In Norway a compulsory seven year elementary school was introduced in 1889, significantly later than in Denmark. In 1969 it became a nine year school, and in 1997 a 10 year school with pupils starting in grade 1 at the age of six. Iceland introduced in 1880 a system where parents were responsible for their children learning to read, write and count, and also to receive instruction in Christianity. The state church exercised supervisory responsibility. In Iceland it was more a question of compulsory learning than compulsory schooling. In 1907 compulsory schooling was introduced for children aged between 10 and 14, but children were expected to have already learned to read and write before starting school. In 1937 compulsory seven year elementary school was introduced, and in 1974 the nine year compulsory school (Eurydice, Iceland). The Faroe Islands have had seven year compulsory learning since 1912, which was extended to nine years in 1998. 
The extent to which school systems are decentralised varies between the Nordic countries. By tradition Denmark has a highly decentralised system, but has moved towards greater centralisation. The same applies to Iceland. Norway, on the other hand, has always had a centrally steered school system with a large measure of state control. The same can also be said about both the Swedish and Finnish school systems. In Sweden, as well as in Finland, however, during the last 20 years there has been significant decentralisation, and today the municipalities are responsible for the schools and for employing and paying teachers' salaries, providing teaching and other materials etc. According to the OECD, Sweden has transformed itself from one of the most centralised school systems into one of the most decentralised (OECD, 1998). In the Faroe Islands, teachers' salaries are paid centrally, whilst other costs e.g. premises and teaching materials are paid out by 34 separate municipalities. Sweden has the same conditions, and today there is no central control over teaching materials, as selection of material is a local responsibility.

Denmark for some time has had a relatively large proportion of independent schools in relation to the other Nordic countries, even though they have not been particularly common in Denmark. Since the beginning of the 1990s, the regulatory system in Sweden has been changed, and the proportion of independent schools has increased rapidly, particularly in larger towns. The table below shows the proportion of pupils in compulsory school, who in the early 2000s attended independent schools in the Nordic countries.

Table 1.2. Proportion of pupils attending independent compulsory schools

\begin{tabular}{lcccccc}
\hline Country & Denmark & Finland & $\begin{array}{c}\text { Faroe } \\
\text { Islands }\end{array}$ & Iceland & Norway & Sweden \\
\hline $\begin{array}{l}\text { Proportion of } \\
\text { pupils (\%) }\end{array}$ & 12 & 2 & 2 & 1 & 2 & 9 \\
\hline
\end{tabular}

(Eurydice)

Independent schools in the Nordic area are mainly financed from public funds (grant-aided) and not by fees as in many other countries. Sweden, however, deviates from other countries as independent schools can be run along commercial lines. In the other countries the non-profit principle applies, i.e. any surplus is reinvested in the school. 
Another change in Finland and Sweden is that municipalities no longer decide which school pupils should attend, although they usually attend the closest, but parents do have the right to request a place in a school they choose. If there is a lack of places, children in the immediate surrounding area receive priority. In both countries choosing schools other than the closest is more common in bigger municipalities.

In the Faroe Islands, it is only in the largest municipality of Torshavn that personal choice can to some extent be exercised.

In Norway, it is the municipalities that decide how to regulate choices of different schools.

According to Lysne (2006) the Nordic countries have throughout their history taken parallel development paths. The countries are linked to each other through historical connections and close cultural and social relations. Strong social democratic and liberal movements laid the foundations relatively early on for the welfare state which today is regarded as more or less self-evident, not only in the Nordic area but also in Europe and many other countries. The compensatory role of the school in evening out social differences and giving all children the opportunity to study was also an important element in this policy of increasing equality and equivalence, even though experiences subsequently demonstrated that the mere provision of equivalent opportunities for school is in itself not sufficient to reduce the importance of social heritage.

As mentioned the transition to nine year compulsory schooling took place during the 1960s and 70s in all the Nordic countries, and Sweden was in this respect a pioneer. According to Lysne, the general pattern is that Sweden was 5 to 10 years ahead of the other Nordic countries in its adoption of reforms. He believes the school reforms reflect not only changes in political ideals regarding the organisation and societal function of the school, but also different pedagogical ideas and approaches on the content of teaching, how it is carried out, and its aims. However, during the 20th century the ideal has varied. Progressive ideals inspired by Dewey from the 1930s have been replaced by more behavioural views mainly during the 60s, which in their turn have once again given way to more progressive ideals during the 1980s and 1990s. The trend today is a movement back towards more measurement and checking of pupil performance and accountability of those who at different levels are responsible for pupils' education. The role of the school in developing the indi- 
vidual and of society in imparting values, general all-round education and knowledge is less emphasised, whilst education as an economic factor of production is being given increasingly greater prominence.

\section{Examinations and national tests}

In many respects developments in the Nordic area have been parallel albeit not simultaneous. However, there are some areas where development has not been the same, one such area being examinations, and another grades.

As regards grading when finishing compulsory schooling, in both Sweden and Finland this is completely based on teachers' assessments. No formal exams are set and there are no examinations. Although in Sweden there are compulsory national tests in four subjects, Swedish, Swedish as a second language, English and mathematics, these tests are only for support purposes and just one of a number of different sources and tools teachers can use to assist them in determining grades. In addition, tests have been introduced this spring 2009 in biology, physics and chemistry, and it is possible that the right of teachers to award grades will be restricted when new syllabuses are introduced in a couple of years, but currently no decision has been taken on any change in the role of the national tests. National tests have also been used since 2009 in the third year, and since the middle of the 1990s in the fifth year.

In Finland there are no national tests in the compulsory school, and evaluations are only carried out on a random basis in different subjects.

The "realskola" (lower secondary school) which can be said to correspond to the compulsory school level and which were replaced by the introduction of the compulsory school in Sweden and Finland, had exams and tests, but these were not retained in the transition to the compulsory school. In the other Nordic countries on the other hand, the examination system was retained in the compulsory school. This means that centrally designed tests are carried out in a varying number of subjects, and these determine pupils' grades in the subjects. Apart from examinations, in Denmark, Norway and the Faroe Islands there are also national tests. However, these are not used to provide support for awarding grades, but serve more as instruments for follow-up and evaluation at different levels, national, municipal, school level, as well as teacher and pupil levels. As 
in the Swedish national tests, the results are collected and published on the Internet so that municipalities and schools are able to use the results for quality reporting and improvement measures, and parents and other stakeholders can have access to the results, e.g. when choosing a school for their children.

In Finland today, no results of this kind are published on the Internet. The same applies to the Faroe Islands where schools are individually informed of their test results.

In general, it can be said that greater use of tests, accountability, publication of results, methods of measuring value-added, and the use of different types of quantitative indicators for assessing results are currently growing in the Nordic countries, the sole exception to this being Finland.

\section{Grades}

Another area where differences exist between the Nordic countries is the grading scale and the basis on which grades are assessed.

In the Nordic context, Finland can be said to be unique as the same grading scale has been used there for so long that no one remembers when it was actually introduced. A question to the Education Board, elicited the response that the grading scale in any case was older than Finland as an independent nation, since it was introduced during the time Finland was a Russian Grand Principality. The Finnish grading scale is a numerical scale between 4 and 10, where 10 is the highest grade and 5 is the lowest passing grade. Criteria are laid down for grade 8 , but the teacher determines what requirements apply for the other grades.

Since early in the 20th century Sweden has changed grading scales on two occasions, in 1962 and 1994. On the first occasion from a seven level "absolute" letter scale to a five level relative numerical scale, the national distribution for grades in percentage terms was determined in advance by the use of a normal distribution curve. This relative grading scale was widely criticised, and in 1994 a goal and knowledge related grading scale was introduced where grades were assessed in accordance with the criteria formulated for different grades. This grading scale has three passing grades, but in the compulsory school there is no equivalent grade for "failing”. A pupil who does not fulfil the goals in a subject quite simply doesn't receive a grade. 
Within a couple of years a new grading scale will be introduced in Sweden. It will closely resemble the current scale. The difference is mainly that two new grading levels will be introduced, and that the grades will be denoted differently. The grading scale is inspired by the ECTS scale $^{3}$ which is used as a conversion scale for universities in Europe, and it has also provided the foundations of the new Danish scale, although it is described differently.

Over the years Denmark has changed grading scales many times, and also shifted between norm referenced relative grades, and criterion referenced grades, as well as between various combinations of grade levels and descriptions. Today they have a seven grade scale developed from the relative ECTS scale. In Denmark this has been constructed in such a way that it is goal related at the local level, but relative at the national level. This means that the individual teacher awards grades on the basis of national criteria formulated for certain grade levels, but if the national statistics show that the prescribed percentage distribution of grades is not achieved at the national level, the criteria can be changed to bring about alignment with the prescribed distribution.

Norway according to Lysne (2006) has a unique background concerning tests and grades, with frequent shifts between different grading scales and has experienced major difficulties in getting acceptance for the new directives from the teaching profession. Throughout all the attempts to bring about change, the old six grade scale (1-6) with its roots in the 16th century has survived, and today this is the one applied. In Norway the basis for grading has varied between relative grading, and more criteria or goal referenced grading.

Iceland has a grading scale from 1 to 10 and the Faroe Islands will continue to apply the earlier 13 level Danish scale until 2010 when the new Danish 7 level grading scale is introduced.

The table below provides a summary of grading scales in the Nordic countries and in some others. The highest grade is given first in the scale. 
Table 1.3. Grading scales in some countries

\begin{tabular}{lrrr}
\hline Country & Scale & Levels & Not passed \\
\hline France, Belgium, Portugal & $20-0$ & 21 & $9-0$ \\
Germany, Switzerland & $1-6$ & 6 & $5-6$ \\
Austria, Czech Republic, Slovakia, Russia, & $5-1$ & 5 & $2,2-1$ \\
Hungary, Ukraine, Serbia, Slovenia & & & \\
Italy, Netherlands Spain, Latvia, Lithuania, & $10-1$ & 10 & $6-1,5-1,4-1$ \\
Israel & & & \\
USA, Canada, Australia & $\mathrm{A}-\mathrm{F}$ & $\mathrm{F}$ \\
UK, Ireland & $\mathrm{A}-\mathrm{G},(\mathrm{U})$ & 7,8 & $\mathrm{E}, \mathrm{F}, \mathrm{G}$ \\
New Zealand & $\mathrm{E}, \mathrm{N}, \mathrm{N}, \mathrm{NA}$ & $\mathrm{IG}$ \\
Sweden & $\mathrm{H}, \mathrm{F}$ \\
Sweden (New 2011) & $\mathrm{A}-\mathrm{F}$ & 3,4 & $0,-3$ \\
Denmark & $12-(-3)$ & 7 & $5,03,00$ \\
Faroe Islands & $13-00$ & 10 & 4 \\
Finland & $10-4$ & 7 & $\mathrm{NA}$ \\
Iceland & $10-1$ & 10 & 1 \\
Norway & $6-1$ & 6 & \\
\hline
\end{tabular}

It can be noted that there is wide variation, but most countries have opted for numerical scales. Anglo-Saxon countries and Sweden, however, use letter ratings. Figures make it easier to calculate a final aggregate value and sometimes letter grades are chosen so that grades can only with difficulty be converted into numerical values. However, this has not prevented letter grades from being given numerical values and being used for selection to higher education. In Sweden values of 20, 15, 10 and 0 have been used for the different grades.

The Nordic countries are conspicuous in one respect concerning grades, and that is grades are assessed relatively late. In Denmark, the Faroe Islands, Norway and Sweden grades are assessed for the first time in the autumn in year 8. In Finland grades are set earlier if the municipality wishes, but must be set in the autumn of year 8 at the latest.

In Sweden, however, in a few years grades will be awarded in the autumn of year 6 .

In principle, compulsory schools in the Nordic area can be said to resemble each other as they are coherent and apply to all pupils in the first nine years. Thereafter pupils choose what routes to take for their future studies, in principle all pupils make the transition to upper secondary studies or vocational schools. The view of the school as both fulfilling some of the functions of socialisation, general education and preparation for further studies, for vocational life, and as a member of society is emphasised in all the Nordic countries. Certain differences exist concerning 
grades and examinations, but in general grades are set late in relation to other countries, and there is virtually no doubt that there is a wide measure of consensus between Nordic countries on the role of the school, both for the individual and society.

Nordic PISA results so far

This anthology deals with PISA and primarily the 2006 study. In the concluding part of this chapter, a review is given of trends and changes in knowledge and skill tests available so far.

PISA was carried out for the third time in 2006. The following tables provide an overall picture of results achieved in the Nordic countries within different knowledge areas of reading literacy, mathematical literacy, and science literacy. In each cycle, there is a main area and in the two other areas only certain parts are assessed. In the 2006 PISA study, all three areas were main areas, and in 2009 a first complete follow-up of the first main area, reading literacy, will be carried out. This means that the three studies presented here, do not necessarily show definite trends since two of the three studies are limited to certain parts of the respective knowledge areas. Only one of the three studies covers the whole knowledge area, but despite this the trend measures provide a reasonably good indication of changes, and the following figures show the results and changes for the three years 2000, 2003 and 2006.

The figures cover countries which are either in the EU or the OECD, as well as some countries considered to be comparable to the Nordic countries. A number of countries principally from the Third World, not considered relevant for comparative purposes, with the Nordic countries in this anthology have thus been excluded. Note that the average values given in the tables are the average value for countries in the respective tables.

The Faroe Islands took part for the first time in the full-scale PISA 2006 study and thus this is the only year given for the Faroe Islands in the figures below. The Faroe Islands are not used to calculate average values.

\section{Reading literacy}

Reading literacy was as mentioned the main area for the first PISA study in 2000. Table 1.4 shows the results. 
Table 1.4. Scores placement of EU/OECD countries in reading literacy for different PISA studies

\begin{tabular}{|c|c|c|c|c|c|}
\hline COUNTRY & PISA 2000 & COUNTRY & PISA 2003 & COUNTRY & PISA 2006 \\
\hline Finland & 546 & Finland & 543 & South Korea & 556 \\
\hline Canada & 534 & South Korea & 534 & Finland & 547 \\
\hline New Zealand & 529 & Canada & 528 & Canada & 527 \\
\hline Australia & 528 & Australia & 525 & New Zealand & 521 \\
\hline Ireland & 527 & New Zealand & 522 & Ireland & 517 \\
\hline South Korea & 525 & Ireland & 515 & Australia & 513 \\
\hline Japan & 522 & Sweden & 514 & Poland & 508 \\
\hline Sweden & 516 & Belgium & 507 & Sweden & 507 \\
\hline Austria & 507 & Norway & 500 & Belgium & 501 \\
\hline Belgium & 507 & Switzerland & 499 & Switzerland & 499 \\
\hline Iceland & 507 & Japan & 498 & Japan & 498 \\
\hline Norway & 505 & Poland & 497 & Germany & 495 \\
\hline France & 505 & France & 496 & Denmark & 494 \\
\hline Denmark & 497 & Iceland & 492 & Austria & 490 \\
\hline Germany & 495 & Denmark & 492 & France & 488 \\
\hline Switzerland & 494 & Germany & 491 & Norway & 484 \\
\hline Spain & 493 & Austria & 491 & Iceland & 484 \\
\hline $\begin{array}{l}\text { Czech } \\
\text { Republic }\end{array}$ & 492 & $\begin{array}{l}\text { Czech Repu- } \\
\text { blic }\end{array}$ & 489 & Hungary & 484 \\
\hline Italy & 487 & Slovenia & 482 & Czech Republic & 483 \\
\hline Hungary & 480 & Spain & 481 & Luxembourg & 479 \\
\hline Poland & 479 & Luxembourg & 479 & Portugal & 472 \\
\hline Greece & 474 & Italy & 476 & Italy & 469 \\
\hline Portugal & 470 & Greece & 472 & Spain & 461 \\
\hline Luxembourg & 441 & Portugal & 469 & Greece & 460 \\
\hline Russia & 440 & Russia & 442 & Russia & 440 \\
\hline \multirow[t]{2}{*}{ Mexico } & 422 & Mexico & 422 & Mexico & 410 \\
\hline & & & & Faroe Islands & 409 \\
\hline Mean value & 497 & & 494 & & 489 \\
\hline
\end{tabular}

Finland is at the top, and Sweden is closest, but some distance away. Results for Norway reveal wide variation, whilst Iceland appears to have a downward trend. ${ }^{4}$. Denmark occupies a more modest position, which applies even more to the Faroe Islands.

4 The trends so far shown should be interpreted with some caution as they are only based on parts of the respective subject tests. In the 2009 test a stable measure in trends between 2000 and 2009 can be reported for reading literacy. The same applies to mathematical literacy 2012 and science literacy 2015. 


\section{Mathematical literacy}

Mathematics was the main area in the 2003 study. Table 1.5 shows the results.

Table 1.5. Scores and placement for EU/OECD countries in mathematical literacy for different PISA studies

\begin{tabular}{|c|c|c|c|c|c|}
\hline COUNTRY & PISA2000 & COUNTRY & PISA2003 & COUNTRY & PISA2006 \\
\hline Japan & 557 & Finland & 544 & Finland & 548 \\
\hline South Korea & 547 & South Korea & 542 & South Korea & 547 \\
\hline New Zealand & 537 & Japan & 534 & Switzerland & 530 \\
\hline Finland & 536 & Canada & 532 & Canada & 527 \\
\hline Australia & 533 & Belgium & 529 & Japan & 523 \\
\hline Canada & 533 & Switzerland & 527 & New Zealand & 522 \\
\hline Switzerland & 529 & Australia & 524 & Australia & 520 \\
\hline Belgium & 520 & New Zealand & 523 & Belgium & 520 \\
\hline France & 517 & Czech Republic & 516 & Denmark & 513 \\
\hline Austria & 515 & Iceland & 515 & Czech Republic & 510 \\
\hline Denmark & 514 & Denmark & 514 & Iceland & 506 \\
\hline Iceland & 514 & France & 511 & Austria & 505 \\
\hline Sweden & 510 & Sweden & 509 & Germany & 504 \\
\hline Ireland & 503 & Austria & 506 & Sweden & 502 \\
\hline Norway & 499 & Ireland & 503 & Ireland & 501 \\
\hline Czech Republic & 498 & Germany & 503 & France & 496 \\
\hline USA & 493 & Norway & 495 & Poland & 495 \\
\hline Germany & 490 & Luxembourg & 493 & Hungary & 491 \\
\hline Hungary & 488 & Hungary & 490 & Norway & 490 \\
\hline Russia & 478 & Poland & 490 & Luxembourg & 490 \\
\hline Spain & 476 & Spain & 485 & Spain & 480 \\
\hline Poland & 470 & USA & 483 & Russia & 476 \\
\hline Italy & 457 & Russia & 468 & USA & 474 \\
\hline Portugal & 454 & Portugal & 466 & Portugal & 466 \\
\hline Greece & 447 & Italy & 466 & Italy & 462 \\
\hline \multirow[t]{2}{*}{ Luxembourg } & 446 & Greece & 445 & Greece & 459 \\
\hline & & & & Faroe Islands & 450 \\
\hline Mexico & 387 & Mexico & 385 & Mexico & 406 \\
\hline Mean value & 498 & & 500 & & 497 \\
\hline
\end{tabular}

Finland has a leading position in all three cycles. Iceland and Denmark are in second and third place, while Sweden and Norway have the lowest average scores. Norway appears to have a weak downward trend. 


\section{Science literacy}

Science was the main area in 2006, and is the subject which is the main theme of this report. The two earlier areas investigated have been dealt with in the two preceding versions of "Northern lights on PISA".

Table 1.6 shows the results in science literacy for the three cycles carried out so far.

Table 1.6. Scores and position of EU/OECD countries in science literacy for different PISA studies

\begin{tabular}{|c|c|c|c|c|c|}
\hline COUNTRY & PISA2000 & COUNTRY & PISA2003 & COUNTRY & PISA2006 \\
\hline South Korea & 552 & Japan & 548 & Finland & 563 \\
\hline Japan & 550 & Finland & 548 & Canada & 534 \\
\hline Finland & 538 & South Korea & 538 & Japan & 531 \\
\hline Canada & 529 & Australia & 525 & New Zealand & 530 \\
\hline New Zealand & 528 & Czech Republic & 523 & Australia & 527 \\
\hline Australia & 528 & New Zealand & 521 & South Korea & 522 \\
\hline Austria & 519 & Canada & 519 & Germany & 516 \\
\hline Ireland & 513 & Switzerland & 513 & Czech Republic & 513 \\
\hline Sweden & 512 & France & 511 & Switzerland & 512 \\
\hline Czech Republic & 511 & Belgium & 509 & Austria & 511 \\
\hline France & 500 & Sweden & 506 & Belgium & 510 \\
\hline Norway & 500 & Ireland & 505 & Ireland & 508 \\
\hline USA & 499 & Hungary & 503 & Hungary & 504 \\
\hline Hungary & 496 & Germany & 502 & Sweden & 503 \\
\hline Belgium & 496 & Poland & 498 & Poland & 498 \\
\hline Iceland & 496 & Iceland & 495 & Denmark & 496 \\
\hline Switzerland & 496 & USA & 491 & France & 495 \\
\hline Spain & 491 & Austria & 491 & Iceland & 491 \\
\hline Germany & 487 & Russia & 489 & USA & 489 \\
\hline Poland & 483 & Spain & 487 & Spain & 488 \\
\hline Denmark & 481 & Italy & 486 & Norway & 487 \\
\hline Italy & 478 & Norway & 484 & Luxembourg & 486 \\
\hline Greece & 461 & Luxembourg & 483 & Russia & 479 \\
\hline Russia & 460 & Greece & 481 & Italy & 475 \\
\hline Portugal & 459 & Denmark & 475 & Portugal & 474 \\
\hline \multirow[t]{2}{*}{ Luxembourg } & 443 & Portugal & 468 & Greece & 473 \\
\hline & & & & Faroe Islands & 417 \\
\hline Mexico & 422 & Mexico & 405 & Mexico & 410 \\
\hline Mean value & 497 & & 500 & & 498 \\
\hline
\end{tabular}


Yet again Finland is among the top nations, and in addition demonstrates a rising trend. Sweden is in second place amongst the Nordic countries, but in contrast to Finland there is a downward trend. It can be noted that the difference in scores between different years is not particularly great, but on the other hand, the rankings change as many countries have improved their results.

Norway has experienced a severe downturn from the 2000 study, Denmark's results vary, whilst Iceland has occupied a relatively stable position, a few points under the average of the other countries.

\section{Concluding comments}

This chapter aims at providing a general review of the Nordic area and the Nordic countries from a number of different perspectives: geographical, historical, political and educational. It has been possible to identify many similarities, as well as a number of different characteristics. One of the aims of PISA is to be able to compare different school systems in order to identify good indicators of those conditions in a country that promote pupils' pursuit of knowledge and give good results in PISA. A review of this type, of course, can not provide any explanations as to why, Finland, for example, manages better than the other Nordic countries, but it may well serve as a background for different discussions on possible explanatory factors. The aim of the anthology is that the different studies will contribute to a better understanding of what factors can help explain the results and the apparent differences. 


\section{References}

Eurofond Second European Quality of Life Survey - First Findings http://www.eurofound.europa.eu/ publications/htmlfiles/ef0852.htm Retrieved 2009-02-10

Eurydice, The Education System in Denmark

Eurydice, The Education System in Finland

Eurydice, The Education System in Iceland

Eurydice, The Education System in Norway

Eurydice, The Education System in Sweden http://eacea.ec.europa.eu/ portal/page/portal/Eurydice/ ByCountryResults?countryCode=IC Accessed 2009-02-12

Geber, E. (2003). Frihet och tvång i folkskolans och grundskolans läroplaner
(Freedom and compulsion in the curricula of the elementary and compulsory school). In Klingeberg. H.(Ed.) Skolhistoriskt arkiv.28 Helsingfors: Svenska skolhistoriska föreningen.

Lysne, A. (2006). Assessment theory and practice of students' outcomes in the Nordic countries. Scandinavian Journal of Educational Research.

Vol. 50, No. 3, pp. 327-359

Nordiska ministerrådet (Nordic Council of Ministers) (2008). Nordisk statistisk årsbok (Annual statistics of the Nordic area) 2008.

OECD (1998) Education at a Glance. Paris: OECD Center for Educational Research and Innovation

Ödman, P-J. (2006). Kontrasternas spel. Stockholm: Norstedts Akademiska Förlag 


\title{
2.1 Science education, the science curriculum and PISA 2006
}

\author{
Jari Lavonen, Svein Lie, Allyson Macdonald, Magnus Oscarsson, \\ Claus Reistrup and Helene Sørensen
}

\section{Introduction}

A national level curriculum for compulsory school is one of the most important tools for implementing national education policy. In a national level curriculum there is typically a general part in which the main goals for education in compulsory schools are described (Field \& Leicester, 2000; Concepción, Murray \& Ruud, 2002). In the Nordic countries, these goals indicate that compulsory schooling for children up to age 15 should support their growth towards ethically responsible membership in society, and provide them with the knowledge and skills necessary for life and life long learning. Moreover, education should promote equality in society and the ability to participate as a full member of society. In addition to this kind of overall goal or purpose, in all Nordic countries there are also national level guidelines or goals for each school subject. Consequently, in the Nordic countries the national curriculum provides both general goals and subject specific goals, and in some countries also a syllabus for all school subjects.

For example, in Norway the general section states the overarching goals and principles of all parts of the national education system. These goals are set out in various statements referring to various aspects of the human being (spiritual, creative, working, social, etc). An example under the heading "The creative human being": Education will impart in the 
learner zest for life, the courage to tackle it, and a desire to use and extend what they learn (KUF, 1999, p. 27). The subject-specific sessions specify the attainment targets (and/or instruction principles) for each subject. Individual schools are expected to set up their own local curriculum for each school year and its relations to local industry, economic and biological life, climate and other aspects (KUF, 1999, p.78; Utdanningsdirektoratet, 2008). This kind of local, municipal or even school, level planning of a local curriculum is very common in all Nordic countries.

According to the PISA 2006 Framework (OECD, 2006), the knowledge and skills tested in the PISA 2006 Scientific Literacy Assessment are defined not primarily in terms of a common denominator of national school curricula, but in terms of what knowledge and skills or competences are considered essential for future life. PISA competences cover, in general, communication, adaptability, flexibility and problem solving. The PISA 2006 science framework (OECD, 2006) emphasises science competences which are defined in terms of an individual's scientific knowledge and use of that knowledge to identify scientific issues, explain scientific phenomena and draw evidence-based conclusions. The four content areas of scientific knowledge are physical systems, living systems, earth and space systems, and technology systems. The competences and content areas represent important knowledge and skills that are considered important in understanding the natural world and making decisions. Consequently, PISA evaluates competences which support a capacity for life-long learning. Although PISA does not set out to evaluate the achievement of competences described in national level curricula, it does provide a means for assessing this, especially where there is a good match between the two. This is because the competences described in national curricular documents in general and subject specific sections could be closely aligned with the PISA science framework. For example, the working group which prepared the 1999 Icelandic National Curriculum in Science included two subject specialists who were advisers to the PISA project staff in Iceland. PISA does not exclude curriculum-based knowledge and it is reasonable to have a look at national science curricula in the Nordic countries and assess the extent to which they are aligned with the PISA framework.

The purpose of this chapter is to describe the science curricula for compulsory schools in the Nordic countries from the point of view of the 
PISA framework. Firstly, some national science education policy issues and education systems will be analysed. Secondly, science in the national level curricula is analysed and discussed. Finally, there is a short description of assessment in the Nordic countries. The analyses of national level curriculum were done by one of the authors of this chapter in each Nordic country based on the agreed guidance questions.

There are differences in the terms used in national level documents in the Nordic countries and, therefore, the translation of the meaning of concepts is not simple. In general, goals are used here to describe the overall purpose of a subject or a course within a national level curriculum. Goals are typically broad, vague, intangible and abstract. They indicate general intentions or observations and cannot be validated. Aims (objectives) break goals down into measurable behaviours that demonstrate competence. Objectives are narrower, limited, precise, concrete and measurable, and always stated in terms of what the learner should know or be able to do. Syllabus means a description of the main content of a subject or a course. A syllabus describes in detail knowledge areas and required skills that are to be learned. A standard is a statement of what students are expected to know and be able to do, or have attained by the end of a course or compulsory school.

\section{The education system in Nordic countries}

In all the Nordic countries, students attend compulsory school until they are 15 to 16 years old. Officially in Finland, the Faroe Islands, Denmark and Sweden compulsory school is nine years (grades 1-9) with children starting school at age 7, though it is very common that 6 year-old children attend a non-compulsory preschool year. In Finland, this preschool year is now compulsory. In the Faroe Islands, two small schools offer a noncompulsory pre-school year. In Iceland and Norway there are ten years of compulsory schooling with almost all children entering formal schooling at age 6 . There is no tradition in Nordic compulsory schooling whereby children repeat a year of school.

In addition to compulsory schooling, upper secondary school or vocational school programmes are offered in all the Nordic countries. In Finland, about half the students enter academically oriented three year 
upper secondary school and half vocationally oriented schools. In Sweden, Norway and Denmark there is a solid three year upper secondary school with different academic and vocational programmes, and a large majority of pupils enter one of these programs. In Norway students may finish a vocational study track and add another year to qualify for university studies. In Denmark, Finland and the Faroe Islands there is an opportunity for students who need one more year of schooling to take grade 10 . After this 10th grade in Denmark, students can take additional exams in Danish, mathematics, English and physics/chemistry. The standard length of upper secondary schooling in Iceland, for those wishing to enter university, is four years (aged 16-19), though a new curriculum currently being developed will be based on a National Quality Framework and have more flexible options based on competences. In Iceland there are various systems for vocational education varying in length from two to six years.

\section{National level and local curriculum}

Many countries try to balance two opposing views: some believe students should have a common knowledge foundation, expressed in terms of a national curriculum; others want municipalities or students to be able to pursue their own educational interests, for example, through local curriculum and early specialisation in a major or through a free choice of courses (framework curriculum) (Kelly, 1999). For example, the National Curriculum in England tries to standardise the content taught across schools in order to permit national assessment, which then enables the compilation of league tables detailing the assessment statistics for each school.

In the Nordic countries local municipalities or even individual schools establish a local curriculum based on a national level framework curriculum. In addition, students have had the option of choosing courses or school subjects, especially during the last years of compulsory schooling. For example, in Finland according to the National Core Curriculum for Basic Education (NCCBE, 2004), the local level curriculum should specify which study modules or courses are compulsory for the pupil and which are optional. It is also mentioned in the Finnish curriculum that studies in optional subjects should deepen and broaden knowledge and skills in subjects, such as home economics and arts subjects, as well as in science and technology. In Iceland the 1999 national curriculum allowed 
up to $30 \%$ of the school day to be devoted to optional subjects in grades 9 and 10. However, there are differences in the Nordic countries on the level of prescription and detail of the national guidelines.

There have been changes between the emphasis on national and local level curricula in the Nordic countries. For example, in Finland the basic idea in the Finnish Framework Curriculum in year 1994 (FCCS, 1994) was that it should stimulate a dynamic process in schools by continuously taking into account changes in the environment. As a result, the objectives in the 1994 curriculum did not restrict teaching methods and the development of teaching in each school. This led to variation in assessment of students between schools and between teachers. The authorities were especially worried about equality between pupils. Consequently, it was decided in the National Core Curriculum for Basic Education (NCCBE, 2004) to include final assessment criteria for the end of the ninth grade, and the Finnish education system thus moved one step backward from decentralisation toward centralisation. In Iceland centralised national assessment in science was discontinued in the early 1980s, reintroduced from 2002 in line with the 1999 national curriculum and again discontinued from 2008 with new laws on education.

We will next present the basic characteristics of national level curricula in the Nordic countries, and describe the relation between the national level and local curricula. It is important to recognise that decentralisation makes it difficult to compare accurately similarities and differences in science education between Nordic countries.

The Danish Parliament decides on national educational goals in general and in the Act for the Danish School System ("Folkeskoleloven LBK $n r 1049$ af 28/08/2007”, 2007). The Ministry of Education is responsible for publishing national curricula and defining the national objectives for schools and school subjects. These give an overall description for the different subjects. For grades 1-6 there are standards for the second, the fourth and the sixth year in science. For grades 7-9 there are standards for biology, geography and physics/chemistry for each year and final standards. There is no national syllabus in Denmark. The local municipalities may draw up more detailed plans or ask local schools to define their own local syllabus within the attainment targets. The latest curricula for science subjects were launched in 2009, and applicable from August 2009. 
The Finnish Parliament decides on national educational goals and the minimum number of lesson hours for each grade cluster. The current national curriculum in Finland, the Finnish National Core Curriculum for Basic Education (NCCBE, 2004) was prepared by the Finnish National Board of Education. This office, under the Ministry of Education, is responsible for development of education and teaching in compulsory schools. The national core curriculum covers the nine years of compulsory or basic education for all children aged 7 to 16 . The curriculum framework begins by setting out the underlying values for basic education. General goals and subject specific goals or aims, basic concepts in each subject (syllabus), integration and cross-curricular themes, as well as final assessment criteria (standards) at the end of the ninth grade and descriptions of good performance at the end of the fourth and sixth grade are described in the framework. All school subjects are emphasised, giving equal value to all aspects of an individual's growth of personality, civic awareness, creativity, knowledge and skills. The goals and contents are not related to a specific grade but to grades or grade clusters, for example, grades 7-9. The general goals and subject specific goals are standards which municipalities and teachers are required by law to follow.

The National Core Curriculum is the national framework on the basis of which local curricula are formulated in Finland. The education provider (typically a municipality) takes responsibility for the preparation and development of the local curriculum. In the local curriculum, for example, the educational and teaching tasks are described, and the goals and contents (the allocation of contents to grades) are specified, based on the core curriculum.

The Faroese Parliament decides on the framework and goals for all types of education. This framework is set up in Government regulations. The curriculum is prepared by the Faroese Ministry of Education. At the beginnings of the 90s the trend was that all objectives should be elaborated locally. The local schools use the national objectives as guidelines when doing this. As many schools are very small, they often use the governmental guidelines directly as the curriculum, but a lack of clear standards in different subject resulted in differences between schools and a lack of equality in knowledge and skills. At the moment there is a movement in the Faroe Islands towards more strict central objectives and syllabuses for all subjects from 1st grade to the last grade of upper secondary 
education. The intention is to provide a continuous curriculum from the 1st grade to the end of upper secondary education in order to ensure coherence in the main subjects throughout the educational system, and to ensure gradual and goal oriented growth in knowledge for the individual pupil. Clear and specific assessment criteria are set up for assessment and examinations after the 9th and 10th grade.

A division of the Ministry of Education, Science and Culture in Iceland is responsible for the development and publication of the National Curriculum. An extensive review was carried out from 1996-1999 with new curricula and some new subjects were introduced in 1999 for preschools, and compulsory and upper secondary schools. Most of the compulsory school curricula had been revised by 2007, and all schools are expected to have adapted their own curricula, based on the 1999 curriculum, to the revised curriculum by 2010. The Icelandic National Curriculum (Icelandic Ministry of Education, Science and Culture, 2004) is a single document, with goals, aims and objectives and it is organised into three sections covering grades $1-4,5-7$ and $8-10$. Goals are stated for the end of the $10^{\text {th }}$ grade. In 1999 detailed objectives were written for twelve subjects stating the aims to be attained by the end of the $4^{\text {th }}, 7^{\text {th }}$ and $10^{\text {th }}$ grades, but in the more recent revision, still to be applied, the objectives are published as an appendix to the main curriculum, allowing teachers to exercise more discretion in their teaching plans.

In Iceland individual schools are required by law to develop their own school curricula for each subject, based on the aims and objectives set out in the National Curriculum for Compulsory Schools, which has both a general and individual sections for each subject. Individual teachers make minor revisions annually based on local conditions. All curricula are available on the internet and are no longer printed (http://www. menntamalaraduneyti.is/utgefid-efni/namskrar/).

In Norway, the Ministry of Education is responsible for the development of the National Curriculum for compulsory schooling (Kunnskapsdepartmentet, 2009, published on the internet, not available in printed version to enable easier revision). The present curriculum was implemented in autumn 2006, after many years of discussion and development, as a part of a reform called The Knowledge Promotion. This curriculum could not, however, directly influence the Norwegian results in PISA 2006. The previous national curriculum was implemented from 
1997, and it specified in great detail the relevant subject topics to be taught (and to some extent also how), the 2006 version only lists attainment targets, thus providing teachers with more discretion in teaching than before.

The new Norwegian National Curriculum similar to that in Iceland, is organised in three sections covering grades 1-4, 5-7 and 8-10 (Kunnskapsdepartementet, 2007), while the former curriculum from 1997 gave specifications for each grade. The syllabus for each subject is specified in standards to be achieved by the end of grade 4, 7 and 10 (for some subjects also for grade 2). These standards are relatively specific, but the didactic and instructional approaches are decided locally by schools, teachers and pupils (Utdanningsdirektoratet, 2008). In the syllabus for each subject, five basic skills are integrated in a way that is adapted to each subject. These five skills are: reading, expressing oneself orally, expressing oneself in writing, developing numeracy, and using digital tools.

The Swedish Parliament and Government sets out national goals in The Education Act; Curriculum for the Preschool (Lpfö 98); Curriculum for the Compulsory School System, the Preschool Class and the Leisuretime Centre (Lpo 94); Curriculum for the Non-compulsory School System (Lpf 94); Course syllabi for compulsory school; and Program goals for upper secondary school. The Swedish curriculum for compulsory education aims to support an integration of activities in working towards and reaching the goals of compulsory school. The core document (Lpo 94) is just 16 pages long, and stipulates fundamental values and tasks of the school, goals and guidelines concerning norms and values, assessment, grading and knowledge to be attained. The National Agency for Education in Sweden draws up and takes decisions on course syllabi for upper secondary school. In the syllabus for each subject, there are two types of goals: goals to aim for and goals to attain. Sweden has chosen not to specify content in great detail (syllabus) but instead also have a curriculum that defines the skills or general abilities to be aimed for in student learning. When comparing the national evaluation (NU-03), TIMSS and PISA, it is shown that with such thinking is most clearly in line with PISA. (The National Swedish Agency for Education, 2009)

Within the objectives and framework established by government and the parliament, the individual municipality in Sweden may determine 
how its schools are to be run. A local school plan describing the funding, organization, development and evaluation of school activities is adopted. Using the approved curriculum, national objectives and the local school plan, the principal of each school draws up a local work plan. This is done in consultation with the school's teachers and other personnel, including pupils and parents.

\section{Science in the curriculum in Nordic countries}

A curriculum for a school subject describes what is to be learned in that subject and could be described as a road map on the journey of learning, showing the route to take, the stops to make along the way, the things to see, and the distances between places. Crucial to the syllabus for a subject is the definition of the goals (aims and objectives) for learning. In addition, some important contents or concepts could be specified in the curriculum. Sometimes a curriculum is equated with a syllabus which means an outline and summary of topics to be covered. In addition to goals and contents, assessment strategies could be introduced in the curriculum.

There are two common ways to organise science education in different countries: integrated science and subject specific science. Integrated curriculum is a systematic organization of science content and parts into a meaningful pattern and is rooted in ideas from Dewey about democratic education (Fensham, 1992). Integrated science curricula have a long history in Anglo-Saxon education. The level of integration varies in Nordic countries and according to basic ideas of Dewey several conclusions regarding curricula could be drawn. In Sweden schools can decide if they are following an integrated approach or subject specific approach. In Iceland the approach could not be considered as integrated although topics are allocated to life science, earth science or physical sciences.

In the next section the organisation of school science and time allocation across school years in Nordic countries is described. Secondly, goals and content for science education are identified. Finally, there is a brief discussion on assessment of science. 


\section{Science subjects in Nordic countries}

In Denmark science is defined as an integrated subject in grades 1-6. There are 30 hours per year in grades 1 and 2 and 60 hours per year in grades 3-6. In grades 7-9 science consists of three different courses: Physics/chemistry (60 hours in grades 7 and 8 and 90 hours in grade 9), biology (60 hours in grades 7 and 8 and 30 hours in grade 9) and geography (including cultural geography) (30 hours in grades 7 and 9 and 60 hours in grade 89). These four science courses are described in separate curricula, however from 2009 the ministry of education has made it clear that part of science teaching in grade 7-9 should be as integrated science by defining shared standards in the three school courses in science. Altogether there are 780 hours of science subjects in Danish compulsory school.

In Finland in grades 1-4 there are integrated environmental and natural studies as a subject group comprising the fields of biology, geography, physics, chemistry, and health education (altogether 9 lesson hours/ week/4year $=2.25$ lesson hours/week/year). In grades 5 and 6 there are two science subjects: integrated biology and geography (1.5 lesson hours/ week/year) and integrated physics and chemistry (1 lesson hour /week/year). In grades 7-9 there are separate science subjects: biology (3.5 lesson hours/3 years), geography (3.5 lesson hours/3 years), physics (3.5 lesson hours/3 years), chemistry (3.5 lesson hours/3 years) and health education (3 lesson hours/3 years). In Finland there are altogether 38 weeks in a school year and, consequently 1 lesson hour/week/year means 38 lesson hours. Altogether there are 1,178 (45 min lessons) or 883 hours of science subjects in Finnish compulsory school.

In the Faroe Islands science education begins in 4th grade and is defined as a broad subject, but in 7th grade chemistry and physics are combined. In 8th and 9th grades this integrated subject is not compulsory. In 8th and 9th grades both geography and biology are compulsory subjects. Totally the pupils have 436 lessons (45 minutes) in science during their compulsory education. In addition, they can choose chemistry and physics in 8th and 9th grades and this means approximately 158 more lessons. The local municipality and school to some extent can organise science with a different number of lessons. Science is often learned by observing and drawing conclusions, but as the goals in natural science are not very clear in the curriculum, there is a wide range of variation in teaching be- 
tween schools. A normal approach to natural science is to use the surroundings, which is possible as nature is just a few steps outside the class room. The main objectives in the Faroese curriculum differs from subject to subject and also depending on the grade. The current curriculum for primary and secondary education level dates from 1991. Altogether there are 455 hours of science subjects (60 minutes) in the compulsory school.

In Iceland students should receive on average 2 periods (40 minutes) per week of science in grades $1-4,3$ periods in grades $5-7$ and 3 periods in grades 8-10. Schools can, however, allocate these periods differently across years, offering more in one grade and less in another. Science forms $8 \%$ of the compulsory curriculum, compared with $16 \%$ in Icelandic, 15\% in mathematics and 5\% in English. In total there are a maximum of 624 hours of science instruction offered in Icelandic compulsory school, based on a school year of 36 weeks (180 days) hours of science subjects in the Icelandic compulsory school.

In Norway, teaching hours for the subject Natural science (60 minute units) amount to 328 (grades 1-7) and 256 (grades 8-10). Schools are in principle free to arrange distribution in the school years as they wish, but usually the number of lessons is distributed quite evenly between neighbouring grades. (Natural) Science is taught as an integrated subject throughout grades 1-10 (also in first year of upper secondary). In addition, a substantial amount of science content is covered in other school subjects, particularly in Physical education (e.g. health, human biology, exercise, managing oneself in nature during different seasons) and in Social studies (e.g. environment, location and extent of natural and manmade conditions and changes on earth) and Food and health (e.g. healthpromoting lifestyle, nutrition, food and environment). Accordingly, in addition to the 584 hours of the Natural science subject specified above, around 200 hours of Physical education, Social studies, and Food and health can be regarded as covering natural science instruction. Altogether there are around 800 hours (60 minutes) of science subjects taught in the Norwegian compulsory school.

In Sweden, students are guaranteed 1,066 lessons (800 hours) in science and technology from grade 1 to grade 9 (age 7-16), amounting to $12 \%$ of total hours. Schools are free to arrange each school year to meet the targets of the compulsory school. There are pilot trials with no national schedule and about $20 \%$ of municipalities are involved. Schools are 
free to choose to teach science either as an integrated subject, or as separate science subjects. About $80 \%$ of students receive grades in separate science subjects.

\section{Goals and content of science described in national level science curricula}

Describing goals/aims/objectives for science education in the different Nordic countries is a difficult task because the goals/aims/objectives are described and classified in different ways in each country. Here we have followed the classification based on the main science competences, defined in the PISA framework: goals for the individual's scientific knowledge (content and nature of knowledge):

- use of that knowledge to identify scientific issues;

- use of that knowledge to explain scientific phenomena and;

- use of that knowledge to draw evidence-based conclusions.

In some Nordic countries there is a list of science concepts or a syllabus in national level curriculum documents. In Denmark no syllabus exists. Next examples of descriptions of goals and contents for science education are presented in each Nordic country in accordance with the PISA classification.

In the curricula for science courses in Denmark, it is emphasised that practical work and scientific thinking is an important part of teaching and learning science. Science described in the national curricula covers the same goals as in the PISA framework. Content is also described in terms of goals and these goals serve to provide a framework for science content. One example of content in physics/chemistry and geography is: describe important conditions affecting weather and climate, including man-made activities.

The purpose of science teaching in general is described in the Finnish core curriculum as follows. Science teaching should help the students to (i) appreciate the nature of science and (ii) learn new scientific concepts, principles, and models; (iii) develop skills in experimental work and (iv) cooperation; and (v) stimulate the students to study physics and chemistry (interest). (NCCBE, 2004). The goals for science learning are stated sepa- 
rately for physics, chemistry and biology for grades 5-9. However, the goals are easy to classify in relation to the PISA framework. Examples of goals for science learning in Finland are:

\section{- Content knowledge}

In grades 5-6 progress is made towards the basic concepts and principles of physics and chemistry.

In grades 7-9 the pupils learn in physics to use appropriate concepts, quantities, and units when describing physical phenomena and technological questions.

\section{- Nature of science knowledge}

Instruction guides the pupil into thinking in a manner characteristic of science, in acquiring and using knowledge, and in evaluating the reliability and importance of knowledge in different life situations. The purpose of the experimental orientation is to help pupils to appreciate the nature of science.

Use of scientific knowledge to identify scientific issues to explain scientific phenomena and draw evidence-based conclusions:

- carry out simple scientific experiments clarifying the properties of phenomena, grades 5-6.

- scientific skills, such as the_formulation of questions and the perception of problems, grades 7-9.

- plan and carry out a scientific investigation in which variables affecting natural phenomena are held constant and varied, and correlations among the variables are explored, grades 7-9.

- use various graphs and algebraic models in explaining natural phenomena, making predictions, and solving problems, grades 7-9.

- make, compare, and classify observations, measurements, and conclusions; present and test a hypothesis; and process, present and interpret results, grades 7-9.

In Finland the focus for describing science content in the curriculum is highly subject oriented. However, content can be easily related to the four 
content areas of PISA 2006 as follows. Examples of contents of physical systems:

- producing heat, light (grades 5-6),

- natural structures and proportions (grades 7-9),

- motion and forces, models of uniform and uniformly accelerating motion (grades 7-9),

- interpretation of chemical reaction equations and balancing of simple reaction equations (grades 7-9),

Examples of contents of living systems:

- structure and main vital functions of the human body, reproduction; physical; psychological and social changes accompanying puberty (grades 5-6),

- the ecosystem and its structure and operation, distinctive features of forest and aquatic ecosystems; independent research on one ecosystem (grades 7-9),

Examples of contents of earth and space systems:

- motion of the earth and moon, structure of the solar system (grades 5-6),

- interactions and corresponding forces, motion and equilibrium phenomena that arise from those interactions; occurrence of these phenomena in nature (grades 7-9),

Examples of contents of technology systems:

- various ways of producing electricity and heat; energy resources (grades 5-6), origin, utilisation, and recycling of products and materials belonging to the living environment; safe usage of those products and materials (grades 7-9), 
By the end of the $9^{\text {th }}$ grade pupils in science in the Faroe Islands are taught to do the following:

- Concerning nature and man: Pupils should be able to see the importance that science has in the development of society and acquire knowledge about environmental problems caused by man.

- Concerning scientific activity: Pupils should be able to make some experiments and draw conclusions based on the experiments, and in this way they should increase their knowledge of science.

- Concerning use of knowledge: Pupils should be able to describe their own environment and be able to use words that describe scientific activity in relation to this.

The aims and objectives in the Icelandic science curriculum are presented as learner outcomes, i.e. what students should know and be able to do. In the general introduction to the 2007 science curriculum, it is suggested that school science should encourage curiosity and interest, ensure the active participation of students and support scientific literacy. In a discussion on teaching and learning, science learning is described as the construction of knowledge. In the first stage $\left(1^{\text {st }}-4^{\text {th }}\right.$ grade), the role of vocabulary, reading, communication, and skills and methods are discussed, and in the two later stages, concepts and understanding, skills and methods, and the nature and function of science are mentioned. The explanatory text in both 1999 and 2007 indicates a social constructivist approach to learning.

In the 1999 Icelandic compulsory school curriculum there were several general goals for school science. These include that students should: develop a broad knowledge base and an understanding of the main areas of science, its concepts and methods; have developed a life-view; and have an overview of the role of science in culture and history. Students were also expected to understand the limitations of data: engage in critical discussion of issues concerning nature, the environment and the relationship between science, technology and society: and have sufficient selfconfidence to use their knowledge and skills for further studies, as a personal interest or at work. In 2007 the same or similar goals exist, but there is an increased emphasis on the environment, understanding sustainable 
development, and developing feelings of responsibility with regard to these issues.

The 1999 National Curriculum for Science in compulsory schools in Iceland included aims for the $4^{\text {th }}, 7^{\text {th }}$ and $10^{\text {th }}$ grades concerning the $n a$ ture and role of science and methods and skills. These two themes were to be interwoven with the three content areas of physical sciences, earth sciences and life sciences. Earth sciences was a new addition to the science curriculum, and objectives in this area were written for the $1^{\text {st }}$ to the $8^{\text {th }}$ grades. These curriculum themes and content areas fit well with the competences and knowledge assessed in PISA, though the Icelandic curriculum did not directly address the issues of context, and science and technology in daily life. The 2007 curriculum has been broadened to the National Curriculum for Science and Environmental Education. The two general themes on the nature and role of science and on methods and skills are now incorporated into general introductory text for each school stage and into the aims for $4^{\text {th }}, 7^{\text {th }}$ and $10^{\text {th }}$ grades. The objectives which appeared within each stage for each aim in 1999 have been revised and are presented in an appendix to the curriculum document. The 2007 content areas are generally still the same as the 1999 areas, with sections on physical science, life sciences and earth sciences. In 2007 each of these three areas also includes content related to "man on earth" in keeping with the inclusion of environmental education.

The goals for learning science in Norway are given as detailed attainment targets for the end of each of the grades 2, 4, 7, and 10. Below are specified the actual learning goals for grade 10 . There is no explicit reference to the "subjects" of biology, chemistry, earth science or physics, even though these subject areas are clearly used as the organizing principle. In the new Norwegian syllabus for Natural science, a number of standards are specified within each of the following content areas: Diversity in nature, Body and health, The universe, Phenomena and substances/elements, and Technology and design. In addition, the heading The budding researcher signals a different type of subject matter area concerning the basic idea of the nature of science itself, its epistemological approach, the role of experiments etc. Five of these six content areas can be closely related to the four content areas in PISA by referring to what pupils should be able to do (for grades 8-10). Physical systems: 
Some examples (out of 12) from Phenomena and substances:

- carry out experiments to classify acidic and alkaline substances,

- examine the chemical properties of some common everyday substances,

- explain how we can pro duce electrical power from renewable and non-renewable sources of energy,

- elaborate on the concepts of velocity and acceleration, measure magnitudes using simple aids and give examples of how power is connected to acceleration.

Living systems: Some examples (out of 16) from Diversity in nature (first two)and Body and health (next two):

- elaborate on cell division and genetic variation and heritage,

- explain the main characteristics of evolutionary theory and the basis of this theory,

- explain how the nervous system and the hormone system control body processes,

- describe the development of a foetus and how birth occurs.

In addition, outside the subject Natural science, one example from each of the subjects Food and health and Physical education respectively:

- plan and prepare safe and nutritionally good food, and explain the nutrient substances in the food,

- elaborate on relationships between different physical activities, lifestyles and health.

Earth and space systems: Examples (out of four) from The universe:

- describe the universe and different theories of how it has developed,

- describe the apparent motion of the planets across the sky using simulations and explain how solar and lunar eclipses and seasons come about. 
Technology systems: Two (out of three) examples from Technology and design:

- test and describe characteristics of materials used in a production process,

- elaborate on electronic communication systems on the system level and discuss and elaborate on societal challenges in connection with using these.

In the PISA framework, the various aspects (or systems) of content referred to above, are all included under the heading Knowledge of science. In addition, the Knowledge about science aspect covers themes like the purpose and steps in scientific enquiry, and forms and status of scientific explanations. These themes are closely paralleled by the fifth area mentioned above, The budding researcher. One example from this topic:

- plan and carry out experiments to test the validity of his or her own hypotheses and choose the publication method.

There is a revised version of the science syllabus for compulsory schools from year 2000 in Sweden. The schools' mission is formulated in terms of three objectives and capabilities, i.e. "concerning nature and Man”, "concerning scientific activity" and "concerning use of knowledge". Science is described as a process developed through human activity, a way of describing and making our surroundings intelligible, an important part of our cultural heritage, and it emphasises the need for sustainable development. The three objectives in the Swedish science syllabus have much in common with the three competences described in the PISA Science framework. Explaining phenomena scientifically, Identifying scientific issues and Using scientific evidence.

The goals in the syllabi are for both science and biology, physics and chemistry. There are also goals for technology separate from science. There are goals to aim for, and goals that students should have attained by the end of year 5 and year 9. The different syllabi and goals support and complement each other, and constitute the national task for education in science. By the end of the ninth year in school, students in science should be taught in accordance with the descriptions below: 
Concerning nature and man: have knowledge of the universe, Earth, life, and man's development: have insight into how matter and life are studied at different levels of an organization: and have knowledge of the cycles of nature and the flow of energy through different natural and technical systems on Earth.

Concerning scientific activity: have knowledge of scientific ways of working, as well as be able to present their observations, conclusions, and knowledge in written and oral form: have an insight into the interaction between the development of concepts, models, and theories on the one hand, and experiences from investigations and experiments on the other: have insight into how knowledge of nature has developed and how this has both shaped and been shaped by man's perceptions of the world: and have insight into different ways of making nature understandable, through systematic observations, experiments, and theories, as well as by the approaches used in art, literature, myths, and sagas.

Concerning use of knowledge: have insight into the difference between scientific statements and statements based on values: use their knowledge of nature, man, and his activities as arguments on issues concerning the environment, health, and interpersonal relations: provide examples of how the sciences can be used to create not only better living conditions but also how science can be abused: and have insight into the consequences of different aesthetic views on environmental issues.

In Sweden the content areas described in the curriculum are similar to the content areas in PISA, physical system, living system and in some levels in earth and space systems. However, most of earth science belongs to geography, which is a part of social studies in the Swedish curriculum.

\section{Assessment in science education in Nordic countries}

There is no central assessment in Nordic countries. Actually this kind of discussion has not been recognised in education policy discussions.

In Denmark there is a leaving examination in the different science courses. The examination in physics/chemistry is an individual, compulsory examination based on students' experiments. In geography and biology, the examination is computer-based, and each year one of the two 
subjects is chosen. Furthermore in grade 8 there is a compulsory test in each of the three science subjects.

In the Finnish national curriculum there are final assessment criteria at the end of ninth grade, and descriptions of good performance at the end of the fourth and sixth grades. However, these guidelines are not used for the development of national tests as there are no national tests in Finland in the compulsory school. The guidelines are for teachers and to help teachers calibrate their formal assessment tools, such as course tests. The final assessment (evaluation) criteria determine knowledge and skill levels for grade 8 , on a scale $4 \ldots 10$. The criteria outline what a pupil should know, understand, and be able to do in science and are, thus a complete set of outcomes for pupils - they do not prescribe a curriculum. The Finnish National Board of Education (FNBE) is responsible for the organisation of national evaluations (monitoring) based on random samples.

In the Faroe Islands at the end of $9^{\text {th }}$ grade there can be an oral assessment in biology, geography and in the integrated subject chemistry and physics. Until 2007 an oral examination was optional in some subjects and a written one in others, but a change took place in 2007 and since then the Faroese Ministry of Education decides what examinations and subjects pupils have to take, these might be written or oral. The oral examinations in science subjects are designed in accordance with the objectives in the national curriculum and the pupils get a grade reflecting their achievement. If a pupil wants to continue in an upper secondary education on a scientific or technological line, the integrated subject chemistry and physics is compulsory.

In Iceland the review of the national curriculum in 1999 led to the reintroduction of a national science examination at the end of the $10^{\text {th }}$ grade in 2002, a practice which had been discontinued in the early 1980s. Taking the examination was optional, although students who wished to pursue science studies in upper secondary school needed to take it to gain admission to their chosen school and line of study. The National Testing Institute prepared a check-list for teachers on the content to be covered in the examination, but this check-list was developed from a survey of what teachers were teaching and thus reflected the 1999 curriculum only indirectly (Sigpórsson, 2008). In 2008 a new law on compulsory schooling limited the $10^{\text {th }}$ grade national examinations to Icelandic, mathematics and English. 
In Norway pupils' learning outcomes in science are evaluated regularly from grade 8 . Some municipalities (e.g. Oslo) run their own local written tests in science in order to observe the quality of instruction and to help standardise grades. At the end of grade 10 (end of compulsory education) all pupils may be selected for an oral examination in science with practical elements. The oral examination is prepared and graded locally, but standards are set nationally, and the pupils are evaluated by teachers from neighbouring schools.

When assessing student achievement levels in Sweden at the end of year 9, teachers base their assessment according to the goals to be attained as stated in the syllabi. Basic attainment of these goals corresponds to a Pass grade. Awarding the grades of Pass with Distinction and Pass with Special Distinction follows nationally approved assessment criteria.

\section{Discussion}

We have described above briefly some basic trends in education systems and national and local level curricula for compulsory schools in the Nordic region. We have in particular analysed goals and content for national level science curriculum in each region and have made some comparisons between them and the PISA 2006 framework.

\section{Discussion on education systems}

In Nordic countries the duration of compulsory education is 9 years except in Norway where it is 10 years. Compulsory education is divided into 3 year lower secondary and primary education. In all Nordic countries, there is a national level framework curriculum which includes descriptions of the goals of compulsory education, values it is based on, the aims of the subjects and a short description of subjects.

In all Nordic countries municipalities or individual schools may prepare a local curriculum. However, there are differences in freedom to prepare this curriculum. In Finland and in Norway all municipalities, and in Sweden all schools should prepare a local curriculum. In Denmark municipalities or schools may prepare their own curriculum. In the Faroe Islands and Iceland, schools follow national guidelines. In an Icelandic 
survey carried out on 18 school-sites, it appears that only a few schools made good use of local resources with most teachers following the same published texts. The school curriculum was often "cut and pasted" from the national curriculum. In Denmark municipalities or schools may prepare their own curriculum. In Faroe Island schools mainly follow national guidelines.

From the point of view of teaching and learning in science subjects, teachers' own competence in science subjects plays a role. Only in Finland is a teacher who is teaching science subjects at grades 7-9 highly specialised in the subjects. Typically they study at undergraduate level at the department of the particular subject (e.g. physics). Teacher education has been said, in several papers, to be one of the major explanations for students’ PISA success in Finland (Välijärvi et al. 2002; Simola, 2005; Laukkanen, 2008; Lavonen 2008). In other Nordic countries, student teachers take fewer courses in subjects they are teaching. For example in Iceland, fewer than $40 \%$ of those teaching science have been trained as science teachers (Icelandic Ministry of Education, Science and Culture, 2005). Also in Norway teachers of science in compulsory schooling have little specific education in science. This is a result of Norwegian teachers being expected to teach a wide range of school subjects, all the way up to grade 10. In particular, science teachers tend not to be well prepared for teaching physics (and partially also chemistry), and accordingly they often put little emphasis on these subject areas in their instruction.

\section{Discussion on science as a school subject}

Finland is the most subject oriented country among the Nordic countries. In Finland even at grades 5 and 6, goals for physics and chemistry are separate from the goals for biology and geography, and the subjects are taught separately. In grades 7-9 there are totally separate science subjects in Finland. In Denmark and in the Faroe Islands, science subjects are partly separated at grades 7-9: goals and lessons for physics and chemistry are combined, and biology and geography are taught separately. In Sweden goals are written so that schools can choose if they teach science subjects separately or as an integrated subject. The majority of Swedish schools teach science subjects separately, and all science textbooks for grades 7-9 are for separate subjects. In Iceland and in Norway, all 
schools teach integrated science. The content curriculum (or syllabus) in the 1999 curriculum in Iceland is divided into earth sciences, life sciences and physical sciences from grades 1-10, and most of the textbooks currently in use are aligned with these divisions. It is not uncommon to find physics and biology being taught by different teachers. Even so, in the 1999 curriculum in Iceland options for topics which would allow an integrated approach were introduced for all three phases.

There are differences between descriptions of science subjects in national curricula in the Nordic countries. For example, in the Finnish curriculum goals and content of the subjects (syllabus) are structured in clusters of grades (1-4, 5-6 and 7-9). Moreover, there are descriptions of students' achievements (standards) at the end of the 4th, 6th and 9th grades. The Swedish curriculum lists two types of aims: the aims that streamline the schools' operations towards achieving the goals of compulsory education ("the goals to strive towards"), and the aims that define the minimal expected outcomes students are expected to attain on completion of the compulsory segment expressed in terms of the knowledge, skills, values and attitudes students are expected to have developed ("goals to be attained"). These two types of aims could be compared to Finnish goals and standards. Alongside the framework curriculum document, there are also subject curricula (or syllabi) in Sweden which specify and operationalise the basic elements of the national curriculum framework. The Danish, Faroese, Icelandic and Norwegian national level curriculum also provide summary descriptions of science, following the goals and common structural elements of science for the whole of compulsory education, and the goals for individual educational cycles (grades $1-4,5-7,8-10)$ are expressed in terms of outcomes.

There are differences in the level of detail in the syllabus. For example in Denmark, there is no syllabus, whilst in Finland there is a syllabus for each separate science subject, physics, chemistry, biology and geography, specifically for grades 5 and 6, and grades 7-9. In Sweden and Norway important concepts are listed in the syllabus. In the 1999 curriculum in Iceland an effort was made to develop the complexity of topics or concepts across the three phases, echoing Bruner's (1966) spiral curriculum of the 1960s.

The hours allocated to science education in the Nordic countries could be compared at some levels although differences in the allocation of 
hours make this difficult. For example, in Finland the national level curriculum document provides a framework for lesson hours in each science subject for the clusters of grades (1-4, 5-6 and 7-9).The national curricula in Sweden, Norway, and Denmark define the minimal number of lessons through nine years of compulsory education for science subjects. The largest amount of teaching in science subjects is in Finland (883 hours), then in Norway and Sweden (800 hours minimum), Denmark (780 hours), in Iceland (624 hours, maximum) and in the Faroe Islands (455 hours maximum). However, this comparison is not clear-cut. For example, in Sweden and at some levels also in Norway, technology is included and geography not included in the hours.

\section{PISA framework and science curricula in Nordic countries}

According to the PISA 2006 framework (OECD, 2006), the PISA assessment emphasises science competences, defined in terms of an individual's scientific knowledge and use of that knowledge to identify scientific issues, explain scientific phenomena, and draw evidence-based conclusions. In addition, the framework emphasises understanding of the characteristic features of science as a form of human knowledge and enquiry, and the awareness of how science and technology shape our material, intellectual and cultural environments. These competences are tested in PISA by a large number of complex open-ended tasks.

In the previous chapter, some examples of goals for science, physics, chemistry and biology education are presented for the Nordic countries. In all Nordic countries, there are several goals emphasising learning scientific methods. However, using the PISA wording "identify scientific issues" in the examples of goals, the following expressions are used: to recognise, to observe, to formulate a question, acquiring knowledge, and looking for information. Further, instead of using "explain scientific phenomena" the following expressions are used: to interpret, to apply that knowledge, to test a hypothesis, and to use various graphs and algebraic models in explaining. Finally, instead of using "draw evidence-based conclusions", the following expressions are used: to draw conclusions, to formulate simple models, to make generalisations and to provide capabilities for making everyday choices. 
The contents of science, or biology, chemistry and physics, described in the national level curriculum in Nordic countries is drawn mainly from physical systems and living systems and closely reflects many of the topics presented in PISA 2006. However, in some Nordic countries, contents are presented as goals and in some countries a list of important concepts and topics (syllabus). In particular, traditional topics about the structure and properties of matter, chemical reactions, waves, electricity, motion and forces, energy and its transformation, basics of astronomy, cells, the human being, animals and plants around us, populations and ecosystems, are all mentioned in the PISA 2006 content area list concerning knowledge about the science domain, and are all mentioned in the national curriculum in Nordic countries. In addition, there are a number of content areas which are included in PISA which are classified as being part of geography in Finland, part of social science in Sweden, part of science and geography in Iceland, such as energy resources and energy, raw materials and trade, flow, structures of the Earth's systems (lithosphere, atmosphere, hydrosphere), changes in the Earth's systems, and the Earth in space. In Norway the situation is similar to Iceland, and in addition, science topics are covered also in physical education and food and health (see above).

PISA 2006 also addressed technology systems as a content area. In the Finnish and Icelandic curricula, there is surprisingly little discussion about technology or about science and technology in daily life, one of the key features of the approach used in PISA. This means that issues concerning how physics and chemistry knowledge is applied in technology and health care, in solving environmental issues, in everyday life and with regard to sustainability, were not necessarily part of the material being studied. In the Icelandic curriculum, technology is addressed more as a process than a product in a separate curriculum on Information and technology education. Research in Iceland, however, shows that technology education, as found in countries such as New Zealand or Canada, is very poorly understood or implemented in Iceland (Jónsdóttir and Macdonald, 2008). In Norway, the curriculum reform of 2006 introduced for the first time Technology and design as elements in the science attainment goals (see above). This specific focus on technology did not apply to the students that were tested in PISA 2006, however. Sweden has the longest 
tradition in technology education, and there are separate goals for technology in the curriculum.

The PISA framework identifies two categories of knowledge about science: "Scientific enquiry" and "Scientific explanations". In the list of goals in Nordic countries, there are several examples of goals for both categories. In particular, asking scientific questions, models and modelling, taking measurements, observations and investigations belong to the first category; whereas, presentation of types of scientific explanations (hypothesis, scientific law, model, and theory), formation of knowledge and outcomes of research (new knowledge, new methods, new technologies, new investigations), belong to the second category. In the 1999 Icelandic curriculum "scientific enquiry" was covered by the aims on skills and methods, and the nature of "scientific explanations" were included in the theme on the nature and function of science. These two themes, as mentioned above, have been incorporated into an introductory text in the 2007 curriculum, and no longer appear as specific aims. In Norway the focus on The budding researcher from early age clearly signals a stronger emphasis on various aspects of the nature of science and inquiry methods.

We conclude that goals for science education and contents described in the national level curriculum documents in Nordic countries are in general compatible with the competences described in the PISA 2006 framework (OECD, 2006). We conclude also that PISA evaluates well the achievement of competences described in the national level curricula in Nordic countries.

However, it is not clear how well the goals are realised in the classroom. For example, in Iceland it seems as if the type of teaching (Sigpórsson, 2008, Pórolfsson, Macdonald and Lárusson, 2007) needed to achieve the aims and objectives set out in the 1999 or 2007 curriculum is often absent. Science is not a priority subject in schools, and teachers may lack the self-confidence, skills or understanding to discuss scientific methods and raise controversial issues. It is often assumed that by doing practical work, learners will come to understand the opportunities and constraints of science. A reliance on textbooks in science teaching seems to play a part in this relatively passive and uncritical approach to school science. 


\section{References}

Concepción, N., Murray, P., \& Ruud, V. (2002), Education for Democratic Citizenship in the New Europe: context and reform. European Journal of Education, 37(2), 107-129

FCCS (1994). Framework curriculum for the comprehensive school (in Finland). Helsinki: State Printing Press and National Board of Education

Fensham, P. J. (1992). Science and Technology. In P. W. Jackson (Ed.), Handbook of Research on Curriculum. A Project of the American Educational Research Association. (pp. 789-829). New York: Maxwell Macmillan International.

Field, J., \& Leicester, M. (2000). Lifelong Learning: Education Across the Lifespan. London: Routledge.

Folkeskoleloven - LBK nr 1049 af 28/08/2007. (2007).

Undervisningsministeriet.

IEA (2007) TIMSS 2007 Encyclopaedia: A Guide to Mathematics and Science Education Around the World, Volumes 1 and 2 Retrieved Feb 27, 2009, from http://timss.bc.edu/TIMSS2007/encycl opedia.html

Kelly, A. V. (1999) The Curriculum. Theory and practice 4e, London: Paul Chapman.

KUF (Royal Ministry of Education, Research and Church Affaires, 1999): The Curriculum for the 10-year compulsory school in Norway. Oslo

Laukkanen, R. (2008). Finnish strategy for high-level education for all. In N. Soguel \& P. Jaccard (Eds.), Governance and Performance of Education Systems, pp. 305-324. The Netherlands: Springer.

Lavonen, J. (2008) Finland in PISA 2006 Scientific Literacy Assessment. In J. Hautamäki, E. Harjunen, A. Hautamäki, T. Karjalainen, S. Kupiainen,
J. Lavonen, E. Pehkonen, P. Rantanen \& P. Scheinin (Eds.), PISA 2006: Analysis, Reflections, Explanations, pp. 65-113. Helsinki: Ministry of Education Publications 2008:44.http://www. minedu.fi/OPM/Julkaisut/2008/PISA0 6._Analyses_Reflections_and_ Explanations?lang=en

Lavonen, J. (2007). National science education standards and assessment in Finland. In D. Waddington, P.

Nentwig \& S. Schaze (Eds.), Making it comparable, pp.101-126. Berlin: Waxmann,

NCCBE (2004). National Core Curriculum for Basic Education 2004.Helsinki: National Board of Education. Available online: http://www.oph.fi/english/ page.asp?path=447,27598,37840,72101 ,72106

OECD (2006). Assessing Scientific, Reading and Mathematical Literacy: A Framework for PISA 2006. Paris: OECD.

Simola, H. (2005). The Finnish miracle of PISA: Historical and sociological remarks on teaching and teacher education. Comparative Education, 41(4), 455-470.

The National Swedish Agency for Education, (2009). Med fokus på matematik och naturvetenskap (in Swedish) Retrieved Feb 27, 2009, from www.skolverket.se

The National Swedish Agency for Education, (2009). Syllabuses 2000 - revised version 2008 Retrieved Feb 27, 2009, from www.skolverket.se

Utdanningsdirektoratet (2008): Om lokalt arbeid med læreplaner (http://www.utdanningsdirektoratet.no/ templates/udir/ TM_Artikkel.aspx?id=2125) 
Utdanningsdirektoratet (2009). The Norwegian National curriculum for compulsory and upper secondary school (in English): http://www. utdanningsdirektoatet.no/templates /udir/TM_Tema.aspx?id=3579

Välijärvi, J., Linnakylä, P., Kupari, P., Reinikainen, P. \& Arffman, I. (2002). The Finnish success in PISA - and some reasons behind it. Jyväskylä: Kirjapaino Oma Oy.

(Undervisningsvejledning i biologi, 2009; Undervisningsvejledning i fysik/kemi, 2009; Undervisningsvejledning i geografi, 2009; Undervisningsvejledning i natur/teknik, 2009)

Undervisningsvejledning i biologi. (2009). 2009, from http://www.uvm.dk/ /media/Files/Udd
/Folke/PDF08/081027_nye_faelles_ma al_biologi.ashx

Undervisningsvejledning i fysik/kemi. (2009). 2009, from http://www.uvm.dk/ /media/Files/Udd /Folke/PDF08/081027_nye_faelles_ma al_fysik_kemi.ashx

Undervisningsvejledning i geografi. (2009). 2009, from http://www.uvm.dk/ /media/Files/Udd /Folke/PDF08/081027_nye_faelles_ma al_geografi.ashx

Undervisningsvejledning i natur/teknik. (2009). 2009, from http://www.uvm. dk/ /media/Files/Udd/Folke/PDF08/0810 27_nye_faelles_maal_natur_teknik.ashx Faroe Island References www.mmr.fo (the home site is only in Faroese) 


\subsection{What do principals and students say about schooling and science education? - Comparing views in Nordic countries}

Jarkko Hautamäki, Jorma Kuusela \& Sirkku Kupiainen

\section{Introduction}

The approach of this chapter is descriptive. The goal is to provide a description of Nordic educational systems in the light of the PISA survey data in order to support our general claim that the Nordic countries have largely similar schooling frameworks with relatively small national variation. This is something to be expected given the shared geographical location and the partially shared histories and contemporary social features (Andersen, Holmström, Honkapohja, Korkman, Söderström \& Vartiainen, 2007).

Like the earlier PISA cycles of 2000 and 2003, the PISA 2006 survey (OECD 2007a, 2007b) included questionnaires for both principals and students, which covered several issues relevant from the point of view of schooling and structural factors affecting schooling. Some of the questions related to these factors will be analysed and discussed in this chapter. The items will be referred to using their identification index in the PISA 2006 data. The Nordic student and principal survey data has been extracted from www.pisa.oecd.org, (OECD 2007a, 2007b).

The analyses concern only the Nordic countries but use the OECD as a means of reference when applicable. The questions used in the analyses 
are partially factual in nature (Are there other schools ...), partially they ask for students' or principals' opinions concerning some educationally relevant issue (How much time on average do you use ...). Answers to either type of question have been taken at face value, without trying to evaluate their possible truth or validity. Independent validity confirmation would mean, for example, using other sources of information concerning the respective questions, be it the standards used for assessing students' attainment, parents' role and behaviour vis-à-vis the school, or distribution of working hours at school. The given distributions of answers to different questions have been used. The official view (in terms of legislation or official documents) is not reported as a reference in issues where the distributions of answers might not correspond with the normative regulations and laws. Sometimes there are answers that might not be considered suitable by a country's administration, and it is thus important to bear in mind the reservation "as experienced by principals or students".

The perspective in this chapter focuses on science education, which means that in other chapters there are also references to the same issues. The chapter starts with the major frame factors as these are viewed by principals and then proceeds to complement the principals' views with students' experiences.

\section{School and principal level}

\section{General expectations and options for selecting a school}

The principals were the source of information at the school level. The first issue here deals with expectations parents express with regard to academic standards in schooling ${ }^{5}$. This is assessed by the question measuring pressure for academic standards using the values many parents, a minority of parents or largely absent (Figure 2.2.1).

\footnotetext{
5 Parents pressure on academic standards, item SC16Q1: Which statements below best characterises parental expectations towards your school? There is constant pressure from many parents, who expect our school to set very high academic standards and to have our students achieve them; pressure on the school to achieve higher academic standards among students comes from a minority of parents; pressure from parents on the school to achieve higher academic standards among students is largely absent
} 


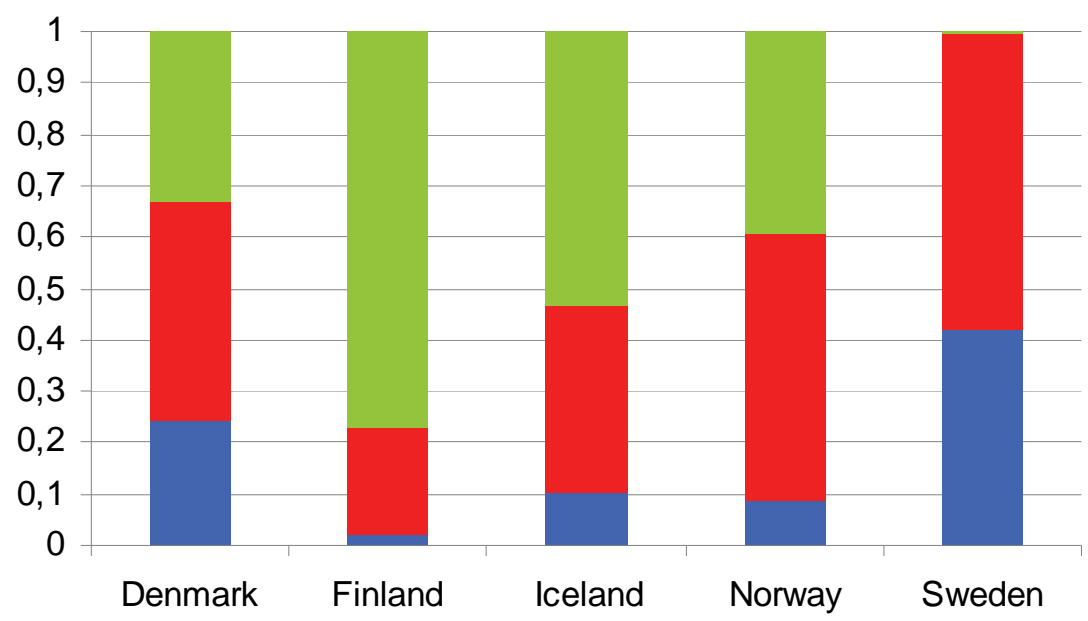

Many parents $\square$ Minority of parents $\square$ Largely absent

Figure 2.2.1. Parents' pressure on academic standards as experienced by principals

There are two major observations. In Sweden many parents are demanding, as experienced by principals, whereas in Finland very few put pressure on schools in relation to academic standards. Sweden is different from the other Nordic countries, whereas the other three - Denmark, Iceland and Norway - are relatively similar. And all are different from Finland in relation to the answer-option "largely absent". However, in all Nordic countries there are indeed options for 15 year-olds (figure 2.2.2) or for their parents ${ }^{6}$.

6 Schooling available, SC18Q01: We are interested in the options parents have when choosing a school for their children. Which of the following statements best describes the schooling available to students in your location? There are two or more schools in this area that compete for our students, there is one other school in this area that competes for our students, there are no other schools in this area. 


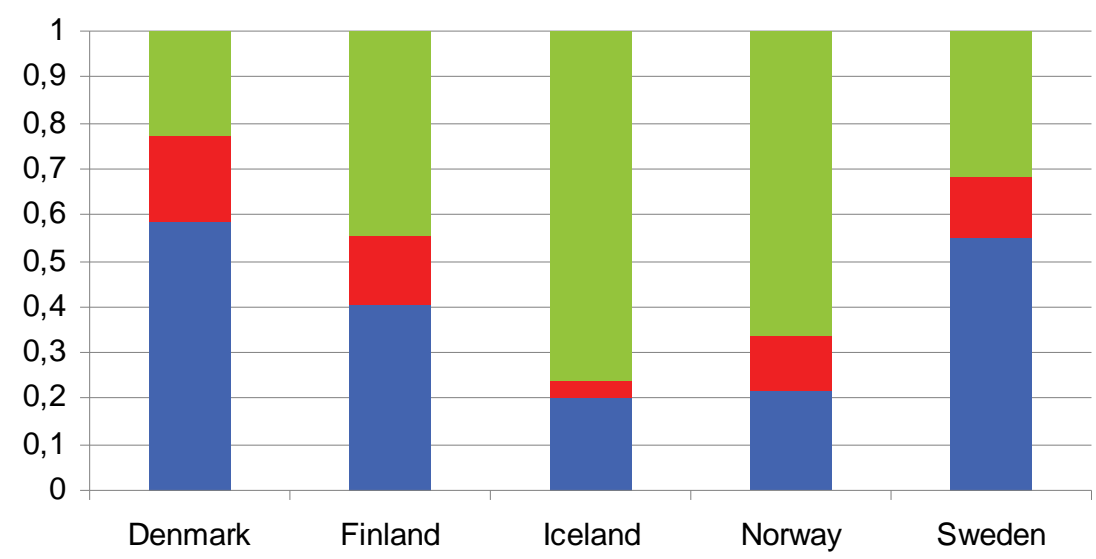

Two or more schools $\square$ One other school $\square$ No other schools

Figure 2.2.2. Schooling options available in Nordic countries (\%) as experienced by principals

Major observations are: a) in Denmark and Sweden, and partly also in Finland, there are options to select from, and b) in Iceland and Norway there is mostly just one local school to attend. In deciding admissions there are also some differences between the Nordic countries (figure 2.2.3) concerning catchment areas, as experienced by principals ${ }^{7}$.

7 Admission, role of residence, SC19Q01: How much consideration is given to the following factors when students are admitted to your school? Alternatives: prerequisite, high priority, considered, not considered; residence in a particular area, student's academic record, recommendation of feeder schools, parents' endorsement of the instructional or religious philosophy of the school, student's need or desire for a special programme, attendance of other family members at the school. 


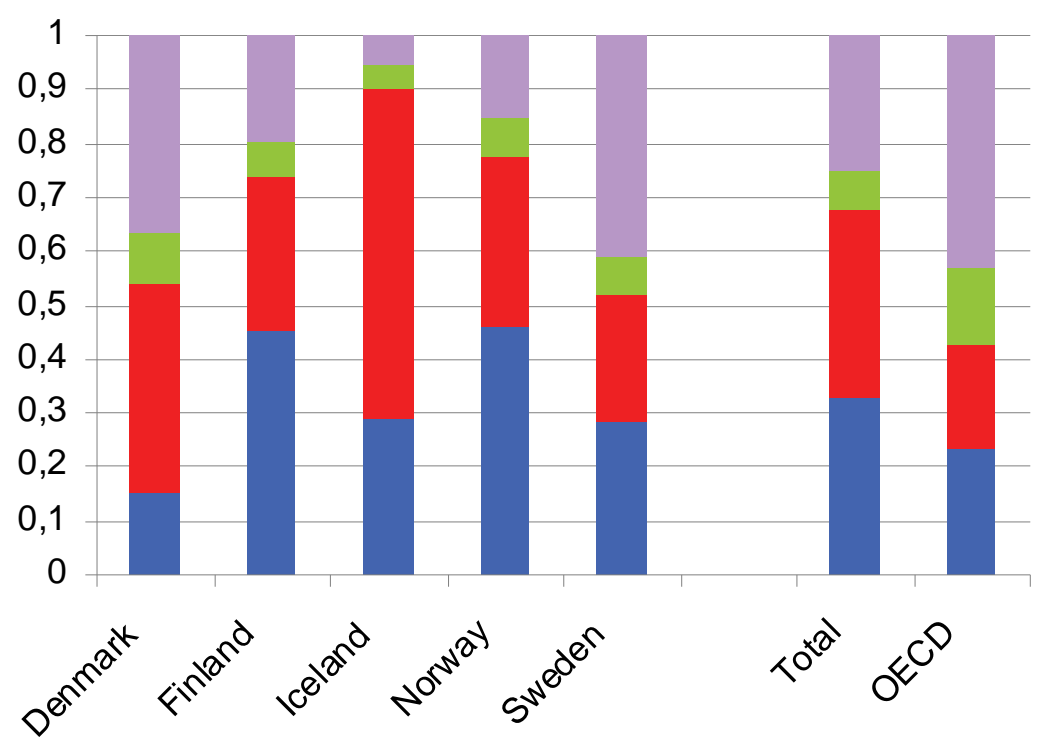

\section{$\square$ Prerequisite $\square$ High priority $\square$ Considered $\square$ Not considered}

Figure 2.2.3. Reasons for admission to schools as experienced by principals

In comparison to the OECD, all the Nordic countries are quite similar and do not often use between class streaming ${ }^{8}$, with the most strict country being Norway and to some extent Denmark. In all countries, with small differences, within-class streaming is more often used for particular subjects $^{9}$. The two countries, with least within-class streaming are Finland and Norway. All these outcomes can be related to the fact that in the Nordic countries, the between-school variation is also low: for PISA science, the figures are 5.8 in Finland, 9.2 in Iceland, 9.9 in Norway, 12.0 in Sweden and 15.4 in Denmark, whereas the OECD mean between-school variation estimate is 34 (OECD 2007).

8 Streaming used in between classes, SC08Q01: Some schools organise instruction differently for students with different abilities. What is your school's policy about this for students, a) students are grouped by ability into different classes, b) students are grouped by ability within their classes - for all subjects $1.4 \%$, for some subjects $22 \%$ and not for any subjects $77 \%$ (means for all Nordic countries).

9 Streaming used within classes, SC08Q02: for all subjects $14 \%$, for some subjects $52 \%$ and not for any subjects $44 \%$ (means for all Nordic countries). 


\section{Accountability}

Generally speaking, accountability refers in this section to the provision of information to parents. Often this information is in the form of reports, but there are also other forms. Reports (school grades, or GPA) are a way to transmit the values of schooling to students, who are expected to adapt themselves according to the information given and received. Reports are forms of official feedback and reporting is therefore also regulated in each country in their respective ways. One educationally important issue is the norms for grading, i.e., which norms are used in assessing students, and what is their relative role, especially in relation to informing parents. The information provided (the type of question may also refer to other forms of information apart from school reports) is relative to certain options (figure 2.2.4): pieces of information given to parents are based on relating students' learning activity and educational outcomes to other students in the school, to given and often written national or regional benchmarks or to the same grade in other schools ${ }^{10}$.

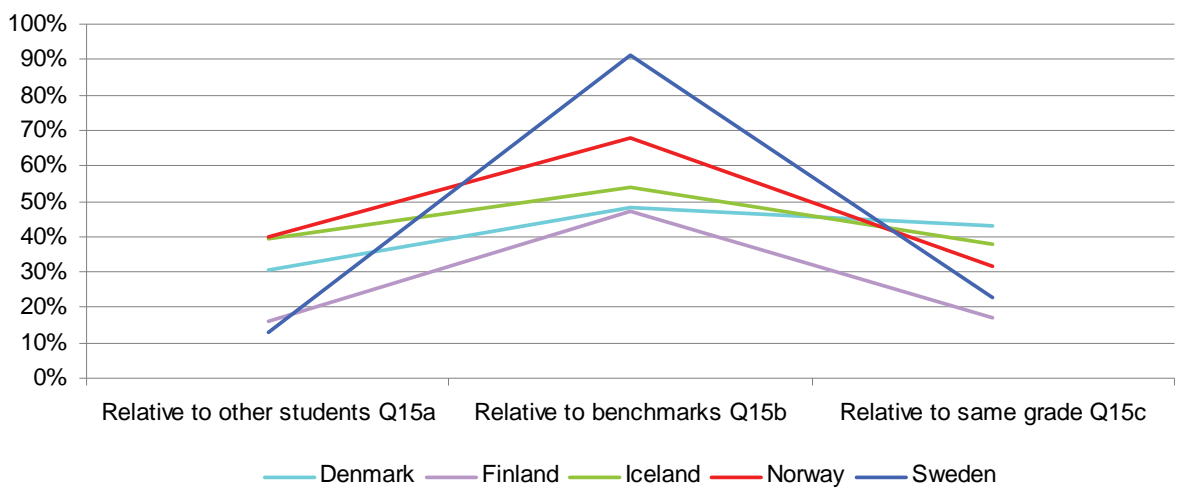

Figure 2.2.4. How information is provided to parents in Nordic countries as experienced by principals

The Nordic total profile is different from the OECD profile so that when, for example, in the Nordic total profile, the percentages are $27 \%, 64 \%$ and $30 \%$ for options relative to other students, relative to benchmarks and 
relative to the same grade, the OECD profile is $55 \%, 43 \%$ and $26 \%$. In Nordic countries the benchmarks are the tool most often used in reporting to parents, and this is the case especially in Sweden. The achievement data and other outcomes of schooling are, however, also used for other purposes (figure 2.2.5) than supporting students in their learning ${ }^{11}$.

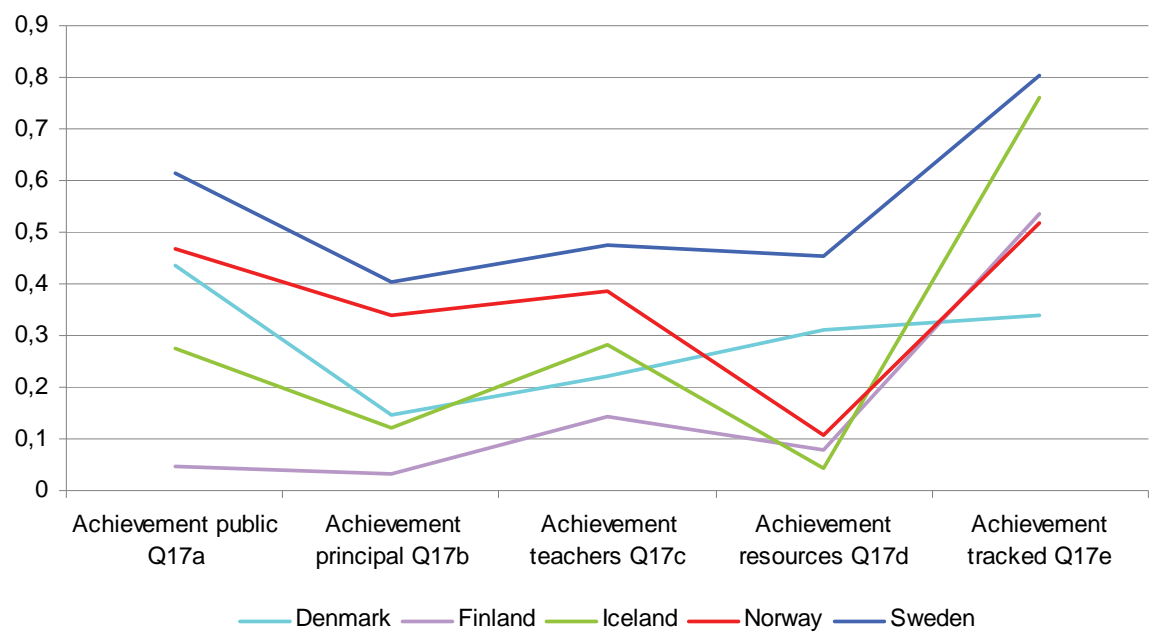

Figure 2.2.5. Achievement data are used also for other purposes as experienced by principals

The clearest difference is in relation to making reports and other outcomes public, which very seldom takes place in Finland, but very often in Sweden. This means that Finland, where almost no public reporting is done, has the highest Nordic level in PISA domains. This seems to have deep educational implications, which, at the same time, are also connected to issues of parental pressure and school choices.

11 In your school, are achievement data used in any of the following (SC17Q01-05): are posted publicly (e.g. in the media), in evaluation of the principal's performance, in evaluation of teachers' performance, in decisions about instructional resource allocation to the school, are tracked over time by an administrative authority? 


\section{Teachers and other resources}

It is important to have qualified teachers in all subjects of PISA domains (table 2.2.1) ${ }^{12}$.

Table 2.2.1. Shortage of teachers (science, math and national language) as experienced by principals

$\%$ within Country

Shortage science teachers Q14a

\begin{tabular}{llrrrrrr}
\hline & Not at all & Very little & $\begin{array}{r}\text { To some } \\
\text { extent }\end{array}$ & A lot & Total & N \\
\hline \multirow{2}{*}{ Country } & & & & & \\
& Denmark & $50,3 \%$ & $26,9 \%$ & $22,2 \%$ &, $6 \%$ & $100,0 \%$ & 171 \\
& Finland & $81,8 \%$ & $14,9 \%$ & $3,2 \%$ &, $0 \%$ & $100,0 \%$ & 154 \\
& Iceland & $47,2 \%$ & $18,9 \%$ & $25,2 \%$ & $8,7 \%$ & $100,0 \%$ & 127 \\
& Norway & $39,5 \%$ & $39,5 \%$ & $20,5 \%$ &, $5 \%$ & $100,0 \%$ & 195 \\
& Sweden & $78,1 \%$ & $14,3 \%$ & $6,6 \%$ & $1,0 \%$ & $100,0 \%$ & 196 \\
& Total & $59,5 \%$ & $23,5 \%$ & $15,2 \%$ & $1,8 \%$ & $100,0 \%$ & 843 \\
& OECD & $61,2 \%$ & $20,9 \%$ & $15,1 \%$ & $2,7 \%$ & $100,0 \%$ & 8,602 \\
\hline
\end{tabular}

$\%$ within Country

Shortage maths teachers Q14b

\begin{tabular}{llrrrrrr}
\hline & Not at all & Very little & $\begin{array}{r}\text { To some } \\
\text { extent }\end{array}$ & A lot & Total \\
\hline \multirow{2}{*}{ Country } & Denmark & $73,3 \%$ & $21,5 \%$ & $5,2 \%$ &, $0 \%$ & $100,0 \%$ & 172 \\
& Finland & $81,2 \%$ & $16,2 \%$ & $2,6 \%$ &, $0 \%$ & $100,0 \%$ & 154 \\
& Iceland & $59,1 \%$ & $18,9 \%$ & $18,9 \%$ & $3,1 \%$ & $100,0 \%$ & 127 \\
& Norway & $44,1 \%$ & $37,4 \%$ & $17,9 \%$ &, $5 \%$ & $100,0 \%$ & 195 \\
Sweden & $80,2 \%$ & $14,7 \%$ & $4,1 \%$ & $1,0 \%$ & $100,0 \%$ & 197 \\
& Total & $67,5 \%$ & $22,2 \%$ & $9,5 \%$ &, $8 \%$ & $100,0 \%$ & 845 \\
& OECD & $64,2 \%$ & $19,6 \%$ & $13,1 \%$ & $3,2 \%$ & $100,0 \%$ & 8,611 \\
\hline
\end{tabular}

$\%$ within Country.

Shortage <test lang > teachers Q14c

\begin{tabular}{llrrrrrr}
\hline & Not at all & Very little & $\begin{array}{r}\text { To some } \\
\text { extent }\end{array}$ & A lot & Total & N \\
\hline \multirow{2}{*}{ Country } & Denmark & $76,2 \%$ & $20,3 \%$ & $3,5 \%$ &, $0 \%$ & $100,0 \%$ & 172 \\
& Finland & $87,0 \%$ & $11,7 \%$ & $1,3 \%$ &, $0 \%$ & $100,0 \%$ & 154 \\
& Iceland & $68,5 \%$ & $18,9 \%$ & $11,0 \%$ & $1,6 \%$ & $100,0 \%$ & 127 \\
& Norway & $49,5 \%$ & $40,7 \%$ & $9,8 \%$ &, $0 \%$ & $100,0 \%$ & 194 \\
& Sweden & $84,8 \%$ & $11,7 \%$ & $3,6 \%$ &, $0 \%$ & $100,0 \%$ & 197 \\
& Total & $72,9 \%$ & $21,2 \%$ & $5,7 \%$ &, $2 \%$ & $100,0 \%$ & 844 \\
& OECD & $69,7 \%$ & $18,6 \%$ & $9,4 \%$ & $2,3 \%$ & $100,0 \%$ & 8,610 \\
\hline
\end{tabular}

12 Is your school's capacity to provide instruction hindered by a lack of teachers (not at all, very little, to some extent, a lot) in science (SC14Q01), mathematics (SC14Q02), in national language (SC14Q03)? 
The observation is clear: the teacher situation is good in Finland and Sweden, and bad in Norway. Denmark and Iceland have some problems in finding science teachers. Here again it is relevant to remember that these results only reflect the opinion and experiences of principals, but there is no reason to doubt their statements.

Also other resources, mainly from the perspective of science teaching, have been estimated. The overall impression is that there is always some need for more, but the majority of the principals feel that there is either no need, or very little need in most areas. However, there are some concerns especially in Iceland and Norway.

Science education activities

The PISA questionnaire included questions which asked about forms of science education (figure 2.2.6) ${ }^{13}$.

13 What activities have been used? The original coding has been recoded so that yes $=1$, and no $=0$, SC20Q01-SC20Q05, 


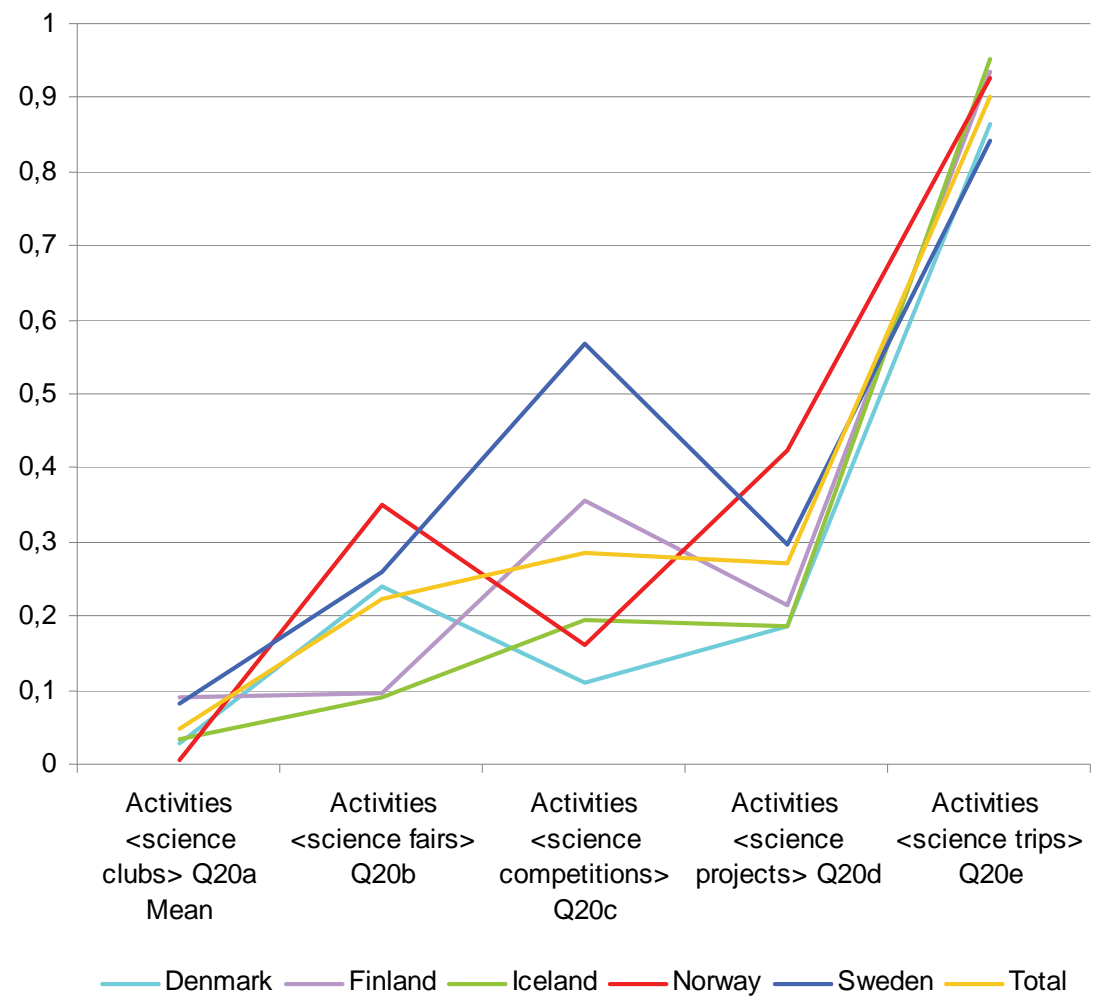

Figure 2.2.6. External forms of science education used in Nordic countries as experienced by principals

The major observation is the relatively low level of external activities with two exceptions: in all Nordic countries science trips are frequent. There are no details of where trips have been made, but one can speculate that visits cover industry and science centres. The other exception is the use of competitive activities in Sweden. It might be interesting to survey this by detailed comparative studies, but this is not done here (see, however, the science chapters). 


\section{Student-level}

\section{Students and the science teaching context experienced}

Students answered questions, which measured their experiences in science learning ${ }^{14}$. These items have been factor analysed (maximum likelihood, with Oblimim rotation and Kaiser normalisation) in order to condense information. The resulting four scales are named using the highest loadings:

- Scale 1 -Science-teaching, which follows the traditions of science education, where experiments and scientific reasoning are emphasised.

- Scale 2 - Student-centred teaching where their opinions and ideas as well as sharing of these are emphasised.

- Scale 3 -Activation and planning and running own experimentation is emphasised.

- Scale 4-Bridging and applications, where the connections between school learning and processes outside school are emphasised in order to enhance transfer and consolidation of learned pieces of knowledge and skills to support the idea of relevance.

The results are presented using mean scores of these four scales, not the standardised scores. The scales have been reversed so that the value of 1 refers to hardly ever and value of 4 to in every lesson (Figure 2.2.7). For interpretation, 2.5 is the mean value of the scale. Given this, the figure means that teaching is not very experimental or flexible to students' ideas or for connecting science lessons to issues outside classrooms, but not so low in asking for their opinions.

14 Students responded on a 4-point likert scale to questions which tapped their experiences as to whether a specific method of science education has been used in their lesson: ST34Q01ST34Q17. There were 17 different options. Based on factor analysis, four scales were formed and named. The figures are means in a scale where the direction has been recoded from the original to 1 = hardly ever ... $4=$ in every lesson. 


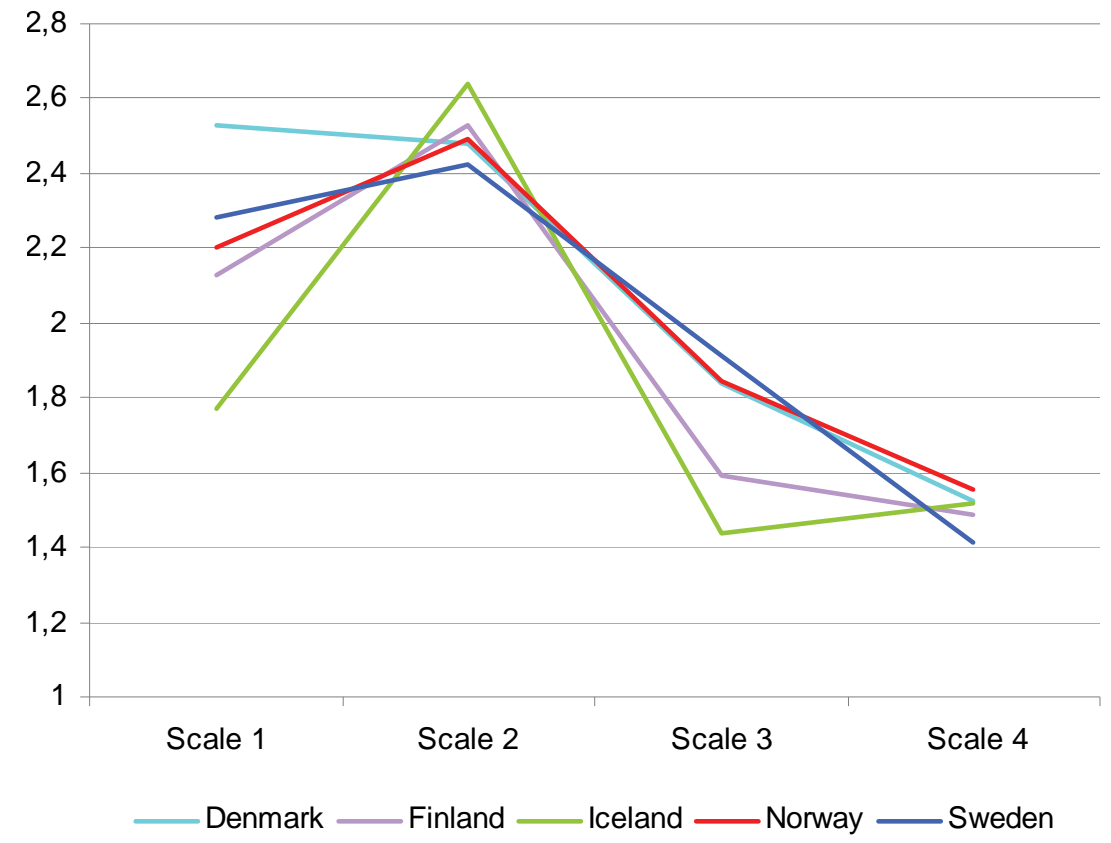

Figure 2.2.7. Means for science teaching scales in Nordic countries (Scale $1=$ Science-teaching, Scale 2=Student-centred, Scale 3=Activation, Scale 4=Bridging) (1=hardly ever, $4=$ every lesson) as experienced by students

The major difference is in Scale 1, using the experimental methods of science in science teaching. The lowest value is for Iceland and the highest value is for Denmark. Iceland and Finland have the lowest mean in the F3 (activation of students, allowing students to do their own things).

The schooling controls some part of the free time of students by giving home tasks for self-study ${ }^{15}$. The Nordic countries are similar in this respect (figure 2.2.8). In almost $80 \%$ of cases in all Nordic countries students stated that they do not do spend more than 2 hours at home doing home-work or other school-related work in science. 


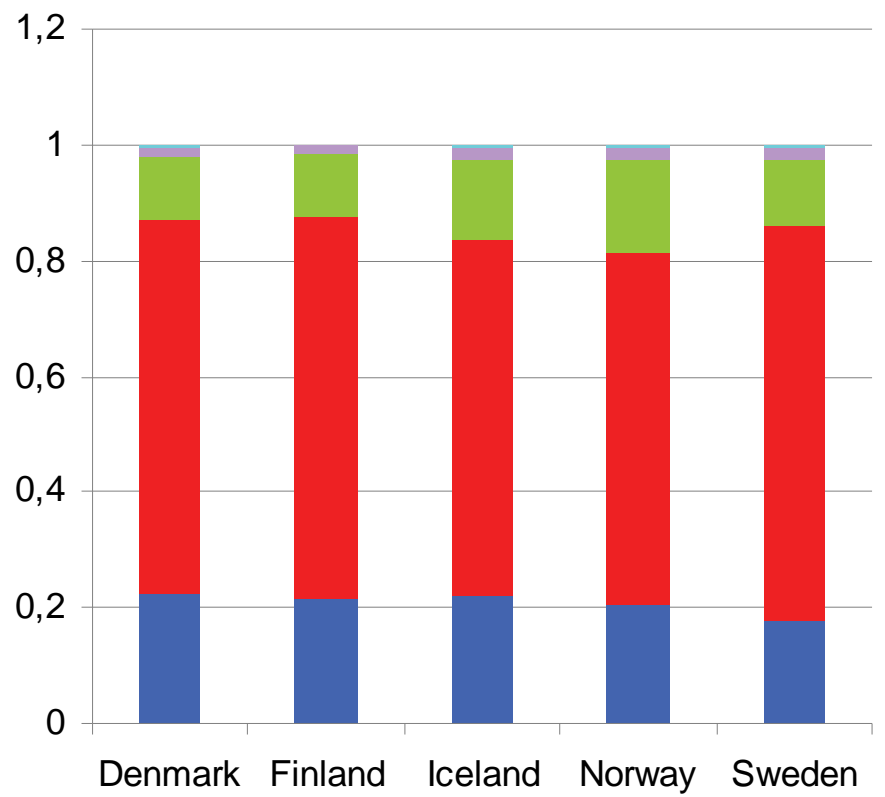

No time

- Less than 2 hours $\quad 2$ up to 4 hours

4 up to 6 hours 6 or more hours

Figure 2.2.8. Self-studying in science subjects in Nordic countries (\%) as experienced by students

\section{Conclusions}

In Sweden many parents are demanding, whereas in Finland very few put pressure on the school in relation to academic standards. Sweden is different from the other Nordic countries. The other three - Denmark, Iceland and Norway - are relatively similar. And all are different from Finland in relation to the answer-option "largely absent". Given the Swedish results, this might mean the staging of a national debate about schooling in Sweden, regarding knowledge-related issues is important for parents. In Finland, it is commonly believed in the research community that one of the most important explanations for good PISA outcomes is trust (Välijärvi et al, 2006; Hautamäki et al 2008). But this trust cannot exist or continue to exist if parents are unable to see that the results of 
every local and public school are good enough. If this were not the case, it would be most likely that some parents would want to have options as to which school their children could study in.

In Denmark and Sweden, and partly also in Finland, there are options for parents when deciding where they want their children to study, but in Iceland and Norway there is mostly only one option, the local school. What types of options exist, needs to be also taken into account - are they local municipal schools, or are there also private schools? This is a question of national educational policies, which is not discussed in this chapter.

In comparison to the OECD, the Nordic countries do not use between class streaming to the same degree, the most stringent country being Norway and to some extent Denmark. In all countries, within-class streaming is more often used only for particular subjects. The two most stringent countries against using within-class streaming are Finland and Norway. All these outcomes can also be related to the fact that in the Nordic countries, the between-school variation is also the lowest in the world: for PISA science, the figures are 5.8 in Finland, 9.2 in Iceland, 9.9 in Norway, 12.0 in Sweden and 15.4 in Denmark, and the OECD mean between-school variation estimate is 34 (OECD 2007).

Given the assumed importance of the role of qualified teachers in producing or supporting the PISA kind of learning, it is also important to note that generally speaking principals are of the opinion that they have a good stock of teachers available. The teacher situation is good in Finland and Sweden, but relatively bad in Norway. Denmark and Iceland have some problems in finding science teachers, which is an area of concern for all the Nordic countries.

There was a major difference in the use of experimental methods of science in science teaching. The lowest value was for Iceland and the highest for Denmark. Iceland and Finland have the lowest mean in the F3 (activation of students, allowing students to do their own work). Given that the idea behind PISA is to test the future knowledge society hypothesis, the Nordic results illustrate that it is surprising how little students have experienced science education as informing about life outside school: the value of 1.60 for Factor 4 (bridging) means that it is seldom performed. This means that even without trying really hard the Nordic countries have succeeded in supporting knowledge-society relevant learning, which is tested by PISA-Science items. 
In almost $80 \%$ of cases in all Nordic countries, students stated that they do not do spend more than 2 hours at home doing home-work or other school-related work in science. This means, that it seems there does not exist a social need or place for shadow-education, where students would repeat or rehearse the official curricula. This would go against the whole idea behind the Nordic societies: public services should serve the public without a need for private extras.

\section{References}

Andersen, T.M., Holmström, B., Honkapojhja, S., Korman, S., Söderström, H.T. \& Vartiainen, J. (2007). The Nordic Model. Embracing globalization and sharing risks. Helsinki: The Research Institute of the Finnish Economy (ETLA).
OECD. (2007a). PISA 2006 Science Competencies for Tomorrows World. Volume 1 - Analysis. Paris: OECD. OECD. (2007b). PISA 2006 Science Competencies for Tomorrows World. Volume 2 - Data. Paris: OECD 



\subsection{Science Performance: The Nordic Countries from an International Perspective}

Marit Kjærnsli and Svein Lie

\section{Introduction}

The present chapter presents and discusses some central findings regarding scientific literacy in PISA 2006. Various aspects of scientific literacy, as they are defined in the PISA framework, are first carefully described. What follows is a presentation of how the Nordic countries scored on the various cognitive science scales. The focus is partly on comparison between the Nordic countries, and partly on a comparison with the OECD average. In addition to comparing scale scores between countries, gender differences (within and between countries) are also of interest and will be discussed. Further, it is of particular interest in PISA to establish scales that provide valid and reliable trend measures between PISA data collection every three years. From a methodological point of view, there are challenges related to such trend measures, but nevertheless such measures are focused on here (with due respect to the limitations), simply because they are very important and illuminating from the viewpoint of educational policy. More detailed analyses, reflections and explanations can be found in the national reports for the Nordic countries (Egelund et al, 2007, Hautamäki et al 2008, Halldorsson et al 2007, Kjærnsli et al 2007, Skolverket 2007).

In this chapter we also have looked somewhat deeper into strengths and weaknesses for each of the Nordic countries. This is partly given in 
the form of scale scores on the various scales mentioned above. But more information can be found by examining the patterns of scores from item to item for each country. By carefully investigating similarities of these patterns, it is possible to calculate a correlation measure of cognitive similarity based on relative strengths and weaknesses concerning students' scores on individual items. Interestingly, not only the degree of similarity between the Nordic countries can be measured, but the method also provides evidence for possible influences in science education. To put it briefly: How similar are we (the Nordic countries), and which countries seem to have influenced us the most?

\section{Scientific literacy in PISA 2006}

\section{Main principles of the framework}

Scientific literacy was the major domain in PISA 2006, and therefore science could be addressed by the majority of cognitive assessment items, as well as topic-related questions in the student questionnaire. This fact led to a considerable broadening of the framework for the science domain in PISA compared to the former two surveys in 2000 and 2003. The 2006 framework (OECD 2006) includes both cognitive and affective aspects of students' "scientific literacy". Using the term "scientific literacy" rather than "science" for the domain underscores the importance of application of scientific knowledge in the context of life situations, as compared with just simple reproduction of traditional school science knowledge. This includes how scientific knowledge is used in everyday situations, such as interpreting information in newspapers and journals. The test items assess the students' scientific knowledge and their ability to relate and reason in concrete situations as described in the text. In the language of the framework, students are not only required to demonstrate knowledge of science in the form of knowledge and understanding of scientific facts and concepts, and their relationships, laws of nature, natural phenomena etc. In addition, they also need knowledge about science in the form of knowledge and understanding of the nature of science, methods of scientific enquiry and types of scientific explanations, etc. 


\section{Science competences}

The everyday aspect of science relevant for every citizen, not only for future scientists and/or for future learning, is fundamental in the framework. Noticeable is also the appreciation of attitudinal factors which is reflected also in the way the science test is designed. Concerning the cognitive aspects of science, perspectives such as the ability to draw conclusions based on scientific evidence and to understand the nature of scientific enquiry, the test demands clearly go beyond just remembering science fact or laws taught at school. This has clear consequences on how the science domain is organised, and how emphasis is distributed among the framework categories. The three main cognitive subcategories will be described in the following. More detailed description of the scientific literacy domain in PISA 2006 can be found in OECD 2006 and OECD 2007.

Identifying science issues requires that students show knowledge of science and what is regarded as the key features of science. Students are also expected to be able to recognize what kind of issues can be investigated scientifically, and show that they are familiar with the main procedures of scientific enquiry. Explaining phenomena scientifically refers to knowing and applying appropriate knowledge of science, such as facts, concepts and laws, especially with regard to interpreting phenomena and predicting changes in a given situation. The students have to use their specific knowledge of science in a given situation, or they have to explain phenomena scientifically. Using scientific evidence requires students to make conclusions based upon the evidence, give reasons and produce arguments for or against a given conclusion and show that they are able to communicate their reasoning and the supporting evidence.

It should be noted that traditionally and in many countries, science tests strongly concentrate on the second type of competence, what we might refer to as "pure" fact oriented content knowledge and conceptual understanding. Accordingly, PISA puts more emphasis on what is sometimes called the "process" aspects of science (competences 1 and 3 above) than what is usual around the world. This distribution obviously influences countries' scores in scientific literacy to varying degrees. In principle, one may well argue that the framework specifications "favour" English-speaking countries compared, for example, to countries from East Asia, and continental Europe. The argument relies on the fact that 
English-speaking countries do put relatively high emphasis on the "process" aspect of science. Nevertheless, the aspect of "fairness" is irrelevant for PISA, as explained earlier. It may well be, however, that the international consensus in PISA is a signal that a number of countries will actually direct their curricula more towards the PISA concept in the future. Needless to say, such a step should not be triggered by the goal of scoring higher in PISA, but rather the opposite, that scoring higher in PISA would be an effect of intentional revision of science curricula in the direction of useful science based on a perspective of "relevance for everyday and everybody".

It should here also be mentioned that the IEA TIMSS study (Martin et al 2008), which is more closely linked to school science, puts much less emphasis on the "process" aspect of science than does PISA. The English-speaking countries consequently have obtained relatively lower science scores in TIMSS than in PISA, and in PISA we also find the same pattern when looking at single items. English-speaking countries perform better on items focusing on "process" aspects, while East-European countries perform better on items with more emphasis on conceptual understanding (Grønmo et al 2004, Kjærnsli \& Molander 2003, Olsen 2005).

\section{Some main results in the science domain}

\section{Overall science scale}

Figure 1 illustrates the overall science results for the Nordic countries. The scores relates to a standardized scale with a mean of 500 and standard deviation of 100 score points at the student level, given equal weight to all OECD countries. In the figure, country averages are displayed as score points above or below the OECD mean. (Bar charts starting at zero score points would have been misleading, since this value does not refer to anything but five standard deviations below the average, and no student can possibly obtain this low score, even by getting all items incorrect.)

In Finland, the students' mean score in science is the best of all the participating countries, and far ahead of all the other Nordic countries, which are not far from the OECD mean. Sweden also comes out above, but not significantly above, the average. Norwegian students have the 
lowest mean score of the Nordic countries, outperforming only six of the 30 OECD countries. The overwhelming Finnish success in PISA stands out as a very consistent finding also in the reading and mathematics domains, as well as in former PISA assessments. The reasons behind this high performance have been discussed elsewhere (Välijärvi et al 2002) and will not be commented on here. But one comment might be worthwhile. By comparing data from other studies, particularly the IEA TIMSS 1995 study (Beaton et al 1996), where two adjacent age cohorts per country took part, it is possible to estimate the average increase in score points during one year of schooling (and of increasing age). As a very rough estimate, just to get an idea of how far the Finnish students are above their Nordic peers, between one and a half and two years might be reasonable. This is indeed a large gap!

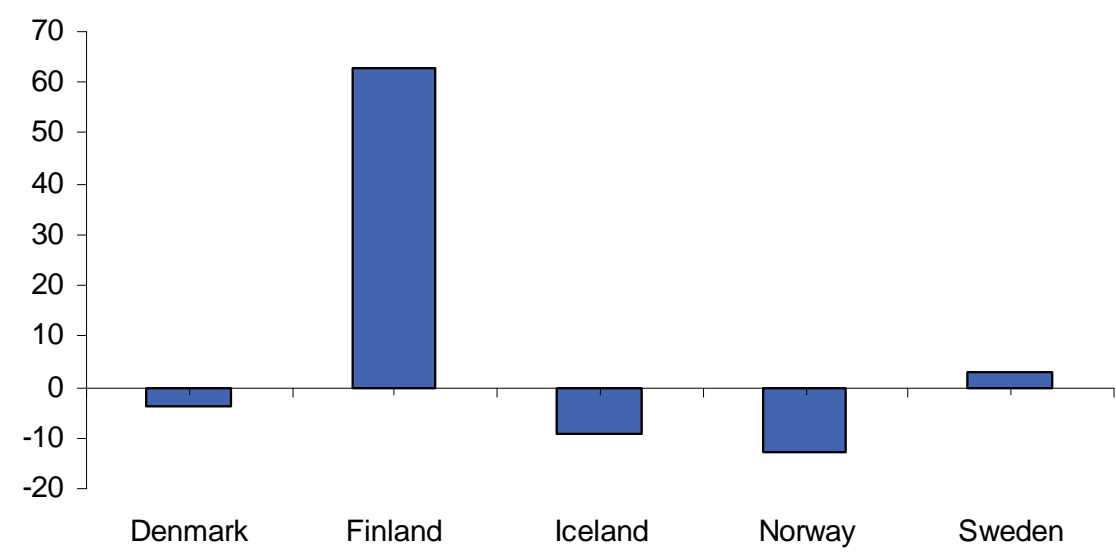

Figure 3.1.1. Science performance of the Nordic countries compared to the OECDaverage. Standard errors are around 2 score points.

Finland not only has the best performing students on average, but is also among the OECD countries with the lowest spread (measured by the standard deviation) of performance. The other Nordic countries have standard deviations close to the OECD average.

\section{Proficiency levels}

Student scores in science are grouped into six proficiency levels, with level 6 representing the highest score. The primary purpose of these lev- 
els is to be able to describe in words what kind of science competences students typically demonstrate at different points along the scale. Thus, the norm-related PISA scale to some extent can be interpreted and considered as goal-related. We can speak of a described norm-related scale. It is important that these levels are not applied to individual students, but it makes sense to describe proficiencies of typical students at certain levels.

The different levels and what students can typically do at each level of proficiency are described in detail in chapter 2 in the international report (OECD 2007). As an example, across the OECD, 94.8 percent of the students can perform tasks at least at level 1 , and what students typically can do at this level is described as:

At level 1, students have such a limited scientific knowledge that it can only be applied to a few, familiar situations. They can present scientific explanations that are obvious and that follow explicitly from given evidence.

(OECD 2007 p. 43)

As follows from the given percentage, a small but distinct group of students did not even reach the lowest level described, and these students are classified as performing "Below level 1". At the other end of the scale, 1.3 percent of students across the OECD can perform tasks at Level 6:

At level 6, students can consistently identify, explain and apply scientific knowledge and knowledge about science in a variety of complex life situations. They can link different information sources and explanations and use evidence from those sources to justify decisions. They clearly and consistently demonstrate advanced scientific thinking and reasoning, and they demonstrate willingness to use their scientific understanding in support of solutions to unfamiliar scientific and technological situations. Students at this level can use scientific knowledge and develop arguments to support recommendations and decisions that centre on personal, social or global situations.

(OECD 2007 p. 43)

The grouping of students into proficiency levels allows us to compare countries concerning their distribution on student proficiencies. Figure 3.1.2 displays the distribution of the five Nordic countries compared to the OECD average. It can be seen that the Nordic countries except Finland, have rather similar profiles to the OECD average. The small variations across the four countries mainly reflect variations in the average science performance discussed above (figure 3.1.1). However, it can 
be interesting to look closer at some of the profiles. As an example, Swedish students score on average very close to the OECD average, but they still have fewer students at level 1 and below (as well as at level 6). Finland's distribution is very different from that of the other Nordic countries. In particular, there are very few students at level 1 or lower. From Figure 3.1.2 one may conclude that this country has succeeded in raising all students to about one full level of proficiency higher than its Nordic neighbours.

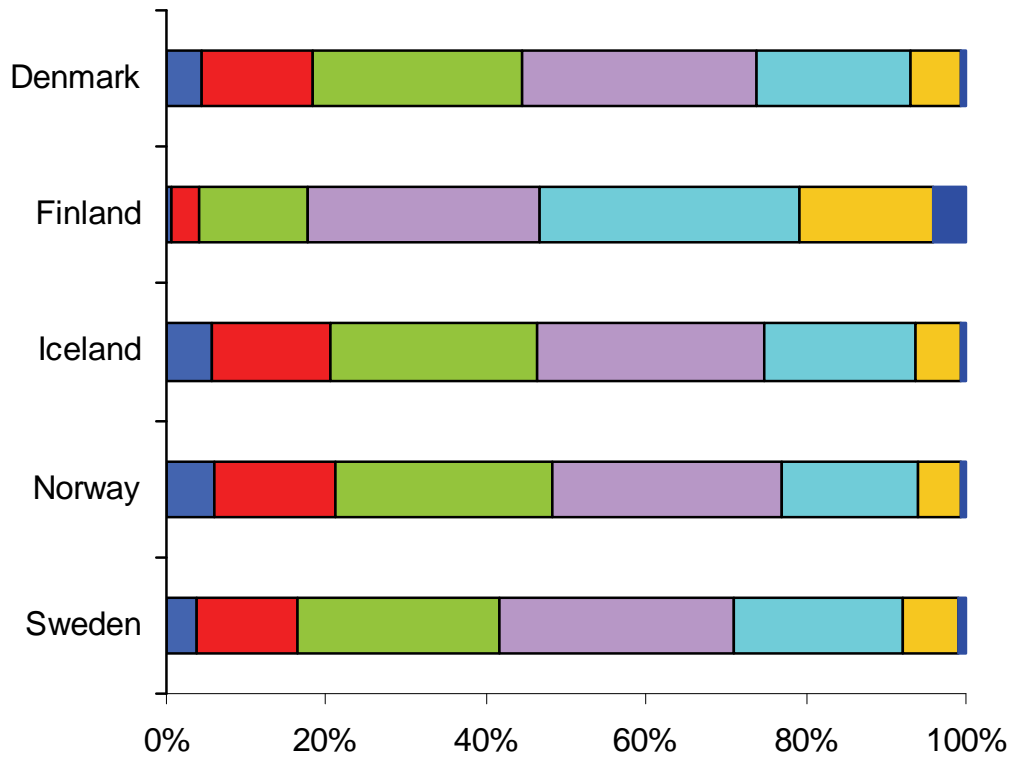

$\square$ Below level $1 \square$ Level $1 \square$ Level $2 \square$ Level $3 \square$ Level $4 \square$ Level $5 \square$ Level 6

Figure 3.1.2. Percentage of students at each proficiency level in science for each of the Nordic countries and the OECD average

Trends for the Nordic countries

Providing reliable and valid trend data is an important aim of international studies such as PISA. However, it is important to underline that such comparisons are difficult from a methodological perspective. In particular, it is more difficult in science (and mathematics) than in reading. Reading literacy was the main domain in PISA 2000, and several of the reading tasks used in 2000 were kept secret and used again for linking 
purposes. Furthermore, the reading literacy framework has been left more or less unchanged. In science, establishing trend measures is more problematic, since a new and broader framework was made for PISA 2006 with a slightly different perspective, where among other things, the demands on reading comprehension for solving the science items, are intentionally somewhat lowered.

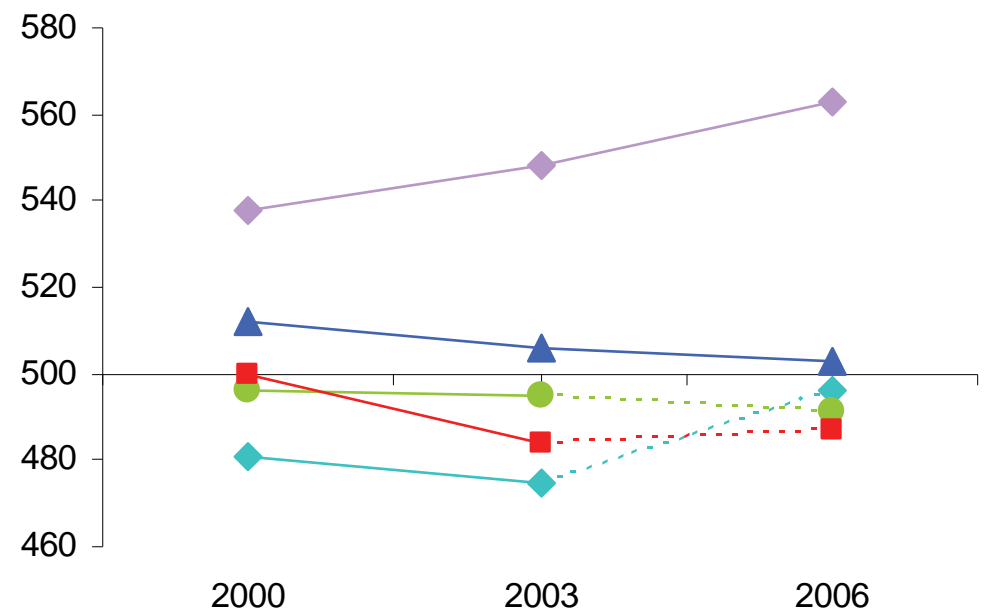

$\multimap$ Denmark $\multimap$ Finland $\_-$Iceland $\_-$Norway $\neg-$ Sweden

Figure 3.1.3. Trends in science literacy in the three PISA surveys in the Nordic countries. (Due to framework changes and methodological difficulties, details of the curves, particularly between 2003 and 2006 should not be overemphasized.)

Despite the uncertainty regarding the changes in the tests, and with certain reservations about the details (OECD 2007), we have chosen to visualize the development over time for science in figure 3.1.3 for all the Nordic countries. Even though there are some uncertainties concerning the details, it clearly appears that even though Finnish students were rated among the best in 2000, there has still been pronounced improvement. In Denmark there has also been a clear increase since 2003, and the Danish students this time achieved scores around the OECD mean. In addition, there has been an overall decline both in Norway and Sweden, whereas the Icelandic results are more or less the same in all three surveys. 


\section{Scientific competences and science areas}

\section{Scientific competences}

As described above, the cognitive part of scientific literacy in PISA is defined by three competences:

- Competence 1: Identifying scientific issues

- Competence 2: Explaining phenomena scientifically

- Competence 3: Using scientific evidence

For each of the three competences students are given separate scale scores, which allow us to compare student performance on each competency scale. Figure 3.1.4 illustrates the country "profiles" of competences for the Nordic countries. Disregarding the general performance difference between the countries, the point here is to focus on the shape of the curves, or profile of each country. Finnish students perform relatively best in competence 3, even though the difference between competence 2 and 3 is small. On the other hand, the profiles for the three Scandinavian countries are more or less the same, characterized by highest scores on competence 2, which we described above as the most content-based aspect of science. Students in these countries performed lower in competence 1 and (in particular) competence 3, with the Norwegian case as the most outstanding. Referring to the description above, we may say that students in these countries show relatively higher strength in knowledge of science than in knowledge about science, or alternatively, relatively more proficiency in the content as opposed to the process aspect of science. 


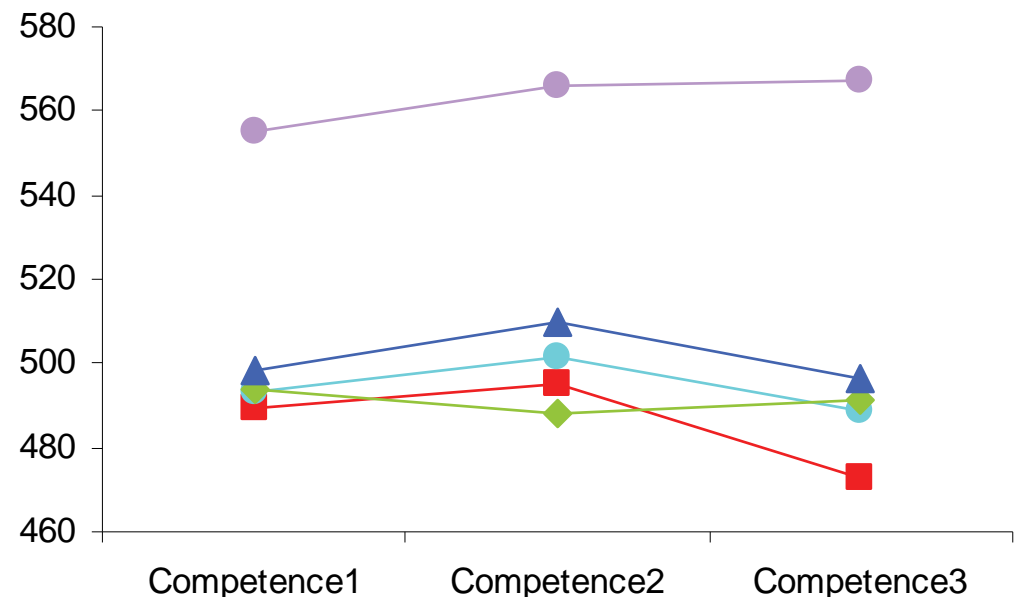

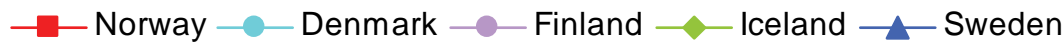

Figure 3.1.4. The average score for each competence in the Nordic countries. Standard errors are of the order of 3 score points. The three competences are defined and described in the text.

Student performance in different topic areas of science

In addition to providing scale scores in each of three different competences, PISA 2006 gives results on different knowledge domains. As explained above, there is the distinction between knowledge of and knowledge about science. The last of these two turned out to be more or less identical to the combined competence 1 and 3, or the process aspect of science. The aspect knowledge of science is further divided into three content areas, labelled "Physical systems", "Living systems" and "Earth and space systems".

In figure 3.1.5 the strengths and weaknesses of these categories are displayed for the Nordic countries. Here the scale is so-called ipsative, that is, for each country the score is compared to its own average. Accordingly, the figure focuses on the relative strengths and weaknesses. 


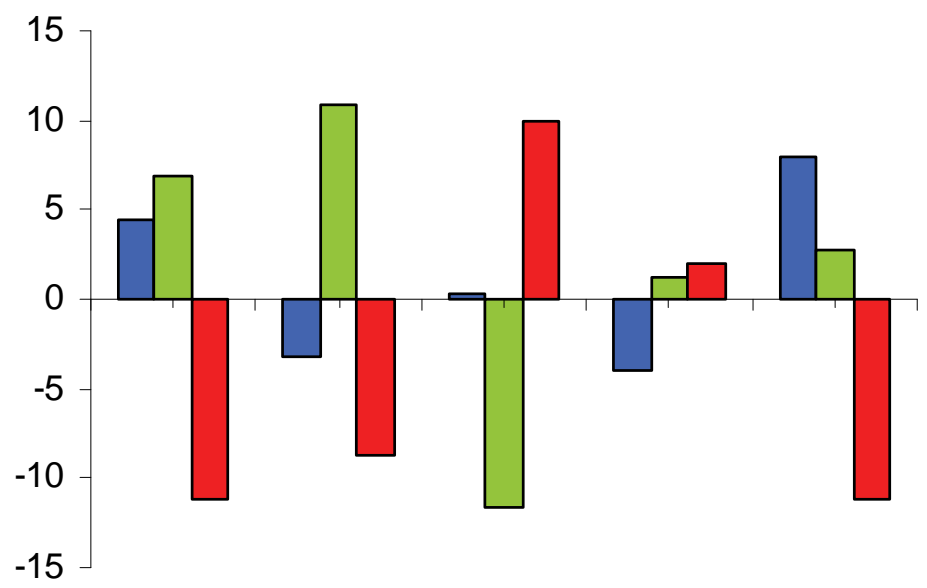

Denmark Finland Iceland Norway Sweden

$\square$ Physical systems $\square$ Living systems $\square$ Earth and space systems

Figure 3.1.5. Relative performance for the Nordic countries in the three content domains. The (ipsative) scale shows for each category the scores above or below its own across-category average. Standard errors are in the region of 2-4 score points.

Figure 3.1.5 illustrates some interesting differences and similarities. To some extent, countries could be expected to put more emphasis on their science curriculum on domains which are considered most relevant from a geographical point of view. Accordingly, Iceland stands out with a particular strength in "Earth and space systems" and a weakness in "Living systems", maybe, or even rather "naturally" due to the country's special geological conditions. On the other hand, Denmark, Finland and Sweden perform relatively weakest within the Earth and space domain, while this is not the case in Norway. Denmark and especially Finland perform relatively much better in Living systems, while Sweden performs relatively best in Physical systems. None of these characteristics turn out to be the opposite of what would be expected from purely simple judgments based on features of the nature and ways of living in the respective countries. 


\section{Gender differences in achievement}

\section{Overall science scale}

Gender differences in performance represent important findings in PISA. In general, gender performances in science (and mathematical) literacy is found to be small across the OECD-countries, both in absolute terms and compared with the large gender gap in reading performance, as illustrated in figure 3.1.6.

In all the Nordic countries there are rather small gender differences in science. Girls achieve slightly better than boys in Iceland, Norway and Finland. In Denmark the gender difference is largest (among the highest and also internationally), but the difference is in favour of boys. An interesting additional feature is worth commenting on, namely that earlier PISA studies also revealed this pattern: boys' performances relative to girls' is better in Denmark than in almost all other comparable countries.

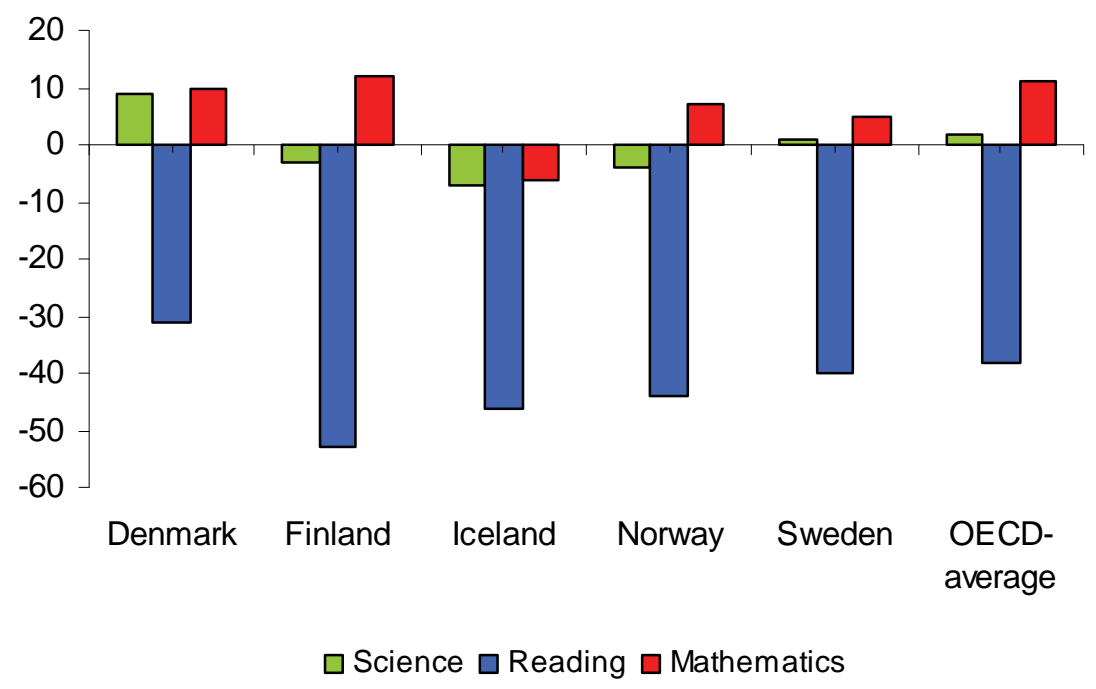

Figure 3.1.6. Gender differences in score points in the three PISA domains. Positive values are in favour of boys. (Standard errors are a few score points.) 


\section{Pattern of competences}

As discussed above, gender differences on the overall science performance scale tend to be minor. However, when it comes to both the different competences and content areas, as these are focused in the framework, gender differences are much more visible. Next we will consider these gender differences in some detail, and look for characteristic features. The first step involves comparing achievement within the topic areas of science. Gender differences by competence and country are shown in Figure 3.1.7. The figure illustrates that there are very strong competence fpatterns of gender differences: Girls perform significantly better than boys in competence 1, Identifying science issues. This is the case in almost all of the participating countries, the difference in girls' favour amounts to as much as 37 score points in the extreme case of Qatar. Among the Nordic countries, the difference is highest in Iceland, closely followed by Finland and Norway. In contrast, boys outperform girls in competence 2, Explaining phenomena scientifically. In the third competence, Using scientific evidence, gender differences are less pronounced, but tend to be in favour of girls.

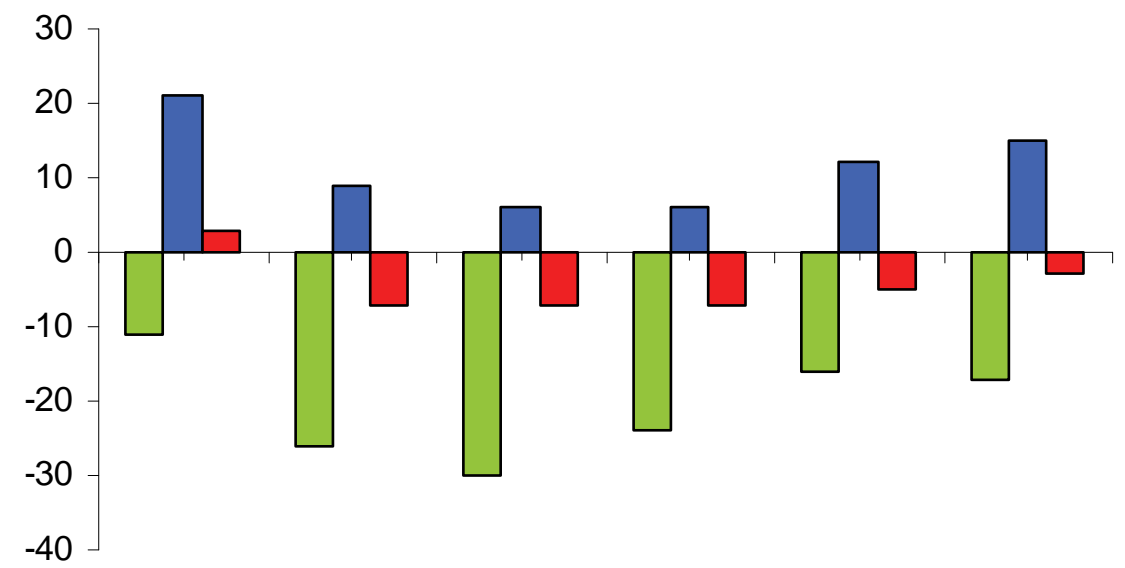

Denmark Finland Iceland Norway Sweden OECD

\section{Competence1 $\square$ Competence2 $\square$ Competence3}

Figure 3.1.7: Gender differences for each competence in science. Positive values are in favour of boys. (Standard errors are a few score points.) 
Two notable aspects of these findings can be summed up. Firstly, the competence pattern described is remarkably stable across countries and can somewhat loosely be stated as follows: Boys tend to know more about science content topics (competence 2), while girls tend to be better on the "process" side, scientific reasoning and understanding what science is about. Secondly, the characteristic differences between the Nordic countries in figure 3.1.7 can mostly be accounted for by the pattern for science overall (figure 3.1.6), with Denmark (favouring boys) and Iceland (favouring girls) as the two extremes.

\section{Pattern of content areas}

When looking at the different content areas in science, boys generally achieve better than girls in physics/chemistry and earth science, something which is a general finding across all participating countries and in line with a number of earlier studies (Kjærnsli \& Lie, 2000, Lie et al 1997, Martin et al 2004, Martin et al 2007). The results for the Nordic countries are displayed in figure 3.1.8.

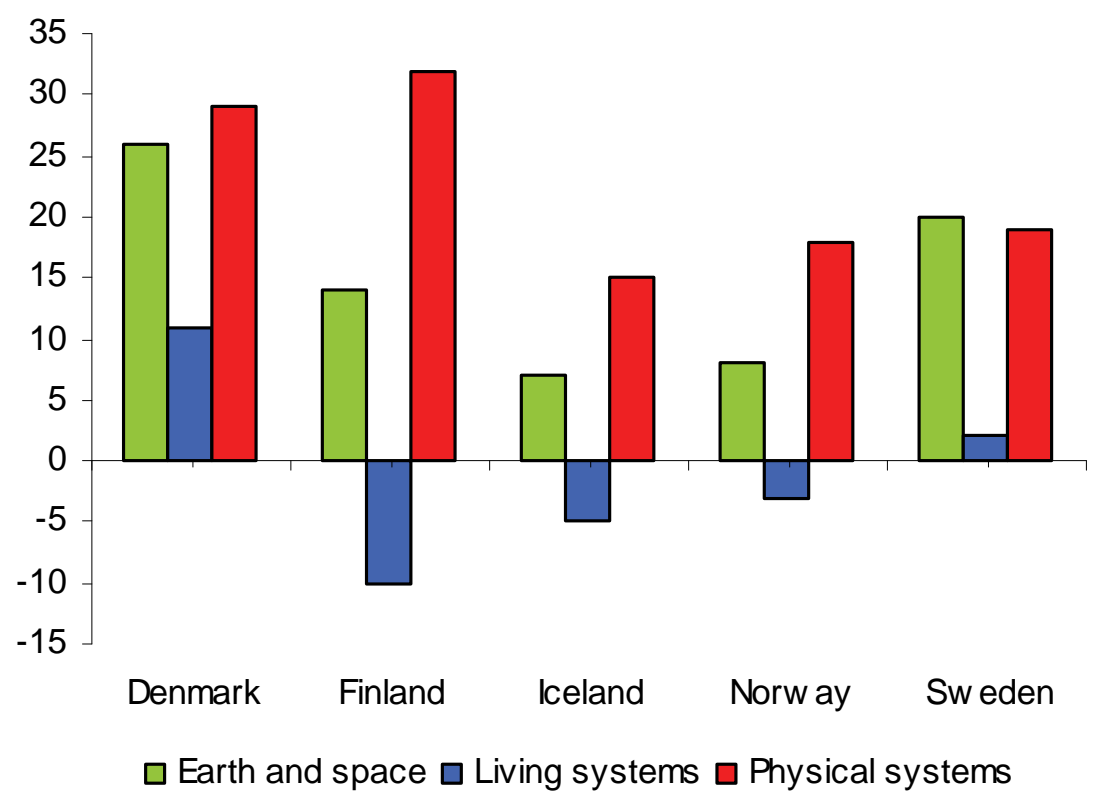

Figure 3.1.8. Gender differences in each area. Positive values in favour of boys. (Standard errors are a few score points.) 


\section{How different are we?}

\section{Similarities and differences on single items}

Now we shall address the following question: To what extent are there pronounced similarities between the five Nordic countries concerning students' detailed responses on individual items? How much better or worse do the students in a particular country perform on a particular item compared to what is expected from the overall achievement of the country and overall difficulty of the item? Any single item can be regarded as a "test" of its own, which in addition to contributing to the different scales, measures some very detailed competence which is specific to the item. Since we have detailed information on p-values (percentage of students with correct response) by country and by item, we can consider country-specific patterns of strengths and weaknesses from item to item. Instead of applying p-values directly, we prefer to subtract the effect of countries' different overall scores, making the patterns more comparable. Likewise, we also prefer to subtract the effect of items of varying difficulty. What we are left with is what we can call residual p-values: how much better or worse in percent terms have students in a particular country performed on a particular item compared to what is expected from the overall achievement of the country and the overall difficulty of the item. Each country comes out with its own pattern across all items, and by simple correlations between countries we have a measure of what we may call "achievement similarity". High correlation between two countries signals that their students tend to score relatively high (i.e. higher than expected from the international difficulties of items and students' general score) on the same items.

The correlations between the five Nordic countries are shown in table 3.1.1, which reveals some interesting characteristic traits. Firstly, all correlations are positive between the Nordic countries, and table 3.1.2 illustrates how the Nordic countries cluster and stand out from all the other countries where the correlations are weaker and also negative. Going back to table 3.1.1, the positive correlations between the Nordic countries are an indication of distinct similarities in strengths and weaknesses. In addition, some characteristic differences are evident. The three Scandinavian countries (Denmark, Norway and Sweden) have particularly high 
inter-correlations and thus demonstrate that they have more in common than with the other two countries. The pattern in this table almost invites us to look at a geographical map. The close connection between the Scandinavian countries (also almost the same language), the strongest link from Finland going to its closest neighbour Sweden, as well as the strongest link from Iceland going to Norway, can all easily be interpreted in a geographical context. Obviously, the roles of linguistic, historical and cultural interrelations and influences between individual countries have played and still play important roles in this respect.

Table 3.1.1. Cognitive similarities between the Nordic countries (correlations between countries' residual $p$-values of items)

\begin{tabular}{lrrrr}
\hline & Denmark & Finland & Iceland & Norway \\
\hline Finland & 0,14 & & & \\
Iceland & 0,27 & 0,05 & & \\
Norway & 0,57 & 0,20 & 0,31 & \\
Sweden & 0,50 & 0,24 & 0,24 & 0,56 \\
\hline
\end{tabular}

We can also look outside the Nordic region and try to find, as it were, our place among all other participating countries. For that purpose, we first calculated the average residual p-values for the five Nordic countries. These Nordic residuals were correlated with all individual countries, including the Nordic countries themselves. The results are shown in table 3.1.2. 
Table 3.1.2. Correlations between the Nordic countries as a group and all individual PISA countries based on residual $p$-values for all science items

\begin{tabular}{llllll}
\hline Country & Corr. & Country & Corr. & Country & Corr. \\
\hline Norway & 0.77 & New Zealand & 0.05 & Chinese Taipei & -0.15 \\
Sweden & 0.75 & Lithuania & 0.03 & Azerbaijan & -0.16 \\
Denmark & 0.73 & Italy & 0.03 & Uruguay & -0.18 \\
Iceland & 0.58 & Estonia & 0.02 & Tunisia & -0.18 \\
Finland & 0.52 & Belgium & 0.02 & Argentina & -0.19 \\
Austria & 0.41 & Latvia & 0.02 & Greece & -0.20 \\
Germany & 0.38 & United States & 0.02 & Serbia & -0.21 \\
Switzerland & 0.38 & Macao-China & 0.00 & Israel & -0.22 \\
Luxembourg & 0.33 & Portugal & 0.00 & Russia Fed. & -0.24 \\
Liechtenstein & 0.33 & Croatia & -0.02 & Qatar & -0.25 \\
Czech Rep. & 0.29 & Slovenia & -0.03 & Mexico & -0.26 \\
Poland & 0.17 & Slovak Rep. & -0.03 & Brazil & -0.27 \\
Hungary & 0.15 & Hong Kong & -0.03 & Colombia & -0.27 \\
United & 0.15 & Japan & -0.04 & Bulgaria & -0.27 \\
Kingdom & & Chile & & & -0.29 \\
Australia & 0.13 & Korea & -0.06 & Jordan & -0.30 \\
Netherlands & 0.10 & France & -0.07 & Indonesia & -0.32 \\
Ireland & 0.09 & Turkey & -0.10 & Montenegro & -0.32 \\
Canada & 0.08 & Thailand & -0.10 & Kyrgyzstan & -0.40 \\
Spain & 0.05 & & -0.14 & Rumania & \\
\hline
\end{tabular}

Many features are evident from table 3.1.2. Firstly, the close Scandinavian link strongly influences the Nordic average, and accordingly these three countries have higher correlations with the "Nordic group" than the other two have. Secondly, there is a remarkable tendency for the Germanspeaking countries (Austria, Germany, Switzerland, Liechtenstein and to some extent also Luxembourg) to have the strongest links to the Nordic group, all with correlations above 0.3. And thirdly, all English-speaking countries (United Kingdom, Australia, Ireland, Canada, New Zealand and USA) also have positive correlations. Finally, no Balkan, Asian or Latin American country links positively to the Nordic countries. The table invites further comments, particularly related to individual European, as well as East-Asian countries, but that is outside the scope of this chapter. For similar studies see Kjærnsli \& Lie 2004, Kjærnsli \& Lie 2008, Olsen 2005.

German or English influence?

Above we discussed the fact that German-speaking and to a lesser extent English-speaking countries also showed positive similarities with the 
Nordic countries. In table 3.1.3 we have provided some more information on these similarities. The table shows the correlation between each of the two country groups and the Nordic countries (as a group and individually). This data confirms that the Nordic countries, taken together or individually have much higher similarity with the German-speaking than with the English-speaking countries. And further, while correlations with the English group are low (but positive) for all Nordic countries, there is a pronounced difference between the Nordic countries concerning correlations with the German group, Finland representing the high and Iceland the low extremes.

Table 3.1.3. Cognitive similarities between the Nordic countries as a group and individually with the German- and English-speaking group of countries.

\begin{tabular}{lrrrrrr}
\hline & $\begin{array}{r}\text { Nordic } \\
\text { group }\end{array}$ & Denmark & Finland & Iceland & Norway & Sweden \\
\hline German group & 0.42 & 0.31 & 0.47 & 0.14 & 0.26 & 0.21 \\
English group & 0.10 & 0.06 & 0.09 & 0.01 & 0.05 & 0.13 \\
\hline
\end{tabular}

This data provides measures of similarities only, but they may well be interpreted as possible signals of influence on Nordic countries from the two strong and different cultural traditions when it comes to views of how science should be taught in school, as well as which aspects of science are given priority in the curriculum. The strong role of Knowledge about science in the English-speaking countries was discussed above. On the other hand, the German tradition in science education puts more emphasis on "pure" subject matter, and accordingly gets relatively higher scores in competence 2. Obviously, there is much more to say about science education in the two different traditions. But the data leads us to the interpretation that curricular emphases in the Nordic countries are more influenced by the German tradition. This is particularly the case for Finland, but not so much for Iceland.

\section{Concluding remarks}

In this chapter we have presented and discussed some central findings in scientific literacy in PISA 2006 for the Nordic countries. In Finland, the students' mean score in science is the best of all the participating countries 
and far ahead of all the other Nordic countries, which perform more or less in line with the OECD average. Norwegian students have the lowest mean score of the Nordic countries. When looking at proficiency levels, it can be seen that the Nordic countries, except for Finland, have profiles that are rather similar to the OECD average. The small variations across the four countries mainly reflect variations in average science performance.

The results furthermore show that students in the three Scandinavian countries have a relatively higher strength in knowledge of science than in knowledge about science, or alternatively, are relatively more proficient in the content than in the process aspect of science. When studying students' performances in different topic areas of science, the results mirror some of the natural geographical differences among the Nordic countries. For example Iceland particularly stands out in "Earth and space systems" and low performance in "Living systems".

Similarities between the five Nordic countries concerning students' detailed responses on individual items have also been analysed in this chapter. These analyses show that the Nordic countries form a cluster and stand out from all other countries, thus indicating that the Nordic countries show similarities in strengths and weaknesses on single items. The three Scandinavian countries (Denmark, Norway and Sweden) have particularly high inter-correlations and thus demonstrate that they have more in common than with the other two countries. This is interesting in the light of the historical and geographical picture given in chapter 1 in this report.

Trend measures may be some of the most interesting, but also some of the most challenging features, in these international studies. When starting with the first IEA-studies, FISS (First International Science Study) to SISS (Second International Science Study), TIMSS 95 (Third International Mathematics and Science Study)and TIMSS 2003 (Trends in International Mathematics and Science Study), we see some interesting patterns among the Nordic countries (Husén et al 1973, Postlethwaite \& Wiley 1992, Beaton et al 1996, Martin et al 2004). This picture is strengthened by the trends from PISA 2000 to PISA 2006 (OECD 2001, OECD 2007).

Trend measures with all their reservations and uncertainties taken into account show that students' performance is improving in Finland while the picture for Norway and Sweden shows the opposite. The trends from 
TIMSS 1995 to TIMSS 2003 show that Norway and Sweden have the largest decline of all the countries that can be compared (Grønmo et al 2004). The same worrying picture we also find in mathematics and reading, and this indicates the existence of a considerable problem, well worth making considerable efforts to understand why and to find relevant remedial measures.

\section{References}

Andersen. A.M. \& Sørensen, H. (2007). Naturvidenskabelige kompetencer en profil over elevprcestationer. I Egelund, N. (red) (2007). PISA 2006 Danske unge i en international sammenligning. Danmarks Pædagogiske Universitetsforlag, København.

Beaton, A. E., Martin, M. O., Mullis, I. V. S., Gonzalez, E. J., Smith, T. A. \& Kelly, D. L. (1996)/Science

Achievement in the Middle School Years./ /IEA’s Third International Mathematics and Science Study. /Center for the Study of Testing, Evaluation, and Educational Policy, Boston College.

Egelund, N. (red) (2007). PISA 2006 Danske unge i en international sammenligning. Danmarks Pædagogiske Universitetsforlag, København.

Hautamäki, J., Harjunen, E., Hautamäki, A., Karjalainen, T., Kupiainen, S., Laaksonen, S., Lavonen, J., Pehkonen, E., Rantanen, P., Scheinin, P., Halinen, I. \& Jakku-Sihvonen, R. (20008). PISA06 Finland. Analyses, Reflections and Explanations. Ministry of Education Publications 2008:44.

Halldorsson, A.M., Olafsson, R.F. \& Björnsson, J.K. Færni og pekking nemenda við lok grunnskóla:Helstu niðurstöður PISA 2006 í náttúrufræði, stærðfræði og lesskilningi. Námsmatsstofnun, Rit. no. 6. 2006. (PISA
2006 Icelandic National Report. Educational Testing Institute 2007).

Husén, T., Bergling, K. Fägerlind, I., Holm, L., Johansson, P. O., Liljefors, R. \& Mattson, I. (1973) Svensk skola i internationell belysning 1. Almqvist \& Wiksell, Stockholm.

Grønmo, L. S., Bergem, O. K., Kjærnsli, M., Lie, S. og Turmo, A. (2004). Hva i all verden har skjedd i realfagene? Norske elevers prestasjoner i matematikk og naturfag i TIMSS 2003. Oslo: Institutt for lærerutdanning og skoleutvikling, Universitetet i Oslo.

Kjærnsli, Lie, S., Olsen, R.V, Roe, A. (2007). Tid for tunge løft. Norske elevers kompetanse i naturfag, lesing og matematikk. Oslo: Universitetsforlaget. Kjærnsli, M. og Lie, S. (2000). Kjønnsforskjeller i realfag: Hva kan TIMSS fortelle? I G. Imsen (red.), Kjønn og likestilling i grunnskolen (s. 70-90). Oslo: Gyldendal Akademisk.

Kjærnsli, M. og Lie, S. (2004). PISA and Scientific Literacy: similarities and differences between the Nordic countries. Scandinavian Journal of Educational Research, 48(3), s. $271 \mathrm{x} 286$.

Kjærnsli, M. og Lie, S (2008). Country profiles of scientific competence in TIMSS 2003. Educational Research and Evaluation. Vol 14(1) (p 73-86), Routledge. 
Kjærnsli, M., Lie, S., Olsen, R. V., Roe, A. \& Turmo, A. (2004). Rett spor eller ville veier? Norske elevers prestasjoner i matematikk, naturfag og lesing $i$ PISA 2003. Oslo: Universitetsforlaget.

Kjærnsli, M. \& Molander, B.O. (2003). Scientific Literacy: Content knowledge and process skills. In Lie, S., Linnakylä, P. \& Roe, A. (Eds). Northern Lights on PISA. Unity and diversity in the Nordic countries in PISA 2000. ILS, Universitetet i Oslo Lie, S., Kjærnsli, M. og Brekke, G. (1997). Hva i all verden skjer i realfagene? Internasjonalt lys på trettenåringers kunnskaper, holdninger og undervisning i norsk skole. Oslo: Institutt for lærerutdanning og skoleutvikling, UiO.

Lie, S., Kjærnsli, M., Roe, A. og Turmo, A. (2001). Godt rustet for framtida? Norske 15-åringers kompetanse $i$ lesing og realfag i et internasjonalt perspektiv. Oslo: Institutt for lærerutdanning og skoleutvikling. Universitetet i Oslo.

Martin, M. O., Mullis, I. V. S., Gonzales, E.J. \& Chrostowski, S.J.(2004). TIMSS 2003 International Science Report. Findings from IEA's Trends in International Mathematics and Science Study at Fourth and Eight Grades. International Study Center, Lynch School of Education, Boston College.

Martin, M. O., Mullis, I. V. S. \& Foy, P. (2008). TIMSS 2007 International Science Report. Findings from IEA's
Trends in International Mathematics and Science Study at Fourth and Eight Grades.Chestnut Hill, MA, TIMSS \& PIRLS International Study Center, Lynch School of Education, Boston College.

OECD. (2001). Knowledge and Skills for Life. First results from PISA 2000. Paris: OECD Publications.

OECD. (2006). Assessing Scientific, Reading and Mathematical Literacy. A framework for PISA 2006. Paris: OECD Publications.

OECD. (2007).PISA 2006: Science Competences for Tomorrow's World. Paris: OECD Publications.

Olsen, R (2005). Achievement tests from an item perspective. An exploration of single item data from the PISA and TIMSS studies, and how such data can inform us about students' knowledge and thinking about science. Oslo: Unipub forlag.

Postlethwaite, T., N. \& Wiley, D.E. (1992) The IEA Study of Science II: Science Achievement in Twenty-Three Countries. Pergamon Press Oxford.

Skolverket (2007). PISA 2006. 15åringers förmåga att förstå, tolka och reflektera - naturvetenskap, matematik och läsförståelse. Rapport 306, Skolverket, Stockholm.

Välijärvi, J., Linnakylä, P., Kupari, P. \&Arrfman, I. (Eds) (2002). The Finnish success in PISA - and some reasons behind it: PISA 2000. Jyväskylä: Institute for Educational Research, OECD PISA, Opetushallitus. 



\subsection{Are Icelandic boys really better on computerised tests?}

Almar M. Halldórsson, Pippa McKelvie and Júlíus K. Björnsson

Interaction between gender, test modality and test performance.

\section{Abstract}

Iceland has participated in the OECD Programme for International Student Assessment (PISA) since the first study in 2000. In PISA 2003 Iceland was the country where girls had the greatest advantage over boys in reading literacy as well as in mathematics. The PISA 2006 cycle included an optional computer-based component assessing scientific competences (Computer-Based Assessment of Scientific Literacy - CBAS) and Iceland's participation in CBAS was intended to investigate this gender gap finding. This article examines modality effects on gender performance by comparing achievement results on the PISA 2006 paper and pencil (P\&P) assessment and CBAS. Gender difference is compared in terms of several factors relating to both student aptitude and item specific factors. These include: Computer familiarity, motivation, enjoyment, effort on the test, interactivity of computer items, reading load of items and item difficulty. A clear-cut finding is that boys in all three participating countries (Iceland, Denmark and Korea) outperformed girls in science literacy when the test was presented via computer regardless of the patterns of achievement across gender on the PISA paper and pencil test. Despite the intuitive relationship between higher motivation, greater experience with and confidence in ICT tasks and achievement on the computer-based test, 
statistical analysis of the correlations between achievement and these factors did not reveal any significant association with achievement. The increase in boys' performance in CBAS may however be partially explained by lower reading load and by boys' greater test fatigue on low difficulty items in paper based tests. Gender differences favouring girls in Iceland is removed in performance on paper based items of low reading load (under 100 words) so it is proposed that the difficulty of the P\&P science items may fatigue boys and encourages them to "give up" on P\&P tests more than girls. Boys may be disadvantaged by the length of the P\&P science items. Some cautionary notes are made about further studies with balanced test design, similar experiments should use a third reference group where a group of matched students are given the same paper and pencil items via computer.

\section{Introduction}

Iceland has participated in the Programme for International Student Assessment (PISA) since the first study in 2000. The PISA study has shown a strong female advantage in Iceland for students age 15, compared to other countries. The results for 2000 indicated that the gender gap in reading literacy favouring girls was substantial in Iceland. However, no gender difference was found in mathematics and science literacy that year. In PISA 2003, Iceland was noted as the only country where girls performed significantly better than boys in mathematics. In all 41 participating countries, Iceland was also the country where girls had the greatest advantage over boys in reading literacy. Furthermore, Iceland was one of only three countries where the science literacy of girls was higher than for boys. In PISA 2003 a special test was administered to assess problem solving skills of students and the greatest gender difference favouring girls by far was found in Iceland.

The PISA results on gender differences in Iceland received international media attention [1] and spurred further research in Iceland where gender differences in educational achievement had already been the subject of extensive research (see, for example, Jóhannesson, 2004; Magnúsdóttir, 2006; Ólafsson et al., 2006 and Ólafsson et al., 2007). There are indications of gender specific learning cultures, where learning plays a 
very different role for girls than for boys in the socialisation processes in adolescence. Magnúsdóttir's (2006) research indicates that getting high marks is part of the image of a girl leader, while for boy leaders high marks are not as important. Research by Kristjánsson et al. (2005) shows that a higher proportion of girls believe it is important to do well at school. More girls claim they intend to study at university and they like school more than boys do. Sigfúsdóttir (2005) also shows that the "cultural capital” of girls is greater than boys': They get greater support from their families, they are more often required to follow rules than boys, parents know their friends better, etc.

The PISA survey is administered in the standard paper and pencil format. More than 400000 students from 57 countries took part in the PISA 2006 assessment. The focus in this assessment cycle was on science literacy and the assessment also included an optional computer-based component assessing scientific competences (Computer-Based Assessment of Scientific Literacy - CBAS). Three countries administered the CBAS component (Denmark, Iceland and Korea).

Previous studies have indicated that use of computers in the home (and greater ICT confidence) is strongly correlated with higher academic achievement (Harrison et al., 2003; Ravitz et al., 2002). Further research shows that only home use of computers for educational purposes was associated with higher performance (in mathematics), whereas out-ofschool use of ICT was negatively associated with performance (Valentine et al., 2005).

Notably, computer-based assessment requires fewer language skills, can present more information succinctly and in a shorter space of time. It is particularly useful in the assessment of science for simulating scientific phenomena that cannot easily be observed in real time such as seeing things in slow-motion or speeded-up, for modelling scientific phenomena that are invisible to the naked eye (e.g., the movement of molecules in a gas). This presents students with the opportunity to perform repeat trials in limited testing time, or for working safely in lab-like simulations that would otherwise be hazardous or messy in a testing situation.

Iceland's participation in CBAS was in a substantial way based on the large gender gap finding in previous cycles of PISA. One hypothesis states that boys could potentially outperform girls on computer-based items because they are more competent in and familiar with the types of 
ICT tasks required of them to complete the items due to their greater ICT familiarity. However, OECD's PISA 2003 ICT report revealed that greater internet use and program use were actually associated with a drop in mathematics and reading performance, stating that "one cannot readily assume that computer usage is bound to be beneficial for students in all cases” (OECD, 2005b, p.65).

An important question is how much of gender difference in test performance can be attributed to the modality of the test, the way the material is presented and student's involvement in the test situation. This article examines modality effects on gender performance by comparing achievement results on the PISA 2006 paper and pencil assessment of science with performance in the CBAS 2006 computer-based component. Gender difference is compared in terms of several different factors relating to both student aptitude and item specific factors. These include: Computer familiarity, motivation, enjoyment, effort on the test, interactivity of computer items, reading load of items and item difficulty.

\section{Method}

\section{Sample}

All students participating in PISA and CBAS in 2006 were born in 1990. A subsample of 100 schools was selected to participate in CBAS from the main PISA 2006 school sample test in Iceland. From these schools, clusters of 5 to 45 PISA-eligible students were sampled from the PISA student sample. All schools and students selected for CBAS had already participated in the paper and pencil PISA 2006 assessment.

It is important to note that the sample considered in the present analysis includes all students that participated in the CBAS test session, as well as all PISA-participating students from the schools that had at least one student participating in CBAS. For Iceland, the original CBAS sample was drawn with 1,104 students out of which 784 students participated (71\% response rate). However, these analyses include data for an additional 2,782 students who participated in the paper and pencil assessment of science, attended a CBAS-participating school but did not respond to the CBAS test. To give achievement scores on the CBAS test for these 
students, plausible values on the CBAS scale were statistically imputed based on the students' PISA paper and pencil achievement and background information. A total of 3,566 students are thus included in the CBAS analyses for Iceland, which is very close to the total number of students participating in the paper and pencil PISA 2006 (3,789). As a result, we can be confident that the Icelandic sample for CBAS is representative of the population of 15 year old students in the country.

To account for any biases in selection of schools and students, the PISA data are weighted using a balanced repeated replication method. This accounts, for example, for any over- or underrepresentation of geographical areas within countries. More information about the weighting techniques in PISA can be found in the Data Analysis Manual (OECD, 2005a) or in the PISA 2006 Technical report (OECD, forthcoming).

In Denmark and Iceland the CBAS sample was approximately equally constituted of boys and girls, but in Korea there is a greater number of boys than girls (see table 3.2.1).

Table 3.2.1. Proportions of girls and boys in the sample analysed in this report

\begin{tabular}{lcc}
\hline & \multicolumn{2}{c}{ CBAS sample } \\
\cline { 2 - 3 } Country & Girls & Boys \\
\hline Denmark & $52 \%$ & $48 \%$ \\
Iceland & $50 \%$ & $50 \%$ \\
Korea & $44 \%$ & $56 \%$ \\
\hline
\end{tabular}

\section{Procedure}

CBAS test sessions took place either on the same day as the PISA paper and pencil assessment of students' reading, mathematics and science performance, or very shortly thereafter. Test administration was standardised so that all students performed the test on the same type of laptop, using the same software and in a similar testing environment. Up to five students participated in each test session under the guidance of one Test Administrator. The computer-based science items were presented to students on laptop computers through CBAS software specially designed for this purpose. This was a fixed-form test where the same 45 items were presented to all students in one of two possible orders. The order of items was split from the middle point of the second form so as to reduce fatigue effects on the items occurring later in the test. 
The software allowed students to move between items as they wished and to return to questions (changing their answers if necessary) until 55 minutes had elapsed from the beginning of the test, at which point the Test Administrator stopped the session. This allowed for just over 1 minute per question. If a student finished early, the items remained on the screen until the completion of the 55 minute test session. Following the cognitive items questionnaire, items were presented and students had 5 minutes to respond to these. In total therefore, test sessions were one hour long.

\section{Hardware}

All laptops used for student testing were required to comply with a number of minimum specifications: A CPU 1.6 GHz Pentium M Processor, memory 512 of RAM, hard disk 40 GB, display 14.1” XGA, an optical mouse, external stereo headphones and the operating system Windows XP Professional.

\section{Cognitive items}

In total, 45 items with multimedia extensions (animations using flash software, video footage or photos) were presented to students. The final analyses are performed on 42 items as two items were dropped prior to the analyses and two items were combined into one as they were considered to be assessing the same knowledge. Two additional items were set to "not administered" for Icelandic students, one showed video footage of a vitamin tablet dissolving in water which was judged to be an unfamiliar concept for Icelandic students, and in one of them specific terms in the item were not translatable into Icelandic. All item designs were either multiple choice or complex multiple choice involving, for example, a number of Yes/No responses for the answers offered. A small number of complex multiple choice items asked the students to place items in a specific order or position in a given diagram. 


\section{Scaling}

Initially, CBAS scores for the three countries (Iceland, Denmark and Korea) were scaled on the traditional PISA scale with a mean of 500 and a pooled SD of 100. Paper and pencil (P\&P) Science, Reading and Mathematics scores for the three CBAS countries were also re-scaled from the same model as the CBAS plausible values so as to allow calculation of correlations between CBAS and the paper domains. Because these new scores were re-scaled for only 3 countries, they are not directly comparable with the OECD reported PISA 2006 test scores where 500 and 100 are the mean and SD of all OECD countries. To avoid confusion between the scales all achievement scores have been re-standardised on a new scale with a mean of 5 and a SD of 2, meaning that over $99 \%$ of students have scores between 0 and 10 on the scale. This removes the possibility of direct comparisons between the scores reported here and the scores reported in the OECD PISA 2006 report which would not be valid because the plausible values are drawn from different models.

\section{Moderating factors}

\section{Item difficulty}

Item difficulties were calculated and figure 3.2.1 below shows that the items were approximately evenly distributed across the item difficulty scale from -3 to 3 with the mean item difficulty at zero, indicating good coverage of all potential competence levels. Percentage correct per CBAS item was also calculated and ranged from $13 \%$ to $94 \%$ with an average percentage correct per item of $60 \%$. Percentage correct per item was strongly associated with item difficulty from the model at 0.90 indicating that percentage correct per item is also an adequate measure of performance for specific analysis purposes. 


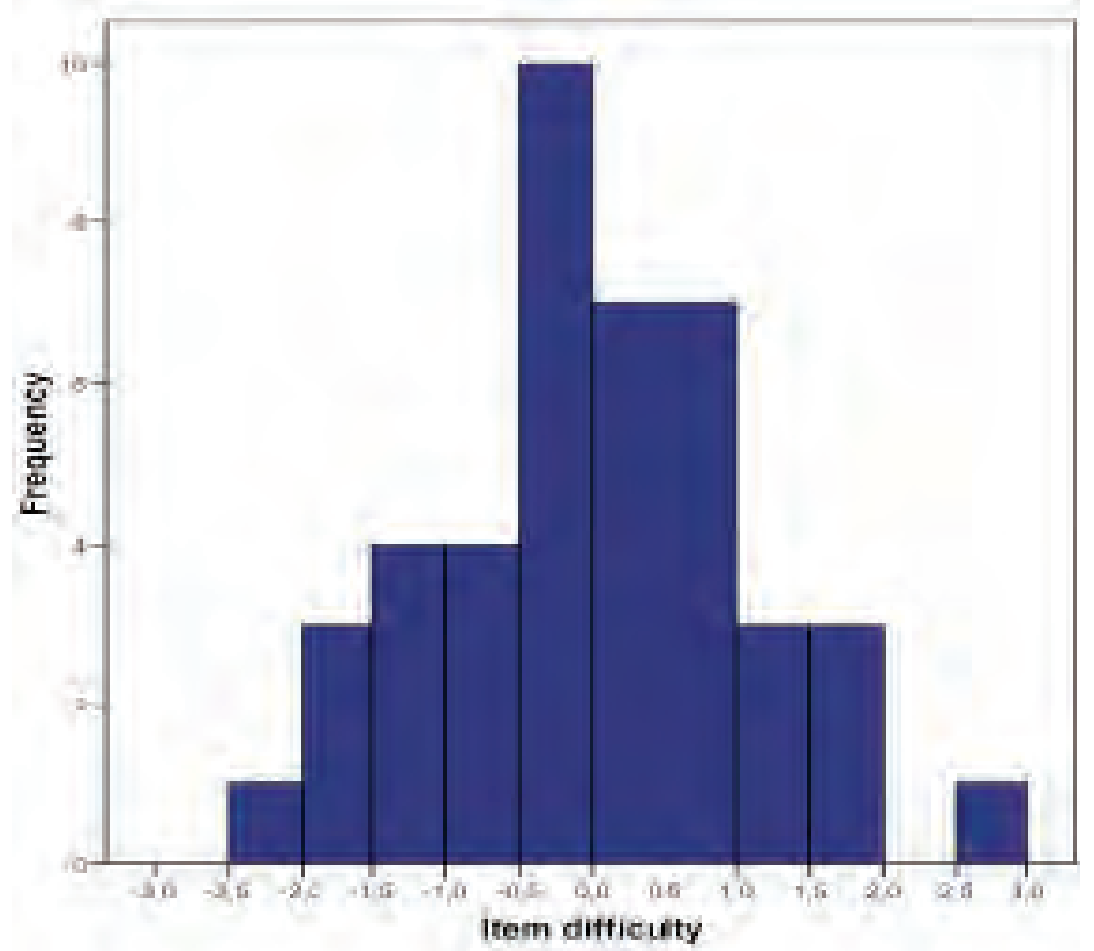

Figure 3.2.1. Distribution of Item difficulty for final CBAS items (Mean: -0,01027; StDev: 1,11964)

\section{Interactivity}

As the computer-based items differ markedly from the P\&P items in terms of how much the student can interact with the item (for example, the possibility of moving levers to adjust levels in experimental trials or dragging and dropping the answer into the correct location in the diagram) an important effect across gender is interactivity of the items.

A panel of three independent judges rated all CBAS items into three groups according to the level of interactivity (low, medium and high) based on the types of activities the student had to perform with the item and based on how much the student needed to engage with the audiovisual material to answer the question. An example of a low interactivity item is the "Assembly Line" item in figure 3.2.2 that shows a short video of an automated car assembly line and asks a question related to the role of robots in society. 


\section{Question 19: Assembly Line}

Robots are used to make cars on assembly lines

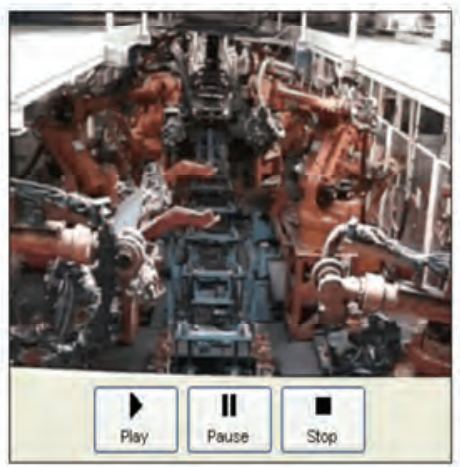

How does this robot technology affect human society? Answer "Ves" or "No" for each statement.

Consumer goods are made more cheaply

Ores O No

Workers avoid exposure to some hazardous materials

$O$ Yes $O$ No

The type of jobs workers do remains the same

O Yes O No

Robots make fewer mistakes than numans

O yes $O$ No

Figure 3.2.2. Sample unit: Assembly Line

Here, the video footage serves as contextual information to the item but does not provide the answer. In fact, this question could be answered correctly without the student watching the video footage and is therefore considered to be of low interactivity. In contrast, the following item in figure 3.2.3, "Plant Growth", where the student is required to move buttons up and down a scale, performing experimental trials on optimal temperature and soil acidity levels for growing wheat, was considered as highly interactive. 


\section{Question 13: Plant Growth}

The height of wheat plants is affected by temperature and the soil acid level. At what soil acid level and temperature does this new variety of wheat grow tallest?

Use the sliders to set your variables (soil acid level and temperature) and then press the "Grow" button. The plant will grow. and the average height of the wheat after 1 month will be shown. You may choose up to ten different combinations of variabies for your experiment.

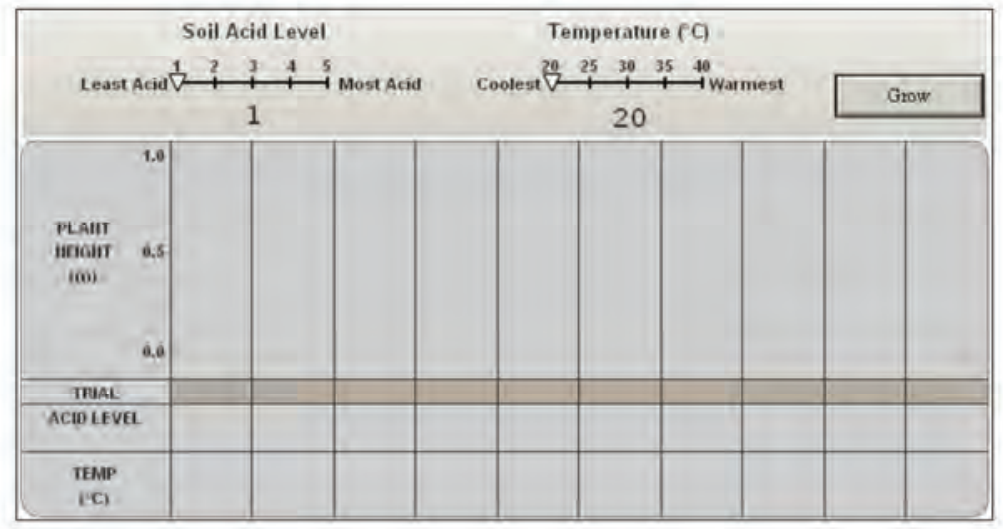

Select the combination of soil acid level and temperature that produces the tallest wheat.

Soil Acid Level:

Temperature $\left({ }^{\circ} \mathrm{C}\right)$ $2_{20^{\circ}} \quad 2_{25^{\circ}} \quad 0.30^{\circ} \quad 3_{35^{\circ}} \quad 040^{\circ}$

Figure 3.2.3. Sample unit of highly interactive item: Plant Growth

Overall, fourteen ims were classified as high interactivity, thirteen as medium and sixteen as involving low interactivity.

\section{Reading load}

Word counts for each CBAS item were recorded including the number of words in the stimulus, embedded in the image, in the question stem and in the multiple choice response options. Based on these figures, the CBAS items were divided into three groups according to reading load: low, medium and high. Eleven items were considered to be of a high reading load, for example as shown in the figure: 


\section{Question 9: Echolocation}

A major hazard for dolphins is getting trapped in fishing nets. Scientists are testing warning devices attached to nets to deter doiphins. The devices send out a sound signal every few seconds. The number of doiphins touching a net was counted over three weeks. In the first week the warning devices were not attached to the net (left). In weeks 2 and 3 the devices were attached (right)
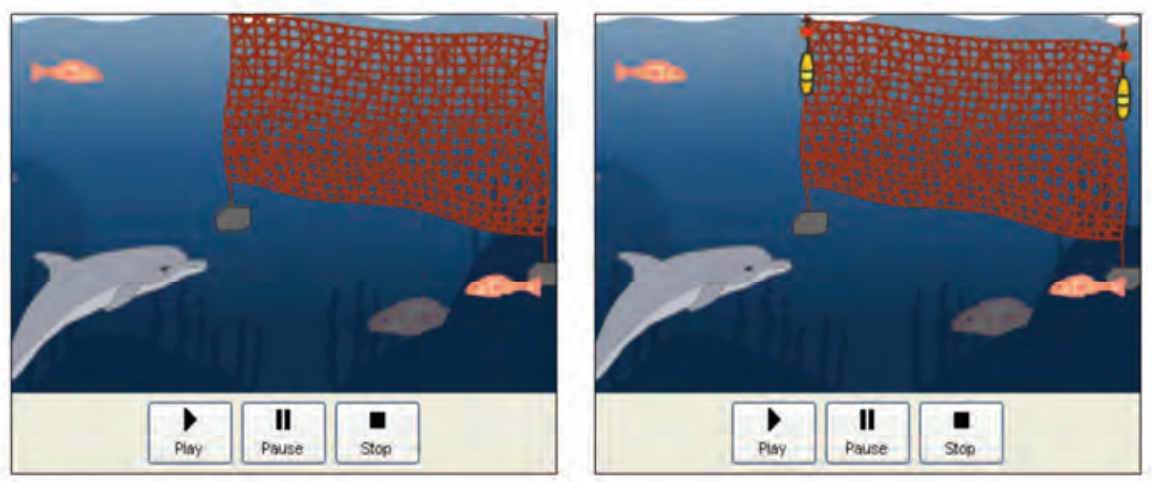

What was the purpose of week 1 of this experiment?

To test whether sounds attract doiphins

To observe the behaviour of dolphins near warning devices.

To collect information for comparison purposes.

To have data on the number of nsh eaten

Figure 3.2.4 Sample item showing high reading load item: Echolocation (Q3)

Fourteen items were classified as medium reading load and eighteen items (including the item in the figure) were classified as low reading load. 


\section{Question 2: Bean Leaves}

The time lapse movie snows the movements of the leaves of a bean plant at intervals of one hour over a 4 a nour period. The plant is provided with adequate water throughout this period.

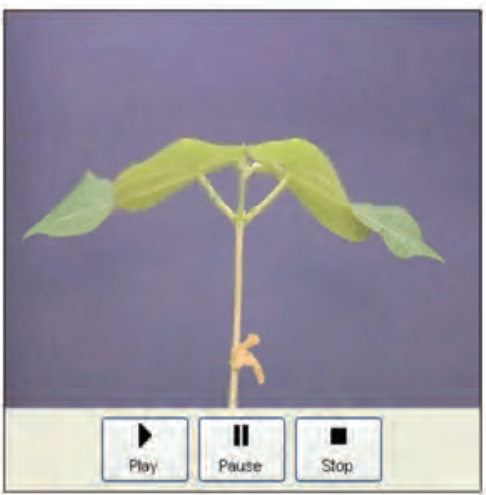

Which picture shows the bean plant when the light intensity is greatest?
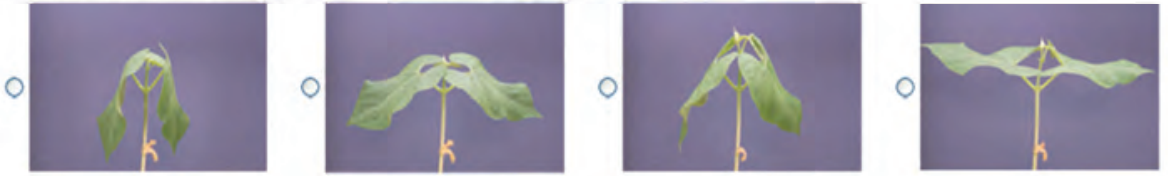

Figure 3.2.5. Sample item showing low reading load item: Bean Leaves (Q1)

\section{Motivation, Enjoyment and Effort}

In CBAS, after the cognitive items, the students were asked to respond to several short questions to investigate the effects of enjoyment, motivation and effort on performance. Students were asked t rate on a four-point Likert scale how much they enjoyed the computer-based and paper \& pencil tests, and whether they would do a similar test where the answers were provided "just for fun" (assessing motivation). The PISA Effort Thermometer was also used where students were asked to imagine an actual situation that was highly important to them personally, so that they would try their very best and put in as much effort as they could to do well. They were told that in this situation they would mark the highest value on the effort thermometer (10) and then they were asked to report: 
how much effort they put into doing the CBAS test compared to the situation they had just imagined; and how much effort they would have invested if their marks from CBAS had counted in their school marks. This questionnaire item was identical to the item used in the PISA paper and pencil test and is displayed in figure 3.2.6.

\section{How much effort did you invest?}

Please try to imagine an actual situation (at school or in some other context) that is highly important to you personally, so that you would try your very best and put in as much effort as you could to do well.

\begin{tabular}{|c|c|c|c|c|c|c|c|c|c|}
\hline \multicolumn{3}{|c|}{$\begin{array}{l}\text { In this situation you would mark the } \\
\text { highest value on the "effort } \\
\text { thermometer", as shown below: }\end{array}$} & \multicolumn{3}{|c|}{$\begin{array}{l}\text { Compared to the situation } \\
\text { you have just imagined, } \\
\text { how much effort did you put } \\
\text { into doing this test? }\end{array}$} & \multicolumn{4}{|c|}{$\begin{array}{l}\text { How much effort would you } \\
\text { have invested if your marks } \\
\text { from the test were going to } \\
\text { be counted in your school } \\
\text { marks? }\end{array}$} \\
\hline$\square$ & 10 & & $\square$ & 10 & & & $\square$ & 10 & \\
\hline & 9 & & $\square$ & 9 & & & $\square$ & 9 & \\
\hline$\square$ & 8 & & $\square$ & 8 & & & $\square$ & 8 & \\
\hline$\square$ & 7 & & $\square$ & 7 & & & $\square$ & 7 & \\
\hline$\square$ & 6 & & $\square$ & 6 & & & $\square$ & 6 & \\
\hline$\square$ & 5 & & $\square$ & 5 & & & $\square$ & 5 & \\
\hline$\square$ & 4 & & $\square$ & 4 & & & $\square$ & 4 & \\
\hline$\square$ & 3 & & $\square$ & 3 & & & $\square$ & 3 & \\
\hline$\square$ & 2 & & $\square$ & 2 & & & $\square$ & 2 & \\
\hline$\square$ & 1 & & $\square$ & 1 & & & $\square$ & 1 & \\
\hline
\end{tabular}

Figure 3.2.6. PISA Effort Thermometer

In addition, students were asked which test they put more effort into between the CBAS test and the PISA paper test (assessing relative effort) and what type of test they would prefer between a two hour paper and pencil test, one hour of each type of test and two hours of computer-based testing. 


\section{ICT Familiarity}

All countries participating in CBAS also administered the PISA ICT questionnaire during the PISA paper and pencil questionnaire session (along with 37 other countries which contribute to the calculation of the scale indices). This questionnaire has 32 questions about the frequency of computer use for specific activities and confidence in performing specific activities on the computer. Two scale indices were computed from measuring ICT familiarity: Internet/entertainment use and Program/software use. More information can be found on these indices in the OECD report on PISA 2006 (OECD, 2007).

Table 3.2.2 shows the model fit for a four-dimensional model for the ICT familiarity items in PISA 2006. Fit indices measure the extent to which a model, based on a particular structure hypothesised by the researcher, "fits the data". Model fit is assessed using Root-Mean Square Error of Approximation (RMSEA), the Root Mean Square Residual (RMR), the Comparative Fit index (CFI) and the Non-normed Fit index (NNFI). The PISA 2006 Technical Report should be consulted for further information about these techniques (OECD, forthcoming). Overall, the model fit was considered satisfactory for all of the CBAS participating countries and for the pooled OECD sample.

Table 3.2.2. Model fit for CFA with ICT familiarity items

\begin{tabular}{lcccc}
\hline & \multicolumn{5}{c}{ Model fit } \\
\cline { 2 - 5 } Country* & RMSEA & RMR & CFI & NNFI \\
\hline Denmark & 0.099 & 0.084 & 0.69 & 0.70 \\
Iceland & 0.089 & 0.078 & 0.71 & 0.72 \\
Korea & 0.077 & 0.060 & 0.79 & 0.80 \\
OECD & 0.084 & 0.082 & 0.81 & 0.81 \\
\hline
\end{tabular}

* Model estimates based on international student calibration sample (500 students per OECD country).

Table 3.2.3 shows the scale reliabilities for the ICT scales in CBAS countries and the overall median for all PISA countries that administered the ICT familiarity questionnaire. The internal consistencies were mostly high across all PISA countries, but are well below the median for all CBAS countries. These scales may therefore be slightly less reliable in the CBAS countries than in the PISA countries as a whole. These scales 
are nonetheless used here and considered to be a fairly good estimate of ICT familiarity in the CBAS countries.

Table3.2.3. Scale reliabilities for ICT familiarity scales

\begin{tabular}{lrr}
\hline Country & Internet/entert. use & Program use \\
\hline Denmark & 0.66 & 0.73 \\
Iceland & 0.69 & 0.75 \\
Korea & 0.66 & 0.71 \\
Median & 0.82 & 0.78 \\
\hline
\end{tabular}

\section{Results}

Gender difference in performance on the PISA P\&P test and the CBAS computer test in science literacy is considered in the light of a number of moderator variables described above. First, gender differences in performance across test modalities in the three CBAS countries are considered, then findings are discussed in terms of ICT familiarity, motivation, enjoyment and effort. Finally, results on interactivity of computer items, reading load and item difficulty are reported.

Gender Differences in student performance across test modalities

As figure 3.2.7 shows, in Denmark, boys performed significantly better than girls on the P\&P test of science by almost $1 / 4$ of a standard deviation. In Iceland, girls slightly outperformed the boys on the P\&P test of science and in Korea there were no significant gender differences. The gender differences were large and clearly directional when science achievement was tested via computer however, with boys performing better than girls on the CBAS test in all countries.

Boys outperformed girls on CBAS by approximately $1 / 4$ of a standard deviation in Iceland and Korea to almost half a standard deviation in Denmark. Denmark has the largest gender difference in favour of boys regardless of test modality, but it should be noted that the increase in size of the gender difference as students moved from one test to the other is similar across all three countries. In other words, in Denmark the gender advantage for boys increased by $1 / 4$ of a standard deviation from $1 / 4$ to $1 / 2$. In Korea it also increased by $1 / 4$ of a standard deviation from 0 to $1 / 4$ and in 
Iceland the increase was slightly larger as the advantage was reversed from $1 / 10$ of a standard deviation to $1 / 4$ of a standard deviation.

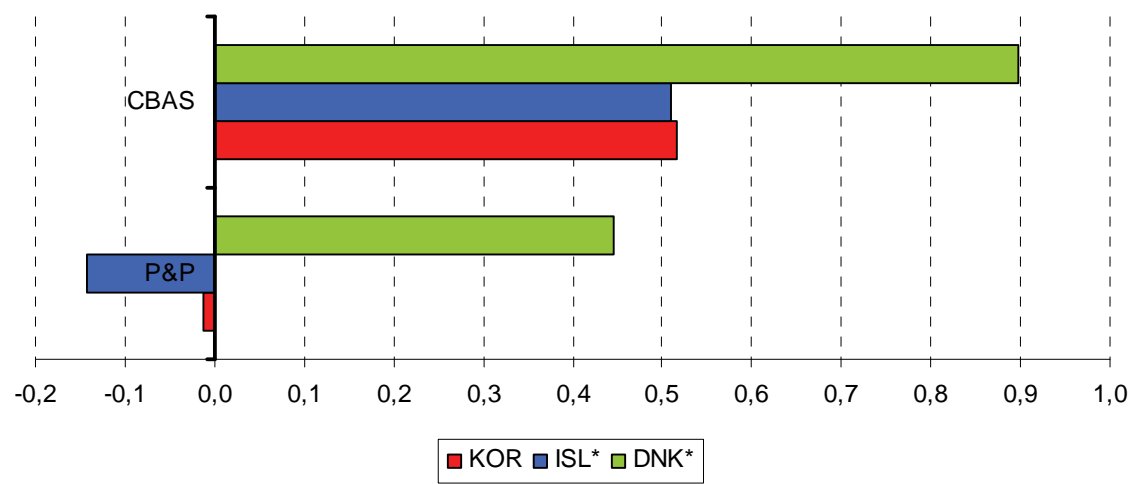

Figure 3.2.7. Boys' achievement advantage across tests and countries (positive values show boys outperforming girls).

When we compare the mean achievement scores for girls and boys in the paper and pencil test to the CBAS test across countries in table 3.2.4, we can see that in Denmark boys' and girls' CBAS performance dropped (with girls' performance dropping more than boys, increasing the gender difference). In Iceland and Korea, boys’ performance increased, leaving behind the girls whose respective performance decreased and creating the gender difference seen earlier. Statistically significant differences are tested with the means and standard errors of the mean calculated through the replicates procedure involving the eighty PISA replicate weights on plausible values. When a gender difference is statistically significant at the $\mathrm{p}<0.05$ level of significance, the boys' and girls' means have been printed in bold in the table below. 
Table 3.2.4. Achievement in Paper \& Pencil test of Science compared to CBAS (se of mean)

\begin{tabular}{lrrrrrr}
\hline Country & \multicolumn{3}{c}{ Paper \& Pencil } & \multicolumn{3}{c}{ CBAS } \\
\cline { 2 - 7 } & Girls & \multicolumn{1}{c}{ Boys } & Total & Girls & Boys & Total \\
\hline \multirow{2}{*}{ Denmark } & $\mathbf{4 . 3 9}$ & $\mathbf{4 . 8 5}$ & 4.62 & $\mathbf{3 . 8 1}$ & $\mathbf{4 . 7 1}$ & 4.25 \\
& $\mathbf{( 0 . 1 6 )}$ & $\mathbf{( 0 . 1 4 )}$ & $(0.12)$ & $\mathbf{( 0 . 1 5 )}$ & $\mathbf{( 0 . 1 2 )}$ & $(0.11)$ \\
Iceland & $\mathbf{4 . 4 9}$ & $\mathbf{4 . 3 4}$ & 4.41 & $\mathbf{4 . 1 8}$ & $\mathbf{4 . 6 9}$ & 4.44 \\
& $\mathbf{( 0 . 0 5 )}$ & $\mathbf{( 0 . 0 5 )}$ & $(0.04)$ & $\mathbf{( 0 . 0 4 )}$ & $\mathbf{( 0 . 0 5 )}$ & $(0.03)$ \\
Korea & 5.06 & 5.03 & 5.04 & $\mathbf{4 . 7 9}$ & $\mathbf{5 . 3 1}$ & 5.08 \\
& $(0.13)$ & $(0.12)$ & $(0.09)$ & $\mathbf{( 0 . 1 4 )}$ & $\mathbf{( 0 . 1 3 )}$ & $(0.10)$ \\
\hline
\end{tabular}

The correlations in table 3.2.5 further show that girls' CBAS performance is slightly less strongly associated with their performance on the P\&P test of science than for boys, indicating that the impact of changing the test method is not the same for girls as it is for boys.

Table 3.2.5. Correlations between P\&P science scores and CBAS scores across genders and countries

\begin{tabular}{lll}
\hline Correlations & Girls & Boys \\
\hline Denmark & 0.89 & 0.91 \\
Iceland & 0.78 & 0.80 \\
Korea & 0.88 & 0.90 \\
\hline
\end{tabular}

Table 3.2.6 presents this relationship in another way, displaying the correlations for familiarity and achievement across countries which are stronger for boys than for girls (although on the whole they are relatively weak).

Table 3.2.6. Correlations between ICT familiarity science scores on the CBAS and P\&P tests.

\begin{tabular}{lrrrr}
\hline \multirow{2}{*}{ Country } & \multicolumn{2}{c}{ P\&P } & \multicolumn{2}{c}{ CBAS } \\
\cline { 2 - 5 } & Girls & Boys & Girls & Boys \\
\hline Denmark & 0.03 & 0.09 & 0.06 & 0.11 \\
Iceland & -0.04 & 0.07 & -0.02 & 0.10 \\
Korea & 0.05 & 0.07 & 0.07 & 0.10 \\
\hline
\end{tabular}

In the paper and pencil PISA 2006 results (OECD, 2007) it was reported that girls performed significantly better overall than boys on the Knowledge about Science items (which combine both the Scientific Explanation 
and the Scientific Enquiry items). This general pattern was also present in the Icelandic data shown in figure 3.2.8 below using a percent correct calculation. Here we see that girls outperform boys on the items assessing the methods of science (Knowledge about Science), whereas overall boys have the advantage on the Knowledge of Science items (despite slight advantages for girls in the Living Systems and Earth \& Space Systems questions).

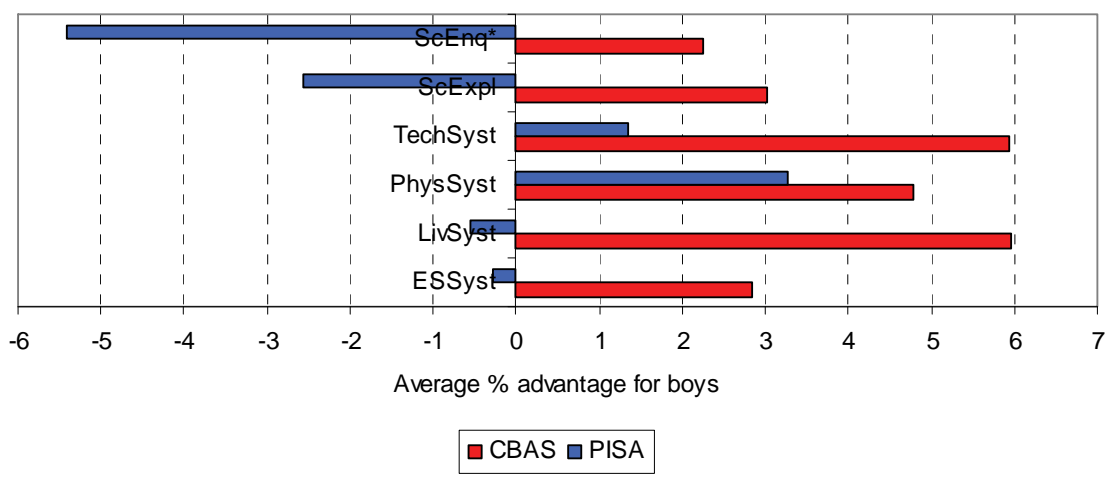

Figure 3.2.8. Average advantage in performance across domains for CBAS and $P \& P$ science items in Iceland

When we compare the performance in domains across test modalities, it is interesting to note that the boys' advantage decreases in the same domains that the girls displayed strengths in on the paper and pencil test (Knowledge about Science). This is a good indication that the items across both tests are assessing the same competences as the gender difference changes in the same manner across domains regardless of test modality.

A general finding from these comparisons is that no country interaction is found for the relationship between science achievement on the paper and pencil test and science achievement on the computer-based test. There seems to be an overall effect in all three countries where boys outperform girls on the computer-based assessment of science in all countries irrespective of the gender difference in the paper based test. 
Familiarity with Information Communication Technologies (ICT) across genders and impact on achievement

The following analyses investigate the relationship between the measure of ICT familiarity and boys' and girls' performance in CBAS and P\&P science for each country. Overall, boys score higher on the frequency of use scales than girls and more ICT familiar students perform better in CBAS than less ICT familiar students irrespective of age, although results for Icelandic girls are an exception.

In Denmark, ICT familiar girls and boys performed better than their "ICT-unfamiliar" same gender counterparts on both the CBAS and P\&P test, although the size of the difference between familiar and unfamiliar students was stronger for boys than for girls. In Korea, ICT familiarity is also associated with higher scores on both CBAS and PISA for both genders, however this effect is stronger on the CBAS test than on the P\&P test and as in Denmark is stronger for boys.
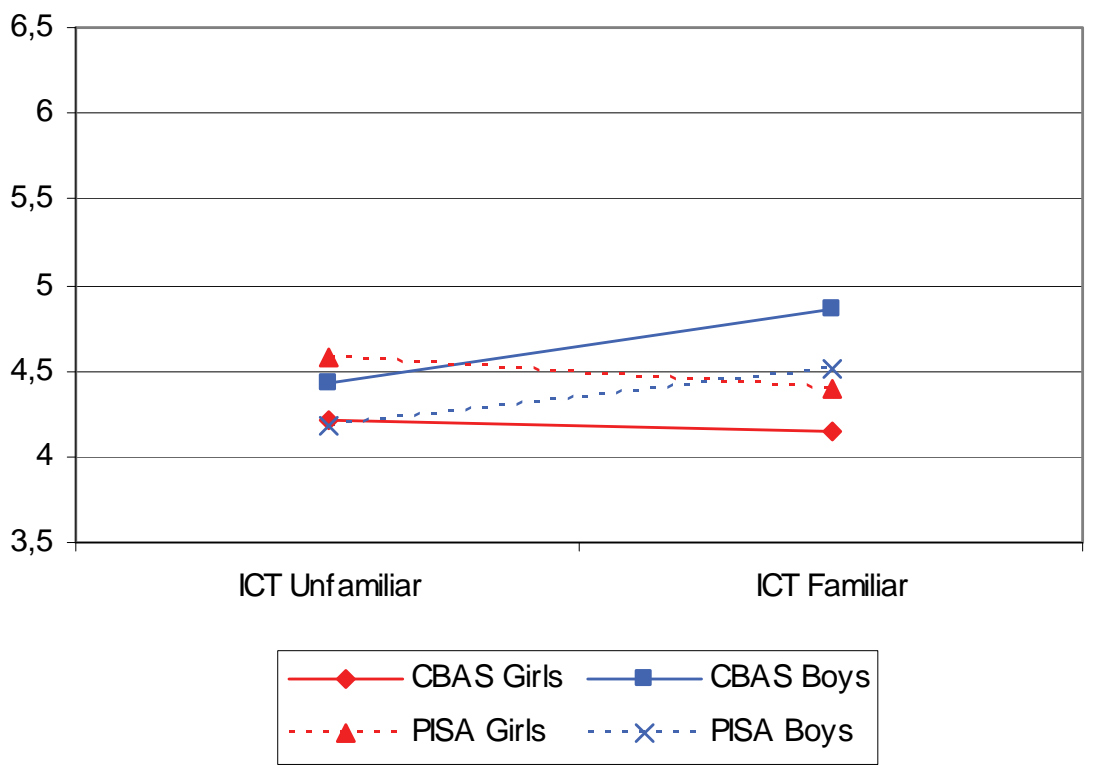

Figure 3.2.9. Impact of ICT familiarity for boys \& girls on CBAS and P\&P scores in Iceland 
Figure 3.2.9 reveals that in Iceland the same pattern is present for boys, but the reverse pattern is observed for girls: high ICT familiarity is associated with poorer performance for girls on both the CBAS and the P\&P tests. On the paper and pencil test, ICT unfamiliar girls outperformed their ICT unfamiliar male counterparts. Nevertheless, the reverse was true for the ICT familiar students where boys outperformed girls on the paper and pencil test of science and on CBAS.

The Icelandic girls are the only group out of the three countries to display a negative correlation between ICT familiarity and achievement. This may reflect the types of activities that Icelandic girls are performing on computers if these activities are not educational and time spent on the computer replaces other educational activities such as homework or outof-school lessons. This pattern of results for Icelandic girls requires further investigation in the future to identify what sorts of girls are ICT unfamiliar and why their performance on both the computer-based and the paper and pencil test is disadvantaged.

Table 3.2.7 shows the size of the advantage for ICT familiar girls and boys in comparison to ICT unfamiliar students and whether these differences were significant or not. The advantage for ICT familiar boys over ICT unfamiliar boys is almost $1 / 4$ of a standard deviation, whereas for girls the only significant advantage is for girls in Korea and here the advantage is smaller.

The Icelandic girls stand out here once again where we see that they are the only group for whom there is no trend towards a performance advantage for ICT familiar students. (Although the advantage for the girls in Denmark is also not significant due to the large standard error, a definite trend in this direction is present).

Table 3.2.7. Effects of ICT familiarity on performance for boys and girls across countries

\begin{tabular}{lccccc}
\hline & Advantage for ICT familiar girls & SE & Advantage for ICT familiar boys & SE \\
\hline Denmark & 0.21 & 0.21 & 0.46 & 0.19 \\
Iceland & 0.07 & 0.10 & 0.38 & 0.16 \\
Korea & 0.29 & 0.13 & 0.43 & 0.16 \\
\hline
\end{tabular}

*Significant differences are displayed in bold $(p<0,05)$ 
Motivation, enjoyment and effort

The CBAS questionnaire was administered so that the relationship between achievement and test engagement factors (enjoyment, motivation and effort) could be investigated. This section examines whether these differences (if any) can explain variations in performance between tests.

The pattern in figure 3.2.19 indicates a clearer trend in Iceland with boys more motivated than girls on the CBAS test. Girls are more likely than boys to strongly disagree or disagree to do the computer-based test "just for fun" whereas boys are more likely than girls to agree or strongly agree. The Fisher's exact test reveals, however, that these differences are not significant (FET $=5, \mathrm{p}>0.05$ ). We note that the patterns of motivation are relatively similar for the paper and pencil test of motivation with most Icelandic students disagreeing or strongly disagreeing to do the test "just for fun". No gender differences are, however, apparent in motivation for this test $(\mathrm{FET}=3, \mathrm{p}>0.05)$.

Icelandic students, both boys and girls, are the "least motivated" out of students from all three countries, with the most common response being that they strongly disagree to do another test (regardless of modality) "just for fun". 

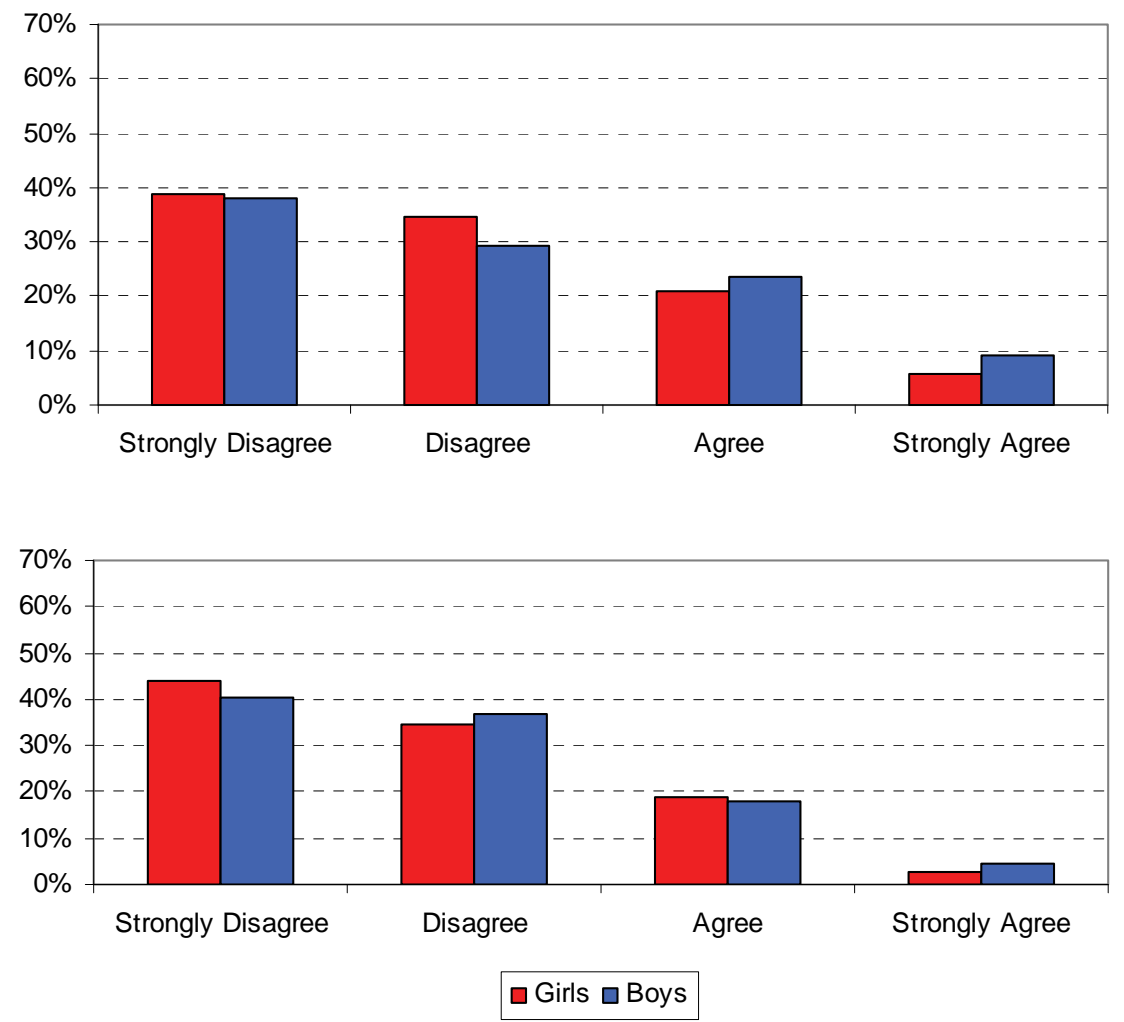

Figure 3.2.10. Icelandic students' endorsement of the statement "I would do another computer-based test for fun" (top) and endorsement of "I would do another paper and pencil test for fun" (bottom).

In comparing the three countries we noted that Icelandic students overall show less enjoyment of the CBAS and the P\&P test compared to students in Denmark and Korea, indicating a specifically cultural pattern of low enjoyment reported by students.

Figures 3.2.11 and 3.2.12 show that, overall, there is no association between achievement and test motivation or test enjoyment. The only pattern appearing in Denmark seems to be that as boys' motivation increases, their achievement decreases. In Iceland, again the girls' response pattern differentiates them from all other groups, as they are the only group to show a real association between higher motivation and enjoyment and higher achievement. The boys in Iceland also slightly support this pattern but achievement drops off in the highest category of motiva- 
tion. In Korea, greater enjoyment is to some extent associated with higher achievement for boys and girls.

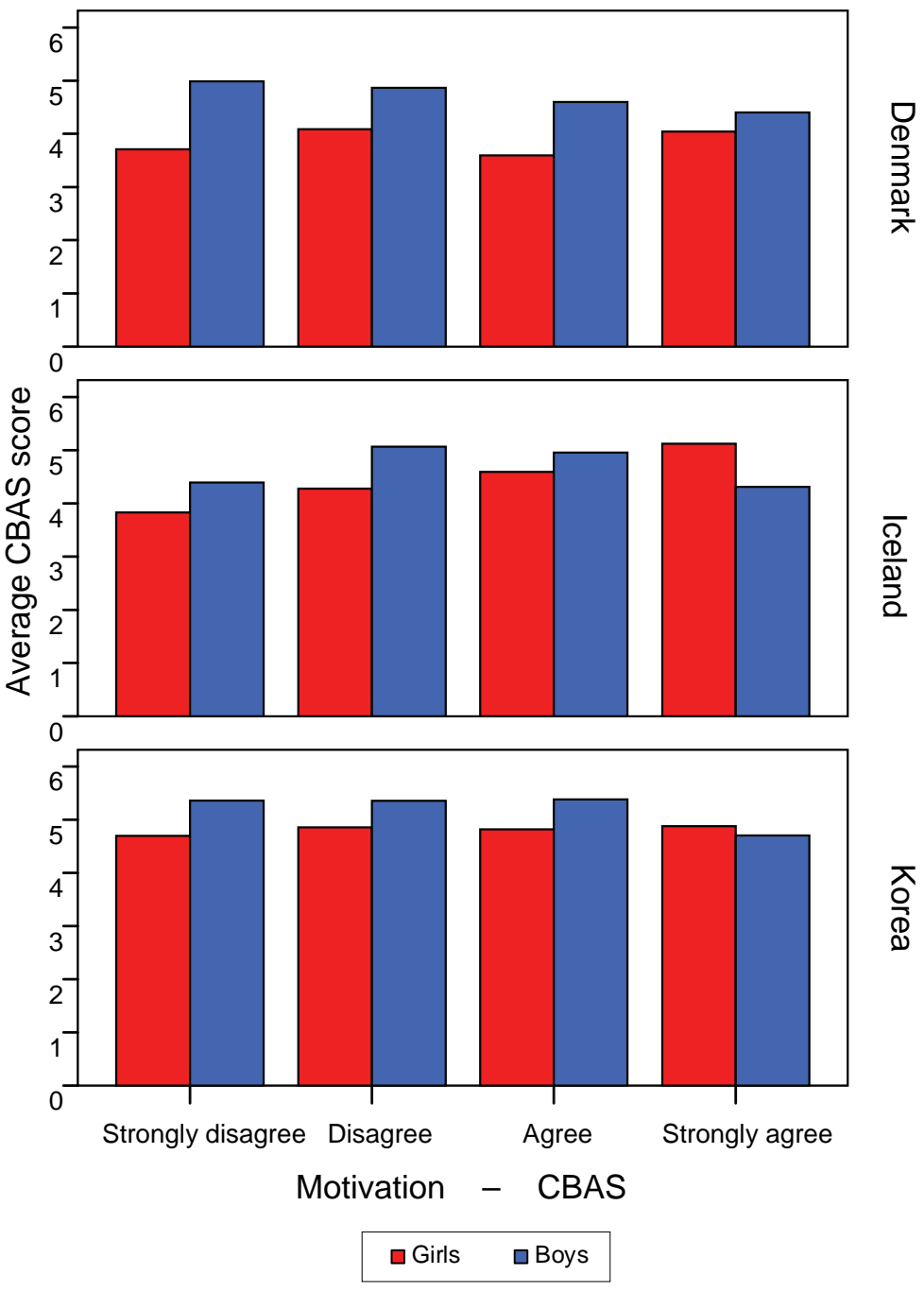

Figure 3.2.11. Motivation for CBAS and science achievement. 

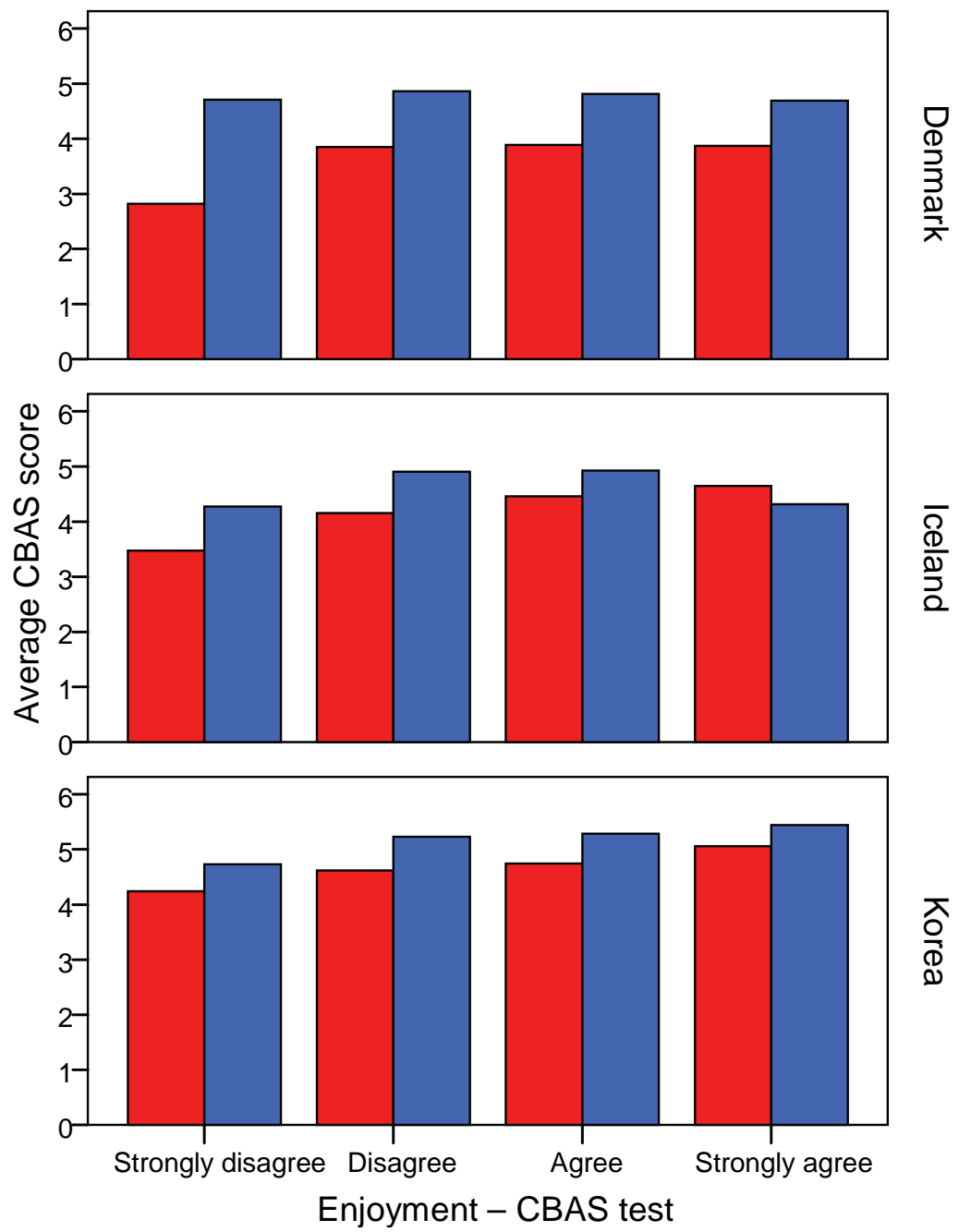

$\square$ Girls $\quad$ Boys

Figure 3.2.12. Enjoyment of CBAS test and science achievement.

Figure 3.2.13 shows the relationship between effort reported on the CBAS Effort Thermometer and CBAS science achievement for boys and girls across the three countries. Only effort thermometer scores with at least five percent of overall responses are displayed (from 5/10 upwards). 
The figures show only a slight tendency towards higher achievement as reported effort increases across all three countries.

In contrast, as figure 3.2.14 shows, the relationship between PISA P\&P reported effort and PISA P\&P science achievement is clearly shown as a positive relationship; achievement increases with reported effort for both boys and girls across all three countries.

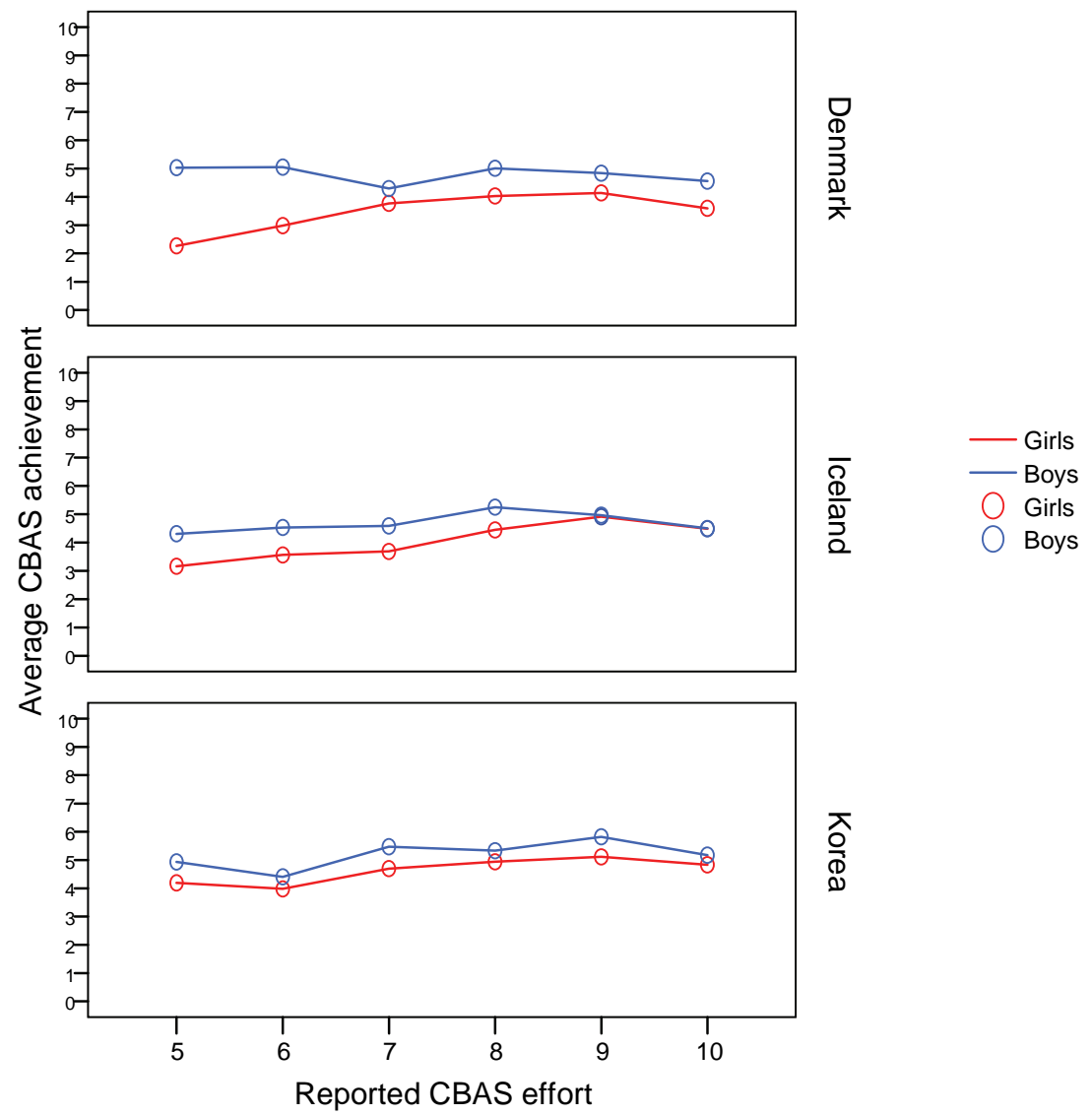

Figure 3.2.13. CBAS reported effort and science achievement across countries. 


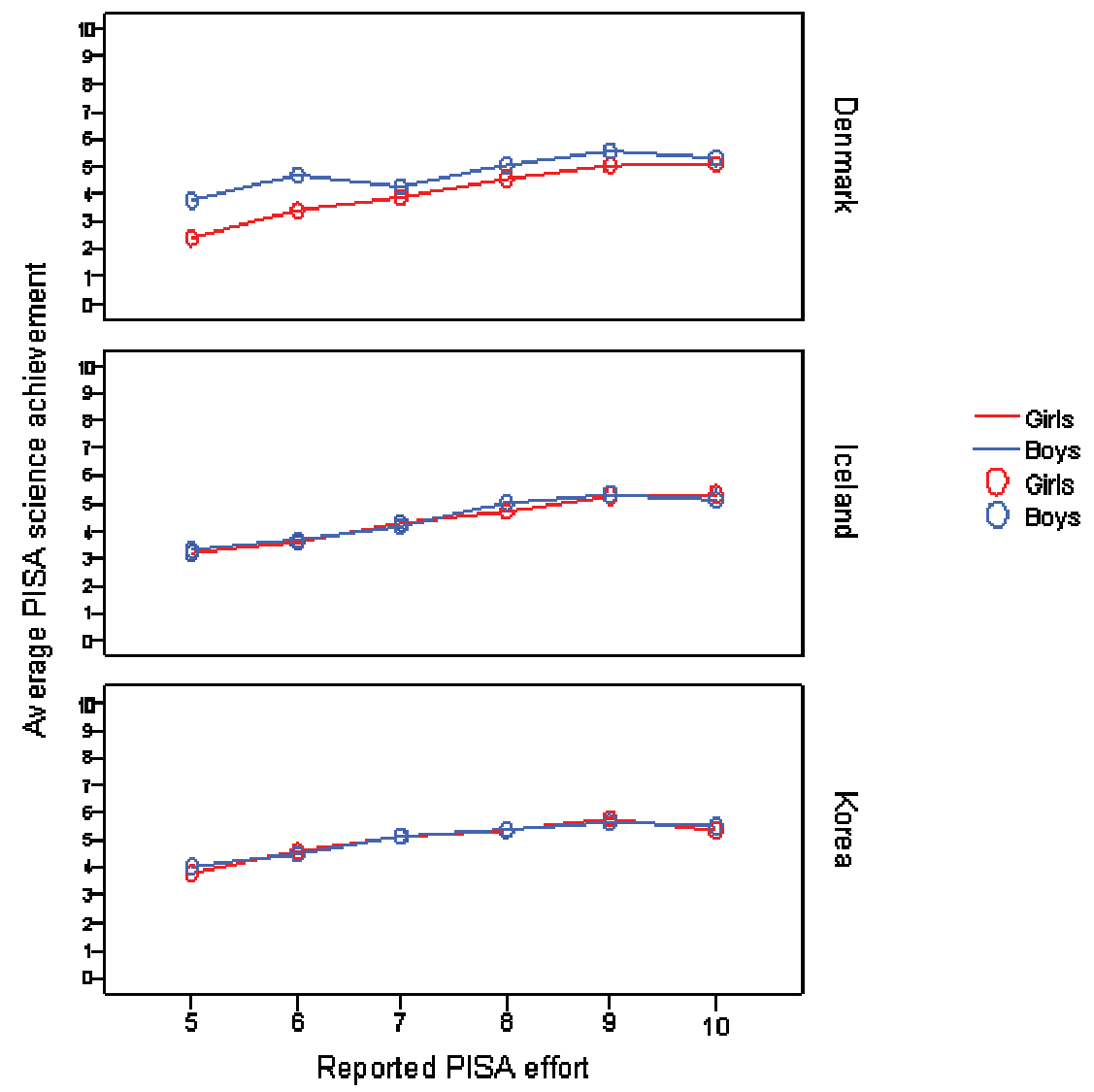

Figure 3.2.14. PISA reported effort and PISA science achievement across countries

The correlation data in table 3.2.8 confirm these trends, showing that for the P\&P test, if a student reported that they had put a lot of effort into the test, this was associated with higher performance across all countries and for both boys and girls. For the CBAS test this relationship was much weaker, particularly for the boys. 
Table 3.2.8. Correlations between reported effort and achievement

\begin{tabular}{lccccccccc}
\hline Country & \multicolumn{2}{c}{$\begin{array}{c}\text { P\&P effort and } \\
\text { achievement }\end{array}$} & \multicolumn{2}{c}{$\begin{array}{c}\text { CBAS effort and } \\
\text { achievement }\end{array}$} & \multicolumn{2}{c}{$\begin{array}{c}\text { CBAS report effort and } \\
\text { P\&P reported effort }\end{array}$} \\
\cline { 2 - 10 } & Girls & Boys & Total & Girls & Boys & Total & Girls & Boys & Total \\
\hline Denmark & 0.40 & 0.28 & 0.32 & 0.14 & -0.05 & 0.01 & 0.41 & 0.48 & 0.46 \\
Iceland & 0.42 & 0.42 & 0.42 & 0.31 & 0.17 & 0.23 & 0.37 & 0.31 & 0.34 \\
Korea & 0.26 & 0.25 & 0.25 & 0.12 & 0.11 & 0.12 & 0.60 & 0.52 & 0.55 \\
\hline
\end{tabular}

\section{Interactivity}

One explanation of the gender difference in performance proposed is that boys outperform girls on the computer-based items because they are more competent in the types of ICT tasks required of them to complete the items due to their greater ICT familiarity. To investigate this proposal the CBAS items were categorised in terms of their degree of interactivity for example, whether the item required specific ICT skills such as dragging and dropping or whether it was a relatively simple item involving watching a video and clicking in a response box.

To investigate this, percentage correct was compared for high interactivity items and for low interactivity items. As figure 3.2.15 shows, overall, across both genders and in all three countries, high interactivity items were more difficult than low interactivity items. However, there was no evidence to suggest that the low interactivity items were relatively easier for the girls than for the boys. This is in contrast to the PISA 2003 ICT report (OECD, 2005b) that showed that the more advanced the ICT tasks became, the wider the gender gap. The absence of a gender gap here indicates that the types of ICT skills necessary to answer these questions are at a relatively low level and well within the grasp of most 15 year old students, both girls and boys. 


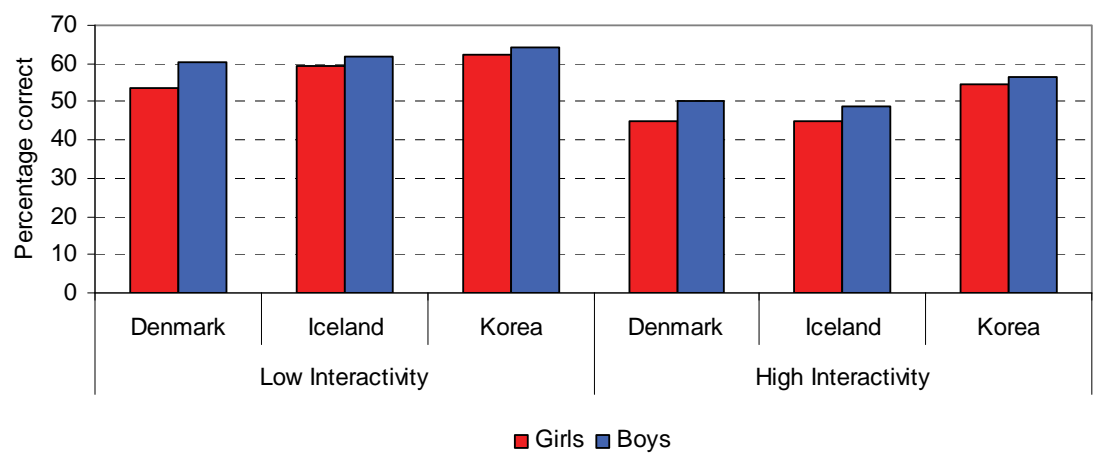

Figure 3.2.15. Percentage correct on High and Low interactivity CBAS items.

For both genders and in all three countries, high interactivity items were more difficult than low interactivity items. The lower percentage correct overall for high interactivity items may in reality be an artefact of the item type in that the more complex items, e.g. items involving dragging dropping or trial experiments, required more complex, often two part, answers, calling upon higher reasoning which students had a higher chance of getting wrong.

\section{Reading load}

One of the goals of CBAS was to reduce the reading load of the questions, but at the same time retain the science content. It was found that the correlation between the CBAS science and PISA reading literacy, at 0.73, was lower than the correlation between PISA science and PISA reading literacy (0.83), so by this measure the goal of reducing the effect of reading ability was successful. The following analyses investigate the differences in performance on science items varying in degree of reading load for both the CBAS and P\&P tests.

All CBAS items were classified as high, medium or low reading load according to the number of words in the item stimulus and question. Percentage correct was calculated for all participating students on the High and Low reading load items. Overall, the higher reading load items were more difficult than the lower reading load items, both for boys and girls across all three countries in both test modalities. 
A marked difference in the size of the gender difference between percentages correct on the high and low reading load items was expected. That is, a reduction in boys' advantage on computer items over girls was expected when the items were of a higher reading load, because based on the general PISA trend, girls have shown higher competence in Reading literacy (OECD, 2007).

As shown in figure 3.2.16, boys outperform girls on the computerbased items regardless of reading load. This advantage is greater in all three countries for items of low reading load, although the size of the advantage on the low reading load items over the high reading load items is relatively small - from under $1 \%$ change in Denmark to $3 \%$ change in Korea.

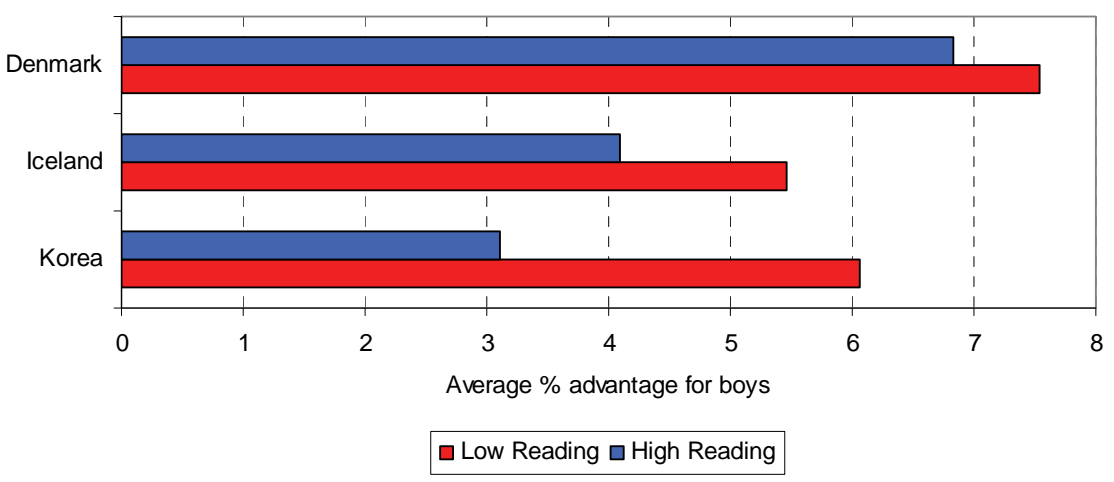

Figure 3.2.16. Average percentage difference in achievement between boys and girls on High and Low reading load CBAS items

In figure 3.2.17 the items have been split into three comparison groups: over 200 words, between 100 and 200 words and under 100 words. Note that there are no CBAS items with more than 200 words. 


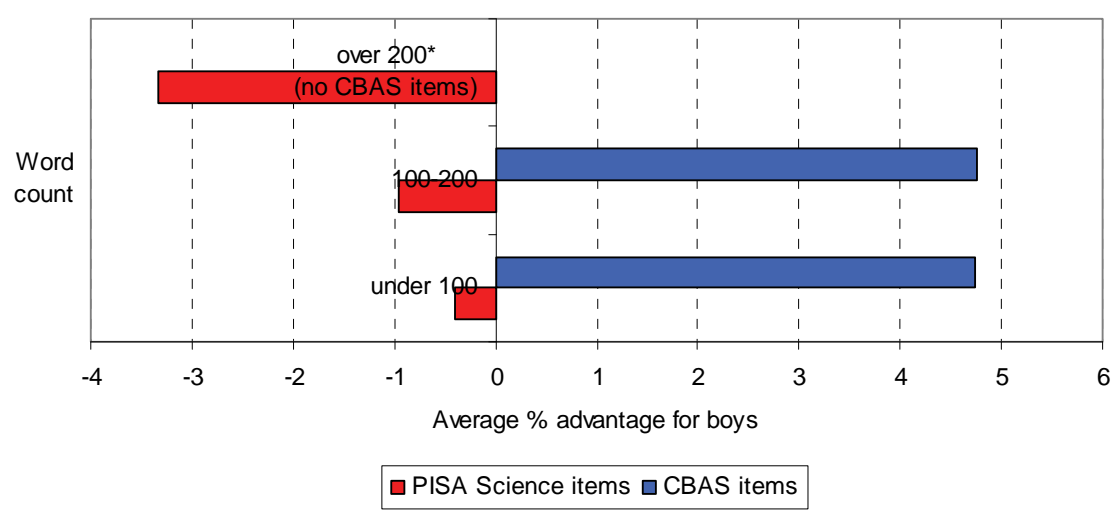

Figure 3.2.17. Average percentage difference in achievement between boys and girls according to reading load across test modalities in Iceland

The results in figure 3.2.17 show that, in Iceland, boys outperform girls on the higher and lower reading load CBAS items. Girls outperform the boys on all paper and pencil items, but by a far greater degree when the items are long. In fact, when the paper and pencil items are similar in length to the CBAS items, the gender advantage for girls is reduced to less than $1 \%$ difference. This is consistent with the results from the PISA 2006 assessment (OECD, 2007), taking into account the overall high reading load of the paper and pencil items, where Icelandic girls outperformed their male counterparts by approximately half a standard deviation. These results indicate that boys may be disadvantaged by the length of the paper and pencil science items, but they cannot explain fully the advantage for boys on the computer-based items.

\section{Item difficulty}

The analyses in this section investigate whether easy CBAS items were comparatively easier for boys or girls. To do this, the PISA item parameters were used for the CBAS items and all CBAS items were classified into three groups according to their item difficulty score: High, Medium and Low. Percentage correct for boys and for girls was calculated for the low and high groups and the average difference between the boys' per- 
centage correct and the girls' percentage was calculated and is displayed in figure 3.2.18.

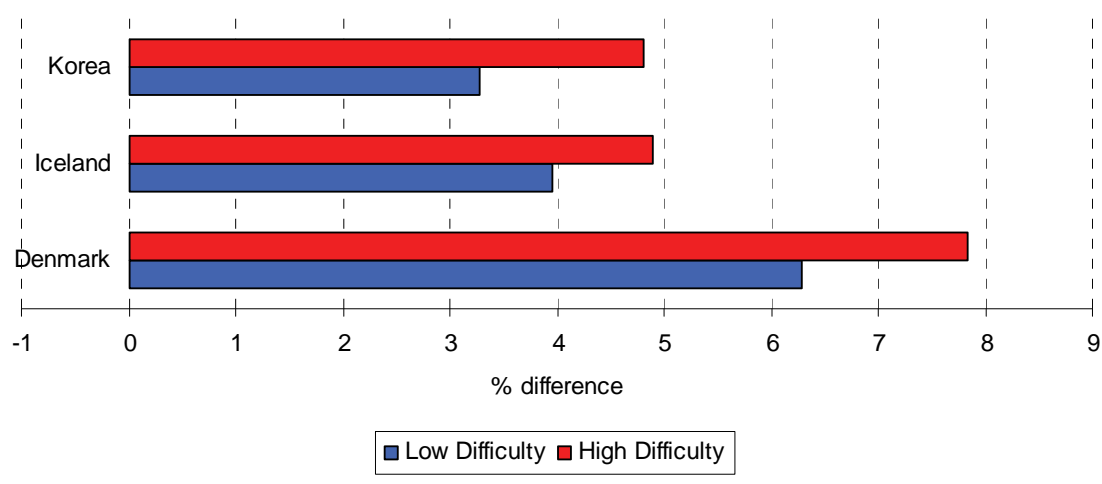

Figure 3.2.18. Percentage correct advantage for boys on high and low difficulty CBAS items

Figure 3.2.18 shows that there is a clear advantage in percentage correct for boys in all three countries regardless of the difficulty rating of the CBAS item. Boys' performance advantage is greater for the high difficulty items (they get 5.8\% more correct on these items than girls) than on the low difficulty items (where they get on average $4.5 \%$ more correct than girls).

While this pattern is notable, it is not, however, unique to the computer-based assessment and a similar pattern is observed in the Icelandic PISA P\&P science achievement results. Icelandic boys do comparatively better on the more difficult paper-based science items. Whereas girls outperform boys on the low difficulty items (and overall), there are no performance differences on the high difficulty items. These patterns are shown in Figure 3.2.19: 


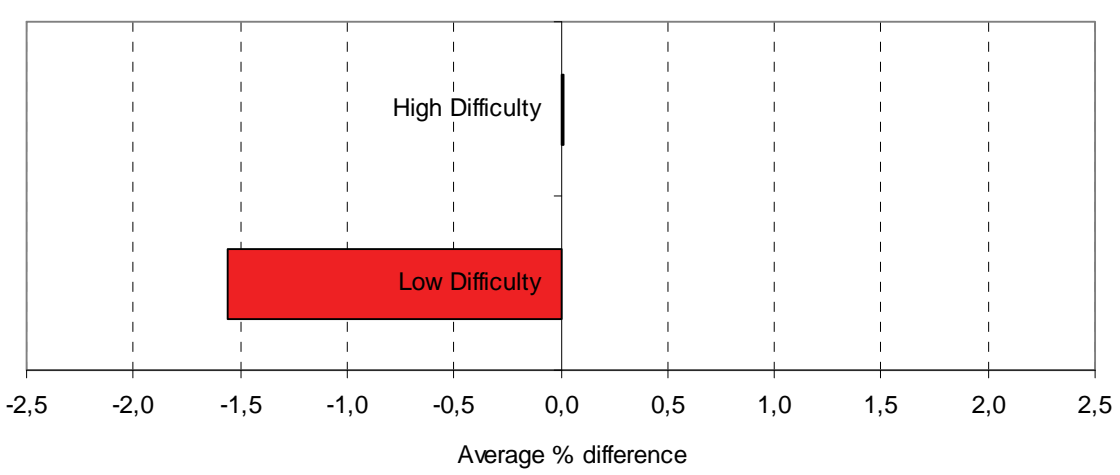

Figure 3.2.19. Gender difference in performance in Iceland on harder and easier PISA P\&P items.

\section{Discussion}

By far the most clear-cut and most interesting finding from this analysis is the finding that, whereas overall country-by-country performance levels did not change between tests, boys in all three countries outperformed the girls when the test was presented via computer. This gap between the boys' performance and the girls' performance occurred regardless of the patterns of achievement across gender on the PISA paper and pencil test of science literacy (recall that in the paper and pencil test boys outperformed girls in Denmark, girls outperformed boys in Iceland and there were no gender differences in Korea).

So, Icelandic boys really are better on computerised tests than conventional ones. The question then becomes why.

The increase in boys' performance may at least partially be explained by the lower reading load. When performance on the paper and pencil items that were similar in length to the CBAS items was compared with performance on CBAS, there is a substantial increase in performance from the boys and the gender advantage for girls is completely removed.

The questionnaire results appeared to shed light on why the boys perform better on the computer test. In particular, boys have more experience with computer-based games, internet, games-type software that would be similar to the flash animations and video footage used for the CBAS items, boys are more motivated on the CBAS test and they enjoy it more, 
boys use computers outside the home more than girls which may contribute to greater confidence in skills transfer and greater familiarity with different keyboards, screens and software.

However, despite the intuitive relationship between higher motivation, greater experience with and confidence in ICT tasks and achievement on the computer-based test, statistical analysis of the correlations between achievement and all of these questionnaire factors did not reveal any significant associations between ICT use factors and achievement. Consequently, we must consider other factors that may influence performance since gender differences in performance cannot easily be linked to motivation, computer item interactivity, enjoyment or familiarity with computers.

With regard to interactivity of computer test items, gender difference in performance does not clearly increase or decrease according to the interactivity of the items. Boys clearly outperform girls on both high and low interactivity items. However, it should be noted that the "interactivity" of the CBAS items was relatively low overall as these items were designed to be accessible for even the most ICT unfamiliar students to successfully complete. Also, at the beginning of the CBAS test there was a 10 minute practice session where these response options were demonstrated and practised. A study such as the PISA 2009 Electronic Reading Assessment with highly interactive items simulating an on-line searching environment will provide researchers with a greater range of item interactivity to examine in more detail potential impacts of interactivity on performance.

Items which show an advantage for boys cannot easily be classified as easier due to low reading load, nor due to higher interactivity. Further, it does not appear to be the domains assessed that affect whether girls or boys will do better on the item, nor the medium of presentation (animation, video footage, still image, etc).

So, why are Icelandic boys better on computerised tests than conventional ones? The computer-based items were easier than the paper-based items as the percent correct is much higher overall for CBAS than for P\&P science for all countries. The increase in boys' performance in CBAS may partially be explained by lower reading load and by boys' greater test fatigue on low difficulty items. It is possible that the difficulty of the P\&P science items fatigues the boys and encourages them to "give up" more than girls. This explanation is supported by the finding that gender difference favouring girls in Iceland is removed in performance on 
paper based items of low reading load (under 100 words). Boys may be disadvantaged by the length of the paper and pencil science items.

Reading load cannot explain fully the advantage for boys on CBAS items. Can the rest be explained by a gender bias in the test items themselves?

Was this "a test for boys”?

Upon closer investigation of the types of items presented in the computer test, it appears that there may be a bias in the gender-typing of the items with a strong content bias towards boys in the video footages used. For example, there are 9 videos over 5 units showing boys performing certain activities, (riding bikes, throwing litter in the bin etc), where the boys are specifically named in the text and sighted in the video footage. There are a further two items in one unit where a boy is named and illustrated as the principal actor in the animated scene. On the girls' side, there are no items showing girls performing activities by video and only one item that refers to a girl by name. The lack of girls in the items may lead to a lower level of engagement with the test for the girls and a consequently lower level of performance.

\section{Cautionary notes on comparisons of test modality effects}

While the overall achievement results were very clear-cut and the gender difference in favour of boys very obvious in each country, finding explanations for the achievement results in the responses to the questionnaire was more difficult due to high levels of variations between countries. The small number of countries involved in this study should be kept in mind when interpreting these results in a wider context. In order to further clarify patterns of changes in performance when testing is presented via computer, further cross-national research will be necessary. For a more balanced test design, valuable insight would be provided in the future by conducting a similar experiment using a third reference group where a group of matched students are given the same paper and pencil items via computer.

When analysing modality effects specifically, any changes to methods of assessment should be made with caution and preferably after an initial analysis comparing achievement on a paper and pencil test with achieve- 
ment on a computer-based test of the same paper and pencil items and achievement on computer-based items in the same domain. In general, changing the test modality to a computer-based presentation platform should not affect performance at the country level, however the current results indicate that it will negatively impact the performance of girls in comparison to the boys. When presenting tests via computer, students may report higher levels of enjoyment, effort and may prefer the computer-based test to a paper-based test but this preference does not mean that achievement will be higher. These domains should be investigated further by national testing institutes wishing to adapt their testing systems, and in particular for Iceland, the reversal of the pattern of achievement by gender and the strange relationship between ICT familiarity and achievement for the Icelandic girls requires further detailed study.

\section{Endnotes}

See, for example, New York Times

(January 24, 2005) and Time Magazine

(March 7, 2005).

\section{Correspondence}

\author{
Almar M. Halldórsson \\ almar@namsmat.is \\ Júlíus K. Björnsson \\ julkb@namsmat.is \\ Educational Testing Institude \\ Borgartún 7A \\ 105 Reykjavík, Iceland
}

Note on this publication:

The article is based on findings from a comprehensive report by the Educational Testing Institude on CBAS for Iceland, Denmark and Korea, scheduled for publication by the OECD in 2009.

\section{References}

Harrison, C., Comber, C., Fisher, T., Haw, K., Lewin, C., Lunzer, E., McFarlane, A., Mavers, Di., Scrimshaw, P., Somekh, B., Watling, R. (2004), ImpaCT2: The impact of information and communications technology on pupil learning and attainment, DfES, UK.
Jóhannesson, I.Á. (2004) Karlmennska og jafnréttisuppeldi. [Masculinity and gender equity pedagogy.], Reykjavík: Rannsóknastofa í kvenna- og kynjafræðum [Research Institute in gender and women studies at the University of Iceland]. (In Icelandic) 
Kristjánsson, Á.L., Baldursdóttir, S.B., Sigfúsdóttir, I.D. \& Sigfússon, J. (2005) Ungt fólk 2004. Menntun, menning, tómstundir, ípróttaiðkun og framtíðarsýn íslenskra ungmenna. [Youth 2004. Education, culture, recreation, sports and youth's visions for the future.], Reykjavík: Rannsóknir og greining. (In Icelandic)

Magnúsdóttir, B.R. (2006). Námshegðun leiðtoga í unglingabekkjum í ljósi rannsókna og kenninga um menningarauðmagn [Educational behaviour of leaders in lower secondary classes and research and theories of cultural capital.], Tímarit um menntarannsóknir, 3, pp. 42-59. (In Icelandic)

OECD (2005a). PISA 2003 Data Analysis Manual: SPSS Users, OECD, Paris.

OECD (2005b), Are Students ready for a Technology-Rich World? What PISA studies tell us, OECD, Paris.

OECD (2007). PISA 2006: Science competencies for tomorrow's world, Vol. 1: Analysis. OECD, Paris.

Ólafsson, R.F., Halldórsson, A.M. \& Björnsson, J.K. (2006). Gender and the Urban-rural Differences in Mathematics and Reading: An Overview of
PISA 2003 Results in Iceland, in J. Mejding, J. \& A. Roe (Eds) Northern Lights on PISA 2003. Copenhagen: Nordic Council of Ministers. Ólafsson, R.F., Halldórsson, A.M., Skúlason, S. \& Björnsson, J.K. (2007) Kynjamunur í PISA og samræmdum prófum 10. bekkjar. [Gender difference in PISA and the National Standard Tests for 10th grade.] Reykjavík: Námsmatsstofnun [Educational Testing Institute]. (In Icelandic)

Ravitz, J., Mergendoller, J. \& Rush, W. (2002, April). Cautionary tales about correlations between student computer use and academic achievement. Paper presented at annual meeting of the American Educational Research Association. New Orleans, LA.

Sigfúsdóttir, I.D. (2004) Kynjamunur í skólastarfi [Gender difference in schools.], Uppeldi 3(17), pp. 34-36. (In Icelandic)

Valentine, G., Marsh, J., Pattie, C. \& BMRB (2005), Children and young people's home use of ICT for educational purposes: The impact on attainment. Department for education and skills research report RR672, University of Leeds, UK. 


\subsection{Norwegian and Swedish students' reading engagement in 2000 and 2006 from a gender perspective}

Astrid Roe and Karin Taube

\section{Introduction}

Reading engagement has consistently been found to be a critical variable in reading achievement. Over the past two decades, research has shown that there is strong evidence for the benefits of engaged reading, and that engagement in reading is a predictor of learning success throughout life. Data from the National Assessment of Educational Progress (NAEP) in the United States show that adolescents who identified themselves as being interested in reading achieved better scores on the tests, and they had better high school averages than students who were less interested in reading (Donahue, Daane, \& Grigg, 2003). Reading engagement is important not only since it might have an influence on students' present reading ability, but also because it can predict to what extent students will read in the future and thus influence their learning success in life (OECD, 2001). Guthrie and Wigfield (2000) put it like this: As students become engaged readers, they provide themselves with self generated learning opportunities that are equivalent to several years of education. (p. 404). Reading engagement is also important for the maintenance and further development of reading skills beyond school. The International Adult Literacy Survey (IALS) found that reading skills can deteriorate after the completion of initial education if they are not used (OECD and Statistics Canada, 1995). 
The PISA 2000 reading engagement was measured on the basis of students' responses to questions covering the following three indicators:

Time spent on leisure reading - the time students reported that they engaged in leisure reading on a daily basis.

Attitude towards reading - the extent to which students agreed with statements such as: I read only if I have to; Reading is one of my favourite hobbies; and I cannot sit still and read for more than a few minutes.

Diversity of reading - the frequency with which students reported reading six types of text (magazines, comics, fiction books, non-fiction books, e-mails, and web-pages).

Students' responses on a questionnaire related to each component of engagement were combined to create an index that could be statistically correlated to PISA achievement scores.

In PISA 2000 it was found that that on average across OECD countries, 44 percent of students reported reading only to obtain the information that they needed, more than one-third reported that they read only if they had to, and 21 percent agreed or strongly agreed with the statement that reading is a waste of time (OECD, 2001, p. 104). However, engagement in reading differed widely between countries. Among the Nordic countries reading engagement was lowest in Norway and Sweden. In only two of the 28 OECD countries participating in PISA 2000, 15 year old students were on average less engaged in reading than their counterparts in Norway. In ten countries students were less engaged in reading than Swedish students. In all the participating countries engaged readers achieved much better results on the reading test than students with very low reading engagement (OECD, 2001).

The PISA data was also explored to find out whether engagement in reading could compensate for low family income and educational background. Students were split into nine groups based on two variables: level of reading engagement and occupational status of parents. For each of the two indices, three groups were created: The low group (below the 25th percentile), the middle group (from the 25th to the 75th percentile) and the high group (above the 75th percentile). Figure 1 shows the test scores for each of the nine groups (OECD 2002:120).

Figure 3.3.1 shows that reading engagement across OECD had a greater influence on achievement than socio-economic status. It is interesting to note that students with low socio-economic background and 
high engagement in reading outperform students with high socioeconomic background and low reading engagement by nearly 50 score points. This shows that engagement in reading can compensate for low family income and poor educational background (see also Guthrie \& Wiegfield 2000, p 404).) It also shows that much must be done to increase students' engagement in reading. Although it is not possible for teachers to change students' socio-economic background, they can make a great difference by inspiring students to read more in their leisure time.

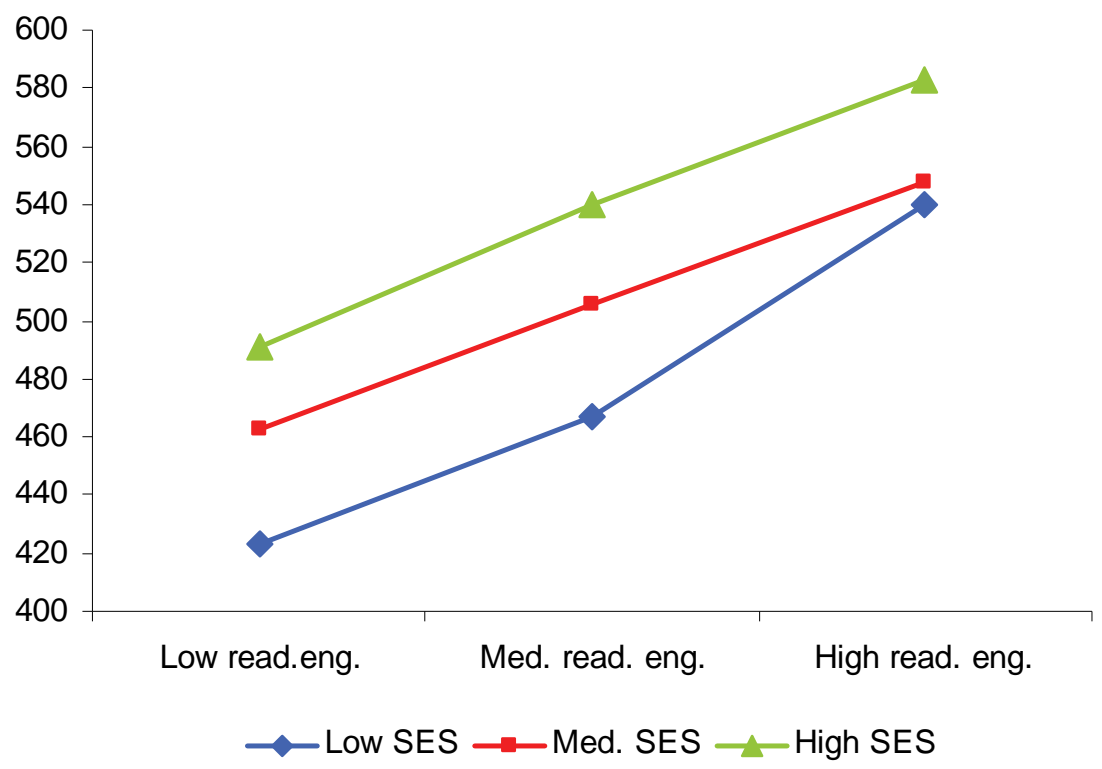

Figure 3.3.1. Reading achievement for students with varying levels of reading engagement and occupational status of parents

Engagement in reading differs between boys and girls. Girls tend to be more engaged in reading than boys, which again makes them better readers. The initial results of PISA 2000 pointed out, in particular, that gender differences in favour of females are associated with voluntary reading activities and reading materials, and that there appeared to be only limited engagement in reading among 15 year-old males beyond what was required of them at school. On average in OECD countries, 46 percent of 15 year-old males reported that they only read if they had to, while only 26 percent of females reported the same. Furthermore, a little more than 
half of the boys compared to one third of the girls reported that they read only to get the information they needed. Almost 50 percent of the girls agreed or strongly agreed with the statement "Reading is one of my favourite hobbies", and that they liked talking about books with other people, compared to only one fourth of the boys. Girls also spent much more time reading for enjoyment than boys. On average across OECD countries 45 percent of the 15 year-old girls read for enjoyment for more than half an hour each day compared to 30 percent of the boys. In PISA 2000, it was also found that girls tend to read more demanding texts than boys. Girls reported reading more fiction while boys read more newspapers, comics, e-mails and Web pages (OECD, 2001).

In the first Nordic PISA report (Lie et al 2003) Linnakylä and Malin studied gender differences in the Nordic countries based on data from PISA 2000. They found that boys in all the Nordic countries reported spending much less time reading for enjoyment than girls did, and that Norwegian boys in particular, rarely engaged in voluntary reading. In Finland and Denmark, gender differences were widest in this respect. However, boys and girls differed in their reading activities not only with regard to their engagement or the time they spent reading, but also with regard to the materials they favoured. The largest difference could be detected in reading fiction (p.41).

Linnkylä and Malin also conducted some further analyses on the PISA data to examine the change in gender differences in reading literacy when controlling for those reading interest and activity factors which showed the strongest discriminating impact on reading proficiency. Attitudes towards reading were what reduced the gender gap most significantly in each Nordic country. When the effect of this factor was controlled for, the gender difference decreased an average of 25 points in the Nordic countries. In Denmark this would decrease the gender difference from 25 points to zero and thus close the whole gender gap. In Finland, controlling for engagement in reading would reduce the gender difference by 33 points, from 53 to 20. In Iceland the reduction would be 21 points from 39 to 18: in Norway 26 points, from 42 to 16, and in Sweden 21 points, from 36 to 15 points. The second strongest reducer of the gender gap was Reading fiction in leisure time.

A comparison of the IEA Reading Literacy study and the PISA study shows that gender differences were much larger in 2000 than they were in 
1991, particularly in the Nordic countries (see table 1). The score points used in IEA and PISA are both based on a Rasch scale with 500 as the mean score and 100 as the international standard deviation.

Table 3.3.1 Gender differences in reading achievement in 1991 and 2000

\begin{tabular}{|c|c|c|c|}
\hline & IEA, Reading Literacy 1991 & OECD , PISA 2000 & Increase favouring girls \\
\hline Denmark & 4 & 25 & 21 \\
\hline Finland & 14 & 51 & 37 \\
\hline Iceland & 13 & 40 & 27 \\
\hline Norway & 4 & 43 & 39 \\
\hline Sweden & 15 & 37 & 22 \\
\hline
\end{tabular}

Although there are always certain problems comparing two different assessments, there is no evidence to support a theory suggesting that the PISA test was more or less favourable to girls or boys than the IEA material. In the IEA Reading Literacy Study gender differences favouring girls were smaller for 14 year-olds than for 9 year-olds, which indicates that gender differences are likely to decrease as students grow older. Consequently one should expect gender differences to be even smaller for 15 year-olds than for 14 year-olds (Roe \& Taube 2003). If boys have become poorer readers since 1991, one obvious explanation may be that in 1991 computers and computer games were less available compared to 2000. If boys have increased the time they spend playing computer games, they will probably have less time for reading in their leisure time, and this will most certainly have a negative effect on their reading ability.

\section{What has changed in six years?}

The questions about reading engagement and reading habits from the student questionnaire in PISA 2000 were not repeated in PISA 2003 and 2006. However, in order to study development over time, they were included as national options in Norway and Sweden in PISA 2006. Unfortunately, they were not included as national options in any of the other Nordic countries. One reason why it is still interesting to compare the results in Norway and Sweden over time is that the PISA 2000 results obviously had a much greater impact on the education system in Norway than in Sweden. When the PISA 2000 results were published in Decem- 
ber 2001, Norwegian policy makers were very disappointed with the results that showed that Norwegian students were no better than the OECD average. The large gender gap favouring girls in reading literacy as well as in reading engagement became one of the major concerns. One of the main efforts carried out was the implementation of the strategy "Make Space for Reading!” The strategy was designed and initiated by the Ministry of Education and Research in 2003, and was completed in 2007. The main goals of the strategy are: teaching reading, presenting literature and using the school library.

A total of 876 projects were initiated under this programme, most in primary and lower secondary school, and many of them focused particularly on boys. The evaluation report published for the Norwegian Directorate of Education states that "Two years with the strategy 'Make room for reading!' appears to have increased reading activities in Norwegian schools, but not enough to improve pupils' reading skills in the short term.” (Buland et al. 2008).

The student questionnaires in PISA 2000 and 2006 contained some identical questions about students' computer use, which we have also included in this study. In the following we will compare Norwegian and Swedish students' responses to the questions about leisure time reading and computer use in 2000 and 2006 from a gender perspective.

\section{Time spent on reading}

The first question about reading engagement that students encounter in the PISA questionnaire is:

Each day, about how much time do you usually spend reading for enjoyment? There are five different response alternatives: I do not read for enjoyment, 30 minutes or less each day, More than 30 minutes to less than 60 minutes each day, 1-2 hours each day and More than 2 hours each day.

Figure 37 shows the percentage of Norwegian and Swedish girls and boys who chose the alternative I do not read for enjoyment in 2000 and 2006. 


\section{I do not read for my own enjoyment}

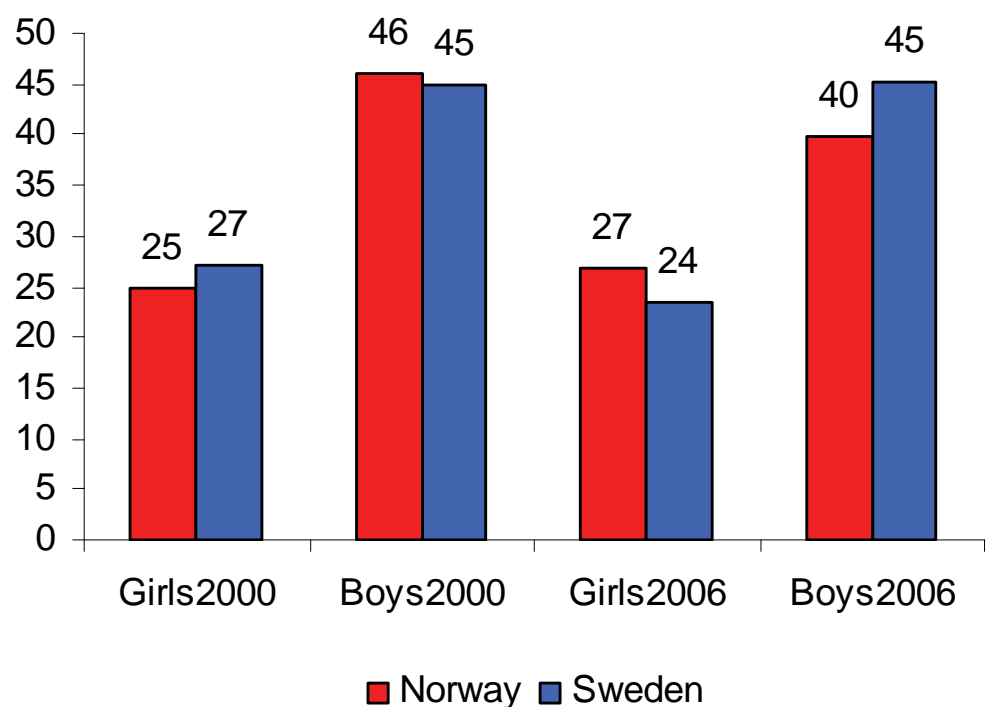

Figure 3.3.2. Percentage of Norwegian and Swedish girls and boys who report that they do not read for enjoyment in 2000 and 2006.

Figure 3.3.2 shows that there are great differences between boys and girls both in Norway and in Sweden. A much higher percentage of boys (4046 percent) than of girls (24-27 percent) chose the alternative "I do not read for enjoyment”. Between 2000 and 2006 some changes deserve attention. The percentage of Norwegian boys who report that they do not read for enjoyment has decreased by six percent while the corresponding percentage for Norwegian girls has increased from 25 to 27 percent. The percentage of Swedish boys not reading for enjoyment has not changed from 2000 to 2006, but the percentage of Swedish girls has decreased by three percent. Norwegian boys seem to have developed positively in six years. Altogether the changes over time have resulted in a smaller gender gap in Norway in 2006 compared to 2000 (from 21 to 13 percent), and a slightly greater gender gap in Sweden (from 18 to 21 percent). 
Attitudes towards reading

All the nine statements that measure students' attitudes towards reading have the following introduction: "How much do you disagree or agree with these statements about reading?" The four response alternatives are: Strongly disagree, Disagree, Agree, and Strongly agree. Four of the statements are positively expressed:

- Reading is one of my favourite hobbies

- I like talking about books with other people

- I feel happy if I receive a book as a present

- I enjoy going to a bookstore or a library

Five statements focus on problematic or negative aspects of reading:

- I read only if I have to

- I find it hard to finish books

- For me, reading is a waste of time

- I read only to get information that I need

- I cannot sit still and read for more than a few minutes 


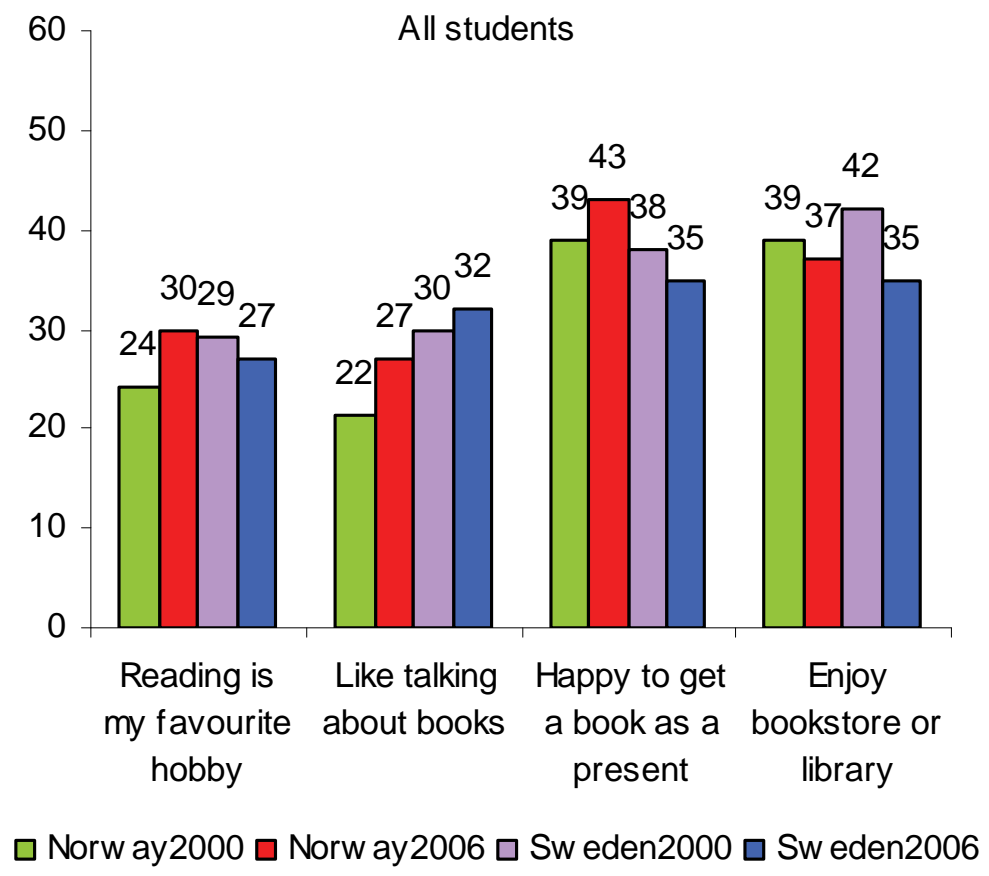

Figure 3.3.3. Percentages of Norwegian and Swedish students who agree or strongly agree with the positive statements about reading in 2000 and 2006.

Figure 3.3.3 shows the percentage of students who agree or strongly agree with each of the positive statements. In 2000 a higher percentage of the Swedish than of the Norwegian students agreed with three of the four positive statements. In 2006 it was the opposite, a higher percentage of Norwegian compared to Swedish students agreed with three of the four statements. Furthermore, in 2000, 22-39 percent of Norwegian compared to 29-42 percent of Swedish students agreed with all four statements. In 2006, 27-43 percent of Norwegian compared to 27-35 percent of Swedish students agreed with all four statements. Thus, on the whole it seems as if Norwegian students have become more positive towards reading activities from 2000 to 2006, while the opposite seems to be the case for Swedish students. 


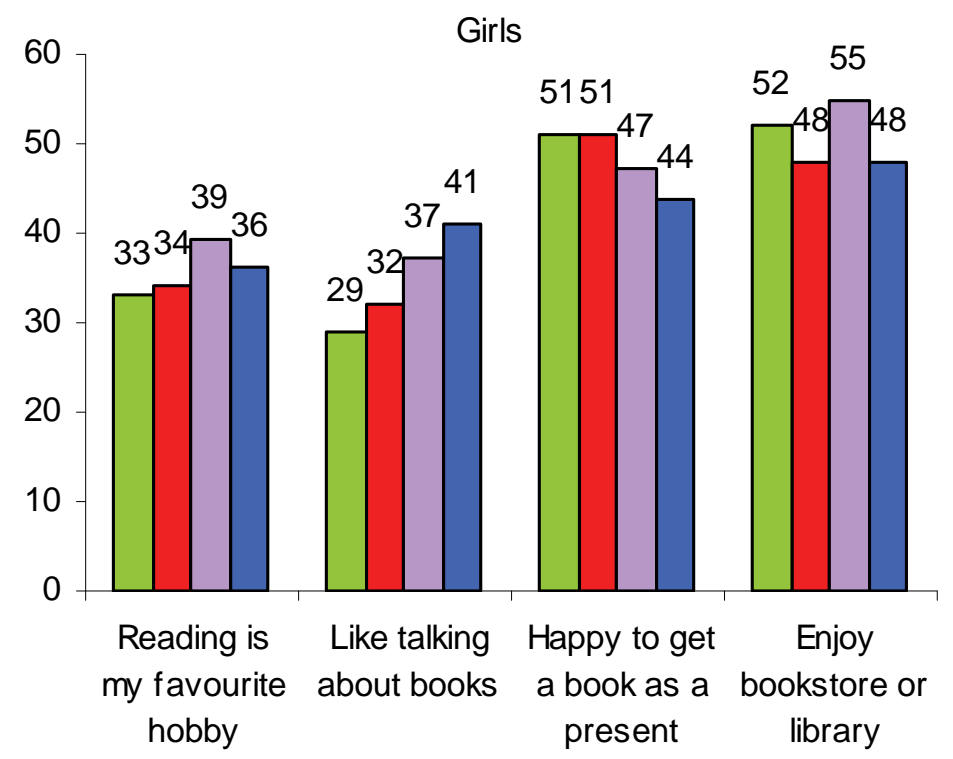

$\square$ Norw ay2000 №rw ay2006 $\square$ Sw eden2000 $\square$ Sw eden2006

Figure 3.3.4a. Percentages of Norwegian and Swedish girls who agree or strongly agree with the positive statements about reading in 2000 and 2006.

If we separate girls and boys in the two studies, the changes over time can be further explained. Figures 3.3.4a and 3.3.4b show the percentage of girls and boys in Norway and Sweden who agree or strongly agree with the four positive statements in 2000 and 2006. In general, a higher percentage of girls (29-55 percent) than boys (15-35 percent) agree with the positive statements. A closer look at the girls' answers in Figure 4a shows that a higher percentage of Swedish girls than Norwegian girls like talking about books and consider reading to be their favourite hobby both in 2000 and in 2006. However, a higher percentage of Norwegian than Swedish girls, appreciate getting a book as a present both years. In 2000 a higher percentage of Swedish than Norwegian girls liked going to a bookstore or a library while the percentages of girls who report that they like this, have decreased to 48 percent in both countries in 2006. 


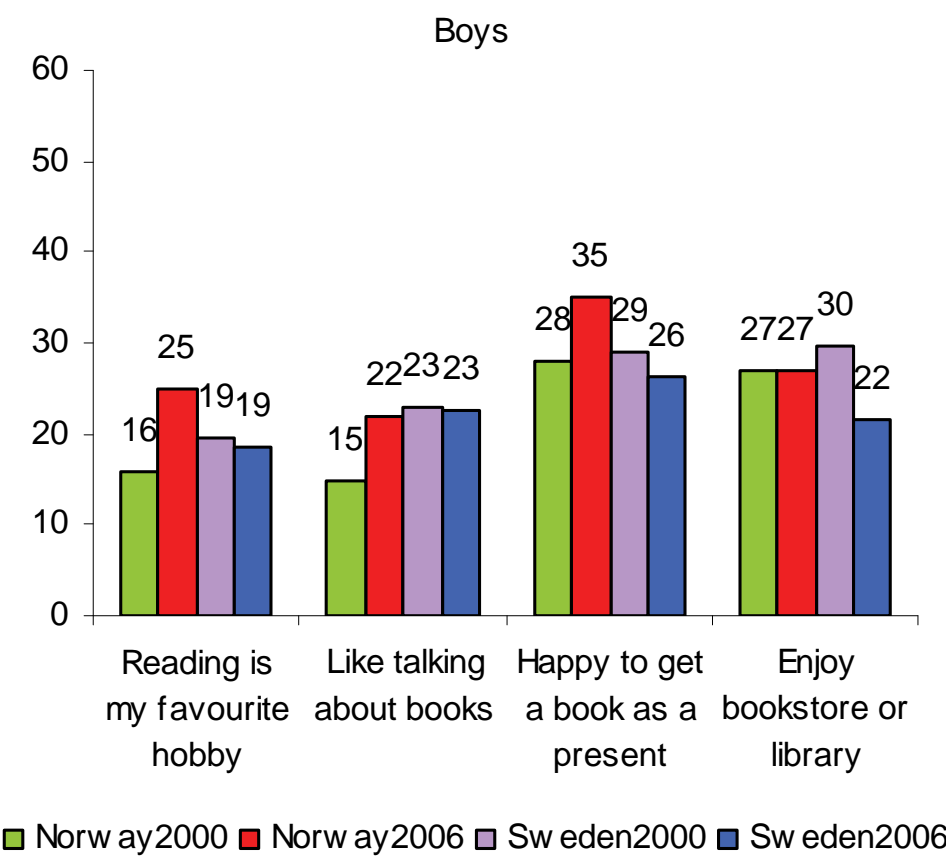

Figure 3.3.4b. Percentages of Norwegian and Swedish boys who agree or strongly agree with the positive statements about reading in 2000 and 2006.

Figure 3.3.4b reveals that the percentages of Norwegian boys who agree or strongly agree with the positive statements have increased by 7-9 percent for three of four statements. The percentage is unchanged for "I enjoy going to a bookstore or a library”. Swedish boys, on the other hand, have not changed regarding the statements "Reading is one of my favourite hobbies" and "I like talking about books with other people". Fewer Swedish boys agreed with the statement "I feel happy if I receive a book as a present" and "I enjoy going to a bookstore or a library" in 2006 than in 2000. Altogether this shows that Norwegian boys have changed more in a positive direction than the other three groups of students measured here. In 2000 they were among the least positive students in the OECD. Six years later they show more positive attitudes than Swedish boys to three of four statements. 




$\square$ Norw ay2000 $\square$ Norw ay2006 $\square$ Sw eden2000 $\square$ Sw eden2006

Figure 3.3.5. Percentages of Norwegian and Swedish students who agree or strongly agree with the negative statements about reading in 2000 and 2006.

Except for the statement For me reading is a waste of time, Swedish students are generally less negative than Norwegian students both years. Development over time shows few significant changes in each country. Compared to 2000 a higher percentage of students in both countries read only if they have to in 2006, but fewer students find it difficult to finish books. When we look at the results for girls and boys, we get a more subtle picture (figures 3.3.6a and 3.3.6b). 


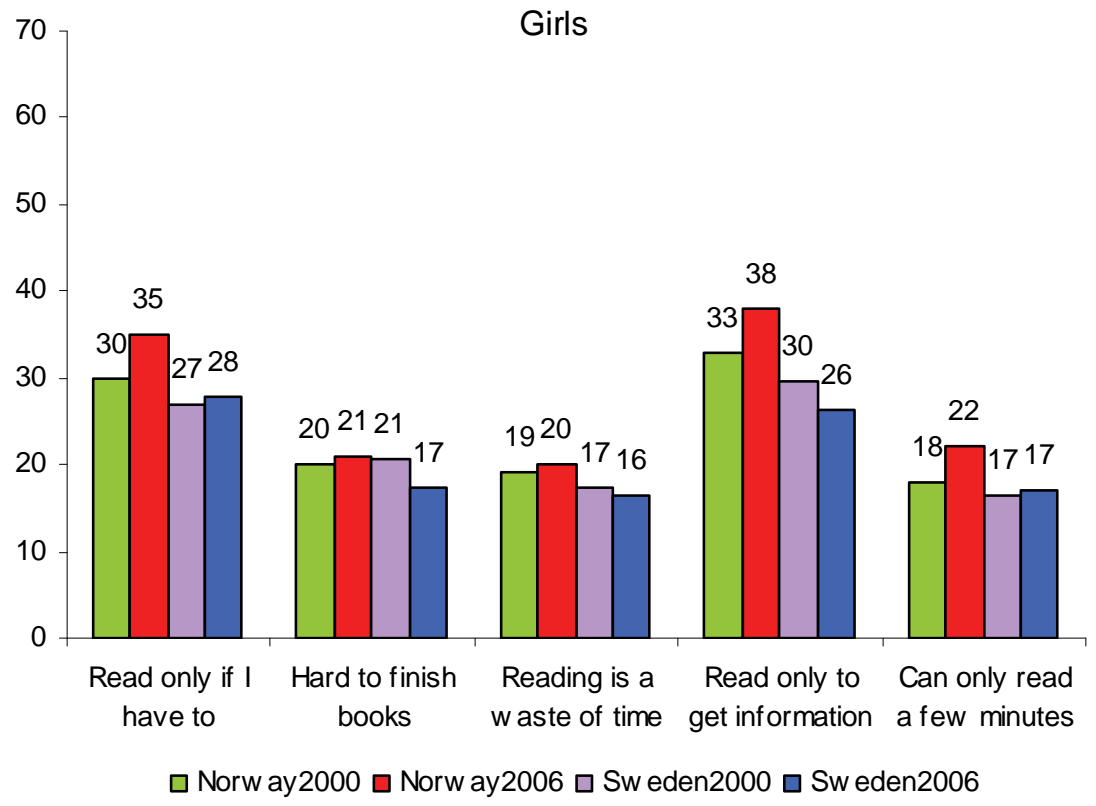

Figure 3.3.6a. Percentages of Norwegian and Swedish girls who agree or strongly agree with the negative statements about reading in 2000 and 2006.

Overall a much higher percentage of boys (26-65 percent) than girls (1638 percent) agree with the negative statements. With only one exception, higher percentages of Norwegian than Swedish girls agree or strongly agree with the five negative statements in 2000 and 2006. Furthermore, a higher percentage of Norwegian girls in 2006 than in 2000 agree with the negative statements. In Sweden a lower percent of the girls in 2006 than in 2000 agree with three of these statements. 


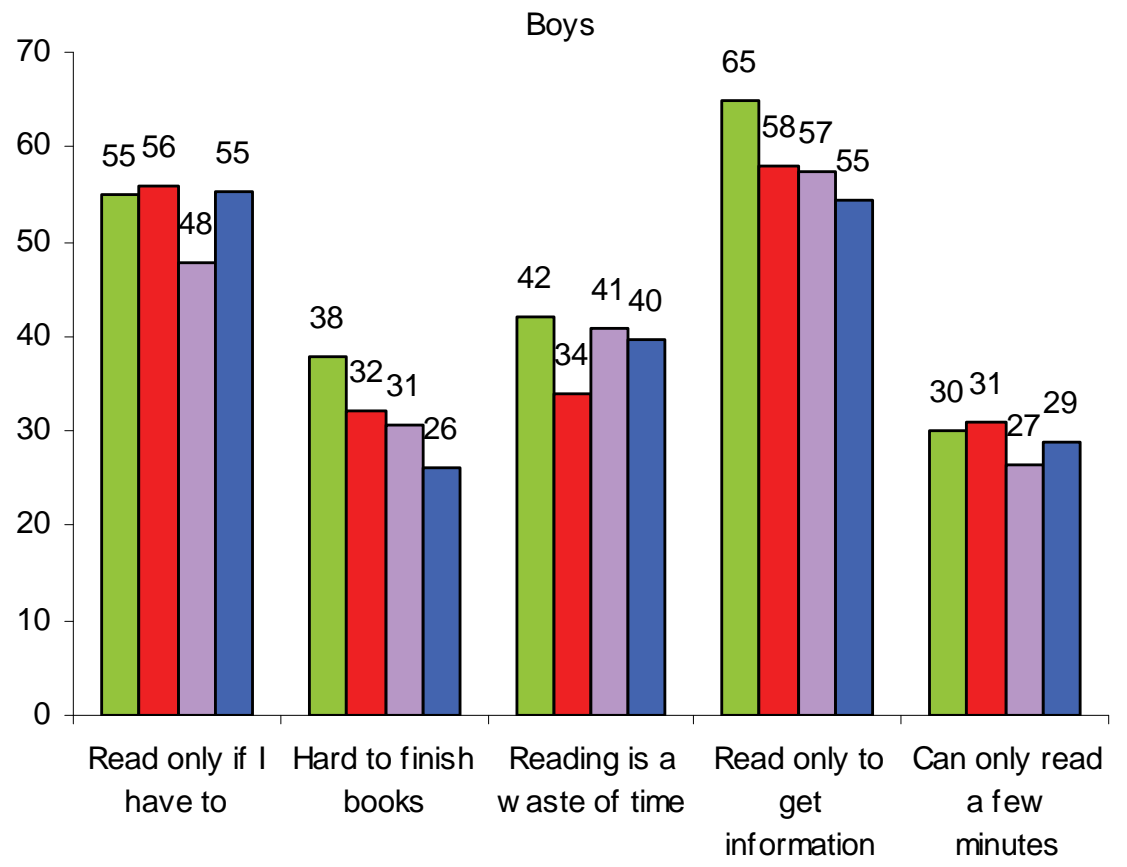

$\square$ Norw ay2000 $\square$ Norw ay2006 $\square$ Sw eden2000 $\square$ Sw eden2006

Figure 3.3.6b. Percentages of Norwegian and Swedish boys who agree or strongly agree with the negative statements about reading in 2000 and 2006.

A higher percentage of Norwegian than Swedish boys agree with the statements "I find it hard to finish books" and "I read only to get information that I need" in both 2000 and 2006. However, in both countries the percentage of boys agreeing with these statements decreases between 2000 and 2006. This is also the case for the statement "For me, reading is a waste of time", and more so among Norwegian boys. For the two remaining statements "I read only if I have to" and "I cannot sit still and read for more than a few minutes", the percentages of Norwegian boys agreeing are almost the same in 2000 and 2006, but the percentages of Swedish boys agreeing are increasing over the same period. Figure 3.3.7a and 3.3.7b show the average results for the four positive and the five negative statements. 


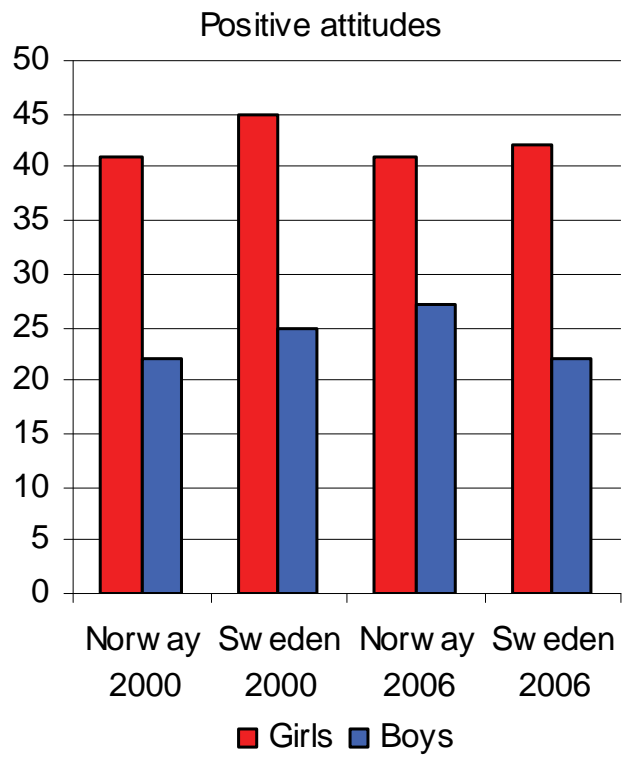

Figure 3.3.7a. Mean percentages of Norwegian and Swedish boys and girls who agree or strongly agree with the negative statements about reading in 2000 and 2006.

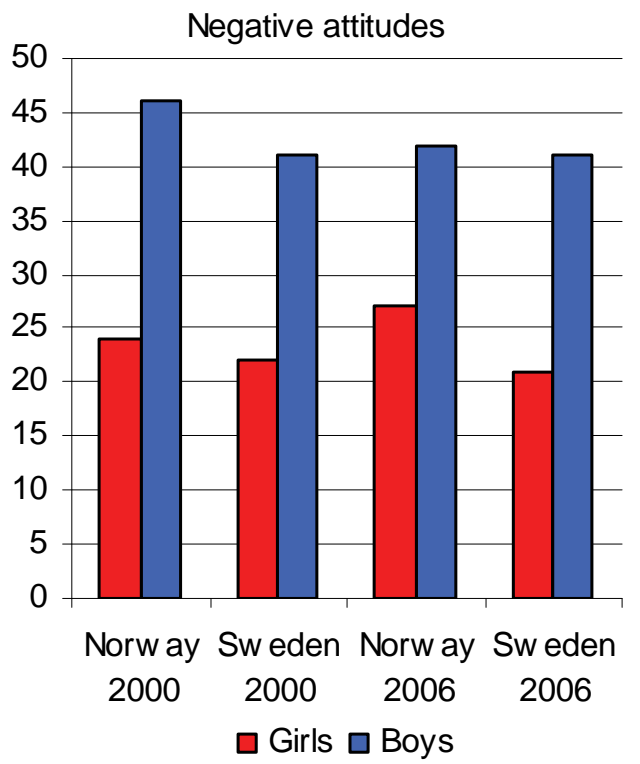

Figure 3.3.7b. Mean percentages of Norwegian and Swedish boys and girls who agree or strongly agree with the positive statements about reading in 2000 and 2006. 
The figures show a surprisingly regular pattern. Boys agree to a higher extent (41-46 percent) than girls (21-27 percent) with statements which express a negative attitude towards reading. For statements which express a positive attitude, the responses show the completely opposite pattern. Girls agree to a higher extent (41-45 percent) than boys (22-27 percent) with these positive statements. Again we see a positive tendency over the years for Norwegian boys. A higher percentage of them are positive, and a lower percentage of them are negative towards reading activities in 2006 than in 2000. The percentages of Norwegian girls who are negative towards reading activities, on the other hand, have increased over six years. In Sweden there is no significant change as far as negative attitudes towards reading are concerned. However, a lower percentage of both girls and boys are positive towards reading activities in 2006 than in 2000.

\section{Diversity of reading}

The introduction to the questions about different reading materials is: "How often do you read these materials because you want to?" The materials that students are asked about are: magazines, comic books, fiction, non-fiction books, e-mails and web pages and newspapers. The answer alternatives are: never or hardly ever, a few times a year, about once a month, several times a month, and several times a week. Figure 8 shows the percentage of students who report that they read different reading materials several times a week. 


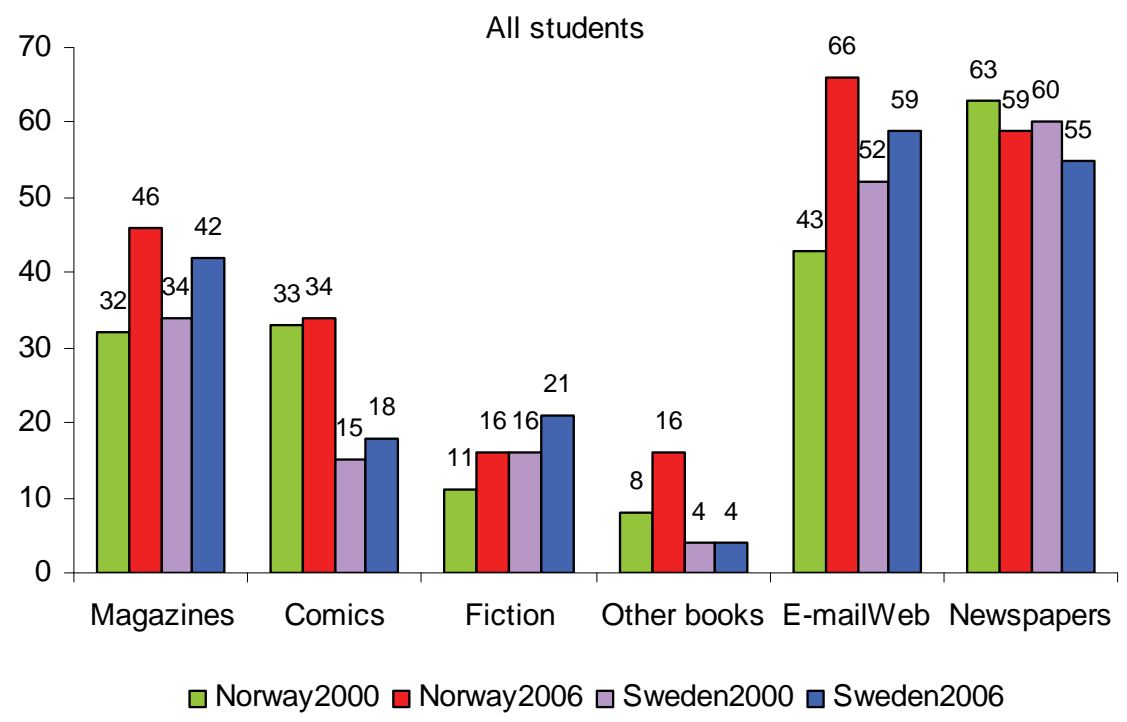

Figure 3.3.8. Percentage of Norwegian and Swedish students who report that they read different reading materials in 2000 and 2006.

Reading magazines seems to have become more popular in both countries from 2000 to 2006. One third of Norwegian students read comic books several times a week both years, compared to 15 (2000) and 18 (2006) percent of Swedish students. There is an increase in both countries regarding the percentage of students who read fiction every week, from 1116 in Norway, and from 16-21 in Sweden. Factual books seem to be more popular in Norway than in Sweden, especially in 2006. Only four percent of Swedish students read factual books several times a week both years, compared to 8 (2000) and 16 (2006) percent of Norwegian students. Reading e-mail and web pages has had a natural increase in both countries, and in 2006 is the material that a highest percentage of 15 yearolds read several times a week. We note a decrease from 63 to 59 percent of students who read newspapers several times a week in Norway and a decrease from 60 to 55 percent in Sweden. The fact that newspapers can be read on the Internet, may explain some of these results. 


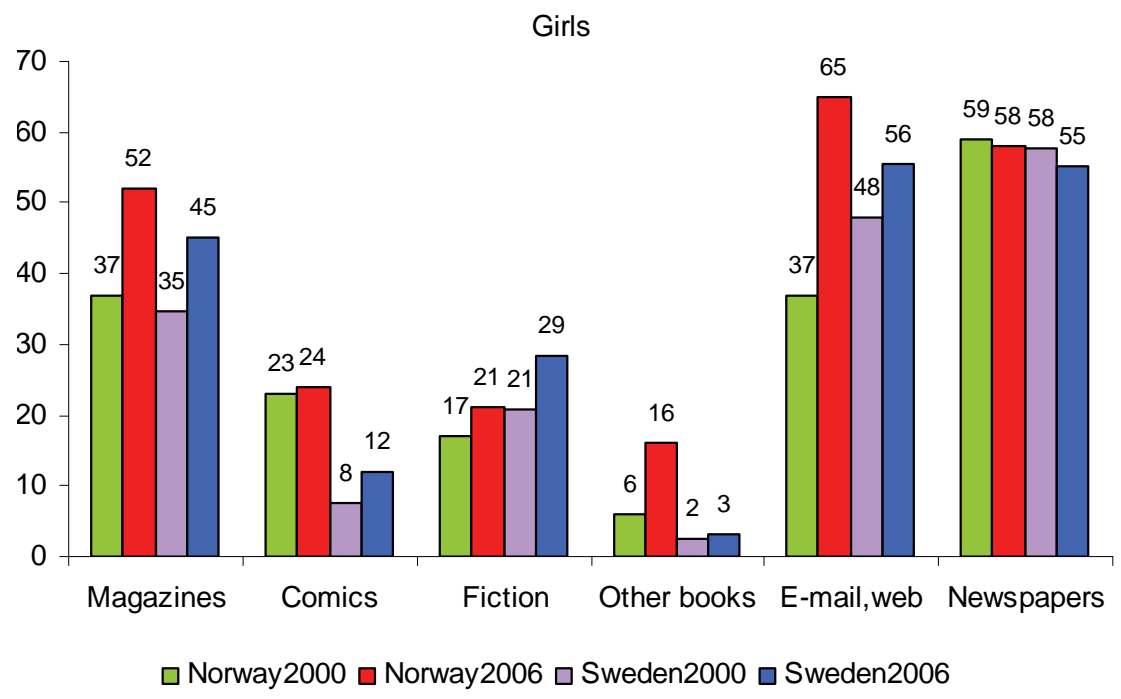

Figure 3.3.9a. Percentage of Norwegian and Swedish girls who report that they read different reading materials in 2000 and 2006.

If we look at the girls, we find the percentage of girls who read magazines several times a week has increased from 37 to 52 in Norway and from 35 to 45 in Sweden. In 2000 only 8 percent of Swedish girls read comic books several times a week, and the percentage has increased to 12 in 2006. In Norway this percentage is much higher: 23 in 2000 and 24 in 2006. An increase in the percentage of girls who read fiction several times a week can be detected in both countries, especially in Sweden where 29 percent of the girls reported reading fiction several times a week in 2006. Only 2 (2000) and 3 (2006) percent of the Swedish girls read factual books several times a week, compared to 6 (2000) and 16 (2006) percent of the Norwegian girls. A much higher percentage of girls in both countries read on the Internet several times a week in 2006 than they did in 2000, Norwegian girls show the largest increase from 37 percent in 2000 and 65 percent in 2006. 58 percent of Norwegian and 55 percent of Swedish girls read newspapers several times a week, which is a small decrease from 2000. 


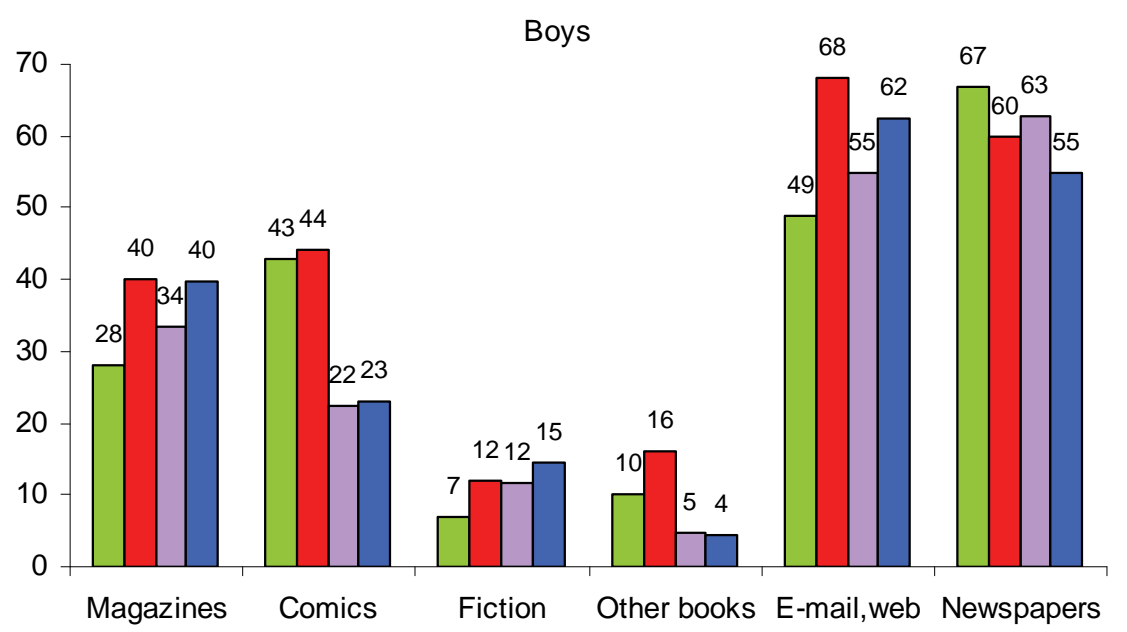

$\square$ Norway2000 $\square$ Norway2006 $\square$ Sweden2000 $\square$ Sweden2006

Figure 3.3.9b. Percentage of Norwegian and Swedish boys who report that they read different reading materials in 2000 and 2006.

Figure 3.3.9b shows that magazines are more popular among boys in both countries in 2006 than in 2000. The percentage of Norwegian boys who read comic books several times a week is almost twice as high as the percentage of Swedish boys who do so. There has been an increase in the percentage of both Norwegian and Swedish boys who read fiction from 2000 to 2006. And like the girls, in 2006 a higher percentage of Swedish (15) than of Norwegian (12) boys read fiction several times a week, and a smaller percentage of Swedish (4) than of Norwegian (16) boys read factual books several times a week. The percentage of boys who read email and web pages several times a week has increased from 49 to 68 in Norway and from 55 to 62 in Sweden since 2000. The percentage of boys who read newspapers every week, however, is decreasing.

To sum up, in both countries girls read more magazines and fiction than boys, and boys read more comic books than girls. Norwegian students in general read more comic books than Swedish students. Magazines seem to have become more popular among 15 year-olds in both countries from 2000 to 2006. The percentage of students who read books several times a week is not very high in any of the groups, but there is an increase for fiction in both countries. Very few Swedish students read 
factual books every week, but the percentage of Norwegian students doing so, has doubled from 8 to 16 in six years. E-mail and the web is frequently read by a higher percentage of all students, and newspapers are read by a slightly lower percentage in 2006 than in 2000. If we look at the six types of reading materials together, we find that the percentage of Norwegian boys who read several times a week has increased more than it has for any of the other groups.

\section{Computer use}

There are many explanations as to the great gender differences in reading performances and reading engagement. One that is mentioned earlier in this chapter is that boys spend more time playing computer games. According to the results from "reading diversity" above, girls read as much e-mail and web pages as boys do. Leino (2003) found that students who never used computers, achieved very poorly on the PISA reading test in 2000. Computer use may indicate quite a lot of reading, but not necessarily. What can really take boys away from reading is playing computer games. Most computer games scarcely demand any reading at all.

Table 3.3.2. Percentages of Norwegian and Swedish students who use computers for various reasons almost every day in $\mathbf{2 0 0 0}$ and 2006.

\begin{tabular}{lllrrr}
\hline Computer use & Country & Students & 2000 & 2006 & Diff 2006-2000 \\
\hline How often do you use a & \multirow{2}{*}{ Norway } & All & $\mathbf{5 4}$ & $\mathbf{8 6}$ & +32 \\
computer at home? & & Girls & 37 & 84 & +47 \\
& & Boys & 70 & 88 & +18 \\
& \multirow{3}{*}{ Sweden } & All & $\mathbf{6 1}$ & $\mathbf{8 5}$ & +24 \\
& & Girls & 48 & 79 & +31 \\
& & Boys & 73 & 91 & +18 \\
\hline How often do you use the & \multirow{2}{*}{ Norway } & All & $\mathbf{4 0}$ & $\mathbf{3 3}$ & $-\mathbf{7}$ \\
internet? & & Girls & 32 & 29 & -3 \\
& \multirow{4}{*}{ Sweden } & Boys & 47 & 36 & -11 \\
& & All & $\mathbf{5 0}$ & $\mathbf{3 5}$ & -15 \\
& & Girls & 43 & 30 & -13 \\
& & Boys & 56 & 40 & -16 \\
\hline \multirow{2}{*}{$\begin{array}{l}\text { How often do you use com- } \\
\text { puter games? }\end{array}$} & \multirow{2}{*}{ Norway } & All & $\mathbf{3 4}$ & $\mathbf{3 4}$ & 0 \\
& & Girls & 13 & 12 & -1 \\
& \multirow{2}{*}{ Sweden } & Boys & 53 & 56 & +3 \\
& & All & $\mathbf{3 1}$ & $\mathbf{3 1}$ & 0 \\
& & Girls & 12 & 8 & -4 \\
& & Boys & 49 & 54 & +5 \\
\hline
\end{tabular}


The table shows that computer use at home has increased for both genders in both countries from 2000 to 2006. In 2006 between 80 and 90 percent of Norwegian and Swedish students use a computer at home almost every day. The gender differences are not as great in 2006 as they were in 2000, especially not in Norway. The percentage of students who use the Internet, however, has for some reason decreased slightly in both countries, but the gender differences are relatively small, especially in Norway.

The percentage of students who play computer games almost every day has not changed from 2000 to 2006, both years it is 34 percent in Norway and 31 percent in Sweden. If we look at boys and girls separately, we see some interesting gender differences. The percentage of girls who play computer games almost every day has dropped slightly from 13 to 12 in Norway and from 12 to 8 in Sweden. Among boys this percentage has increased from 53 to 56 in Norway and from 49 to 54 in Sweden. No other question in 2000 and 2006 reveals greater gender differences.

\section{Summary and conclusions}

The three main aspects that we have addressed in this article are: Gender difference, difference between Norwegian and Swedish 15 year-olds, and change/development over time. The most significant findings are presented below:

Gender difference in both countries, both years

- Girls spend more time reading in their leisure time than boys

- Girls have more positive and less negative attitudes towards reading than boys

- A higher percentage of girls than boys read magazines and fiction several times a week

- A higher percentage of boys than girls read comic books several times a week

- A much higher percentage of boys than girls play computer games almost every day 
Difference between Norwegian and Swedish students, both genders, both years

- A higher percentage of Norwegian than Swedish students read comic books several times a week

- A higher percentage of Norwegian than Swedish students read factual books several times a week

- A higher percentage of Swedish than Norwegian students read fiction several times a week

Development from 2000 to 2006

- A higher percentage of students in both countries read e-mail and web pages several times a week in 2006 than in 2000, and the gender difference favouring boys that we saw in 2000 is no longer significant. The increase is greatest among Norwegian girls.

- The percentage of students who read magazines and books (fiction and factual books combined) several times a week has increased in both countries, particularly among Norwegian students.

- Norwegian boys' attitudes towards reading have become more positive.

- From having the least positive attitudes among all boys in OECD in 2000, Norwegian boys have more positive attitudes towards reading than Swedish boys in 2006.

- Boys play computer games far more frequently than girls.

There is reason to believe that the significant positive change in attitudes towards reading that we see among Norwegian boys is related to the strong efforts that Norwegian schools have made by trying to make boys better and more engaged readers. It is thus somewhat disappointing that Norwegian boys' reading scores are significantly lower in 2006 than in 2000. There may even appear to be a contradiction compared to earlier studies showing strong positive relationships between reading attitudes and reading scores. In this case some further explanation is needed: First, 15 year-olds' reading literacy is developed over a long time, in most PISA countries the students have nine or ten years of schooling behind them when they are 15 years old. Second, reading instruction which students are given during the first school years is very important. According to the school reform implemented in Norway in 1997, teachers were en- 
couraged to let children develop their reading slowly, and to wait and see if the problems that some children had, disappeared after some years. Thus, very few Norwegian children were given special reading instruction during the first school years compared to children in other countries (Solheim and Tønnessen 2003). Third, students’ attitudes towards reading can change from one day to the next, whereas reading proficiency normally takes years to improve. The Norwegian school authorities can hope for better results in PISA 2009 and 2012. Until then focus should be put on encouraging and inspiring children to read in their leisure time. In the long run, it will definitely lead to better reading skills.

\section{References}

Buland, T., Dahl, T., Finbak, L. \& Havn, V. (2008). Det er nå det begynner! Sluttrapport fra evalueringen av tiltaksplanen "Gi rom for lesing!" Trondheim: Teknologi og samfun Gruppe for skole- og utdanningsforskning og NTNU Voksne i livslang laering SINTEF.

Donahue, P., Daane, M., \& Grigg, W. (2003). The nation's report card: Reading highlights 2003 (No. NCES 2004452). Washington DC: National Center for Education Statistics. Guthrie, J.T., \& Wigfield, A. (2000). Engagement and motivation in reading. In M.L. Kamil, P.B. Mosenthal, P.D. Pearson, \& R. Barr (Eds.), Handbook of reading research: Volume III (pp. 403-422). New York: Erlbaum.

Leino (2003). Computer usage and reading literacy. In Lie, S., Roe, A. \& Linnakylä, P. (Eds.) Northern Lights on PISA. Unity and Diversity in the Nordic Countries in PISA 2000. Oslo: Department of Teacher Education and School Development, University of Oslo, Norway.
OECD (2001). Knowledge and Skills for Life. First results from PISA 2000. Paris: OECD publications.

(OECD 2002:120). Reading for change performance and engagement across countries. Paris: OECD Publications. (OECD and Statistics Canada, (2000). Literacy for the information age. Final report of the international adult literacy survey.Paris: OECD Publications/Statistics Canada. Roe, A. \& Taube, K. (2003). Reading Achievement and Gender Differences in Lie, S., Roe, A. \& Linnakylä, P. (Eds.) The Northern Lights on PISA. Unity and Diversity in the Nordic Countries in PISA 2000. Oslo: Department of Teacher Education and School Development, University of Oslo, Norway.

Solheim, R.G. og Tønnessen, F.E. (2003). Slik leser 10-åringer i Norge. En kartlegging av leseferdigheten blant 10-åringer i Norge 2001. Stavanger: Senter for leseforskning. 



\title{
4.1. Educational Equity Account in Nordic Countries
}

\author{
Jarkko Hautamäki, Airi Hautamäki \& Sirkku Kupiainen
}

\section{The Educational Equity Account}

Educational equity refers to the impact of contextual factors on educational outcome ${ }^{16}$. Ideally it should be non-existent. Educational equity is seen to be in balance or to show an educationally relevant positive outcome or "profit" when relevant contextual factors do not explain any of the variation in students' school attainment, that is, the only source of variation in scholastic attainment would stem from students' individual characteristics. The most essential educational equity factors or factors that have been shown to impede educational equity or the equal realisation of individual educability are gender, parents' socio-economic or educational status, immigration status and, of course, schools. There are also other factors that could be taken into account in estimating national educational equity account in the Nordic countries, e.g., ethnic groups or regional differences. But, in this chapter, only between-country differences, between-school differences and the impact of gender, family's socio-economic status, and immigration status in each of the Nordic countries are considered.

16 The concept of (total) equity is not unproblematic. If education is expected to have a lasting impact on an individual's life, it is difficult to see why these should or would not pay dividends in children's lives and future success. Additionally, as Alexander, Entwistle \& Olson (2001) have shown, the negative impact of contextual factors on children's school attainment may take place during the summer and other longer vacation periods and thus be out of reach for the education system. 
Educational equity account, EEA is a way to have condensed information of the effects of important educational factors on educational outcomes. The educational effects can be expressed in terms of explained variances or showing the means of different factors. The statement of "profit and loss", EEA, is a way of providing evidence-based material for educational policy debates. The real benefits of this approach will be apparent when these educational equity accounts can provide long-term evidence of the changes toward or away from the educational aims and goals. For example, because there are no real principal or theoretical reasons to assume gender differences, or a gender gap, EEA is a way of following long term gender effects.

The aim of this chapter is to provide an introduction to educational equity account in the Nordic countries using two outcome indices, one for the level, and one for the relative roles of reading literacy and mathematical literacy in PISA 2006. This condensing allows a general picture to be given of the northern educational landscape.

\section{PISA level and PISA balance}

For testing educational equity with the PISA data, two new variables have been constructed to summarise PISA outcomes for a general analysis, PISA level and PISA balance. To calculate these, principal component analysis was applied to condense the plausible values for the three PISA domains (science, math and reading) for each student into two variables ${ }^{17}$. The correlation of level and balance is by definition zero (principal component analyses without rotation gives uncorrelating components). The first principal component, indicating student's general level of attainment, is named level, following Hunt \& Wittmann (2008; Wittmann 2004). The second component, indicating the profile or the relative role of the three different literacies in students' attainment is named balance. Positive values in balance indicate a performance where reading is relatively stronger in relation to math and science, and negative values indicate a performance where math and science are relatively stronger in

17 The PISA data file (www.pisa.oecd.org,) contains five plausible values for each student's science, mathematics and reading competence to allow for a more reliable assessment of standard errors. See www.acer.au and the technical manual of PISA 2006 (OECD, 2009). 
relation to reading. The loadings of reading, math and science scores on balance are $+.0 .31,-0.24$ and -0.06 , respectively. Balance is, accordingly, an index of a student's competence profile. The estimates for level and balance are based on the whole PISA data (OECD 2007), that is the means for level and balance for the whole student population of PISA 2006 are zero.

\section{The level and balance of the Nordic countries}

The PISA levels for the five Nordic countries are presented in figure 4.1.1 with 95\% confidence intervals, CI. Numbers for figure 4.1.1 and 4.1.2 are taken from Hautamäki, Laaksonen \& Scheinin (2008), in which the CIs have been estimated using a survey design statistical modelling. Reflecting the Finnish students' high performance in all PISA domains, the level value of Finland was the highest in the PISA 2006 survey (Hautamäki et al. 2008). Also the values of the other Nordic countries were higher $(>0)$ than the world mean.

Mean level

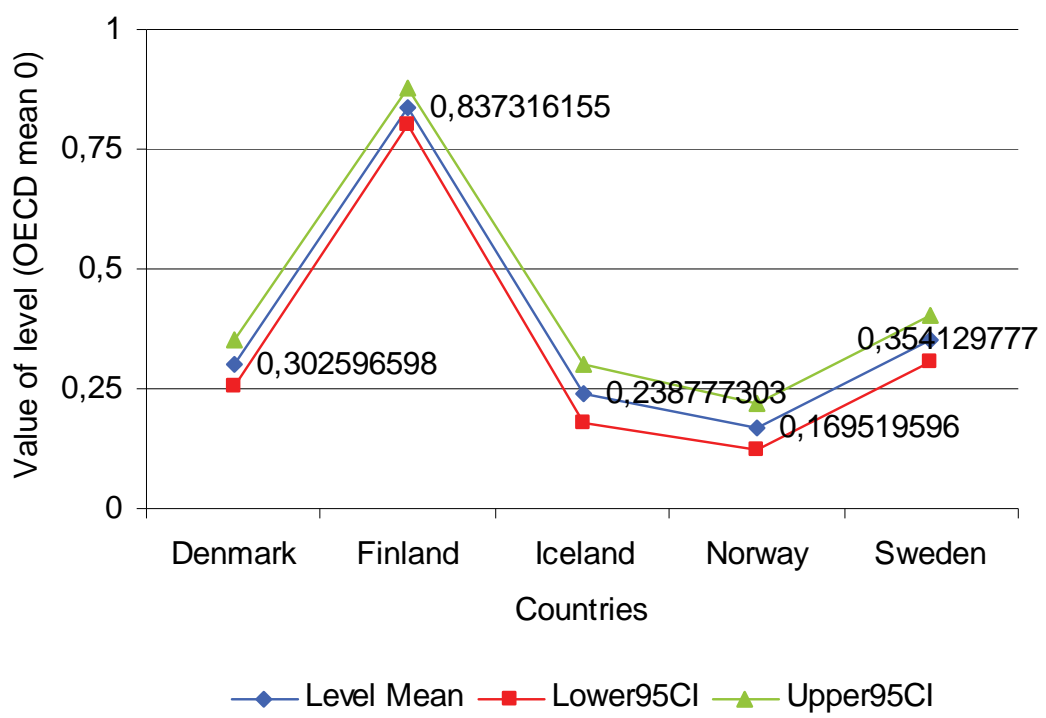

Figure 4.1 1. Values of level for the Nordic countries (95\% confidence intervals, CI estimated) (World mean of all PISA 2006 countries $=0, S D=1$ ). 
The results for balance are presented in figure 4.2.2. The balance values for Finland and Norway were close to zero (0.06 and .007). This means that reading, math and science scores were in balance, high in the case of Finland, and relatively low in the case of Norway. For Denmark and Iceland, the negative value of balance indicated a profile relatively stronger in mathematical and scientific literacy while Swedish students were relatively stronger in reading literacy as compared to their math and science scores.

The name of the component - balance - is selected to pinpoint the relationship between reading and math/science. These are in balance, in an educational sense, when they are of equal size. It is a normative, valueladen conclusion, which is evaluated in different countries differently depending on the goals of the national education. If reading is considered to be more important then a positive value is expected and valued, and if mathematical or science competence is desired then a negative value is a positive outcome. If both reading and math/science are considered equally valued, then a value around zero for balance is a good outcome of course, given that the level is high enough to satisfy the national media and policy makers.

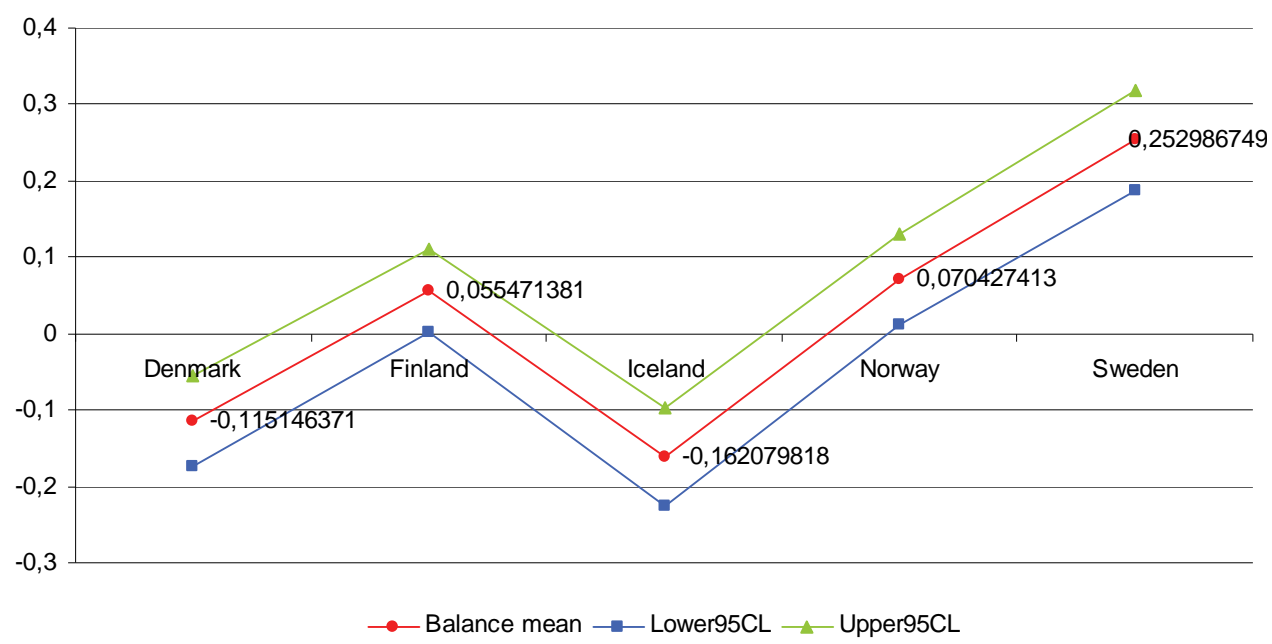

Figure 4.1.2. Values of balance for the Nordic countries (95\% CIs estimated) (World mean of all PISA 2006 countries $=0, S D=1$ ) 
The country scores for PISA-level and PISA-balance were calculated from individual student scores. For these individual scores, the indices did not correlate. At country level, however, this need not be the case and correlations may differ from zero. Hunt and Wittmann (2008; Wittman 2004) calculated for PISA 2003 a correlation -0.5 between level and balance. In PISA 2006 the world correlation was -0.16 (Hautamäki \& al. 2008), but for the Nordic countries correlation was zero. The negative correlation indicates a tendency for countries with a high level to have a negative balance score, reflecting a relatively stronger level of mathematical and scientific literacy. However, this was not the case in the Nordic countries. This is a tentative sign of balanced educational policies according to which both reading and mathematics \& science are emphasised.

\section{Countries, schools and students}

For level and balance, a three-level model (student, school, country; using MLwin 2.10) was significantly better than one- and two-level models with student- or student-and-school-levels included. Country explained $6.8 \%$ and school $11.4 \%$ of the variance in level, while in balance, country explained $2.6 \%$ and school $19.4 \%$ of the variation.

Intra-class correlations, ICC of schools, or between-school differences in level have been estimated for the Nordic countries (figure 4.1.3). The bigger the ICC, the bigger are the differences between schools. There were significantly bigger between-school differences in Denmark and Sweden than in the other Nordic countries. The ICC for Finland was smaller than the ICC for the other Nordic countries. 
ICC



Figure 4.1.3. Intra-class correlations of schools in Nordic countries

\section{Gender}

For level, in the Nordic countries gender was a statistically significant factor explaining less than one percent of total student-level variation. The mean for females was higher than the mean for males.

For balance, gender was a very significant factor explaining $22 \%$ of the variance. This gender difference was the biggest difference in PISA 2006, taking into account all independent variables. Boys' relative achievement was better in mathematics and science than in reading, in all Nordic countries. In figures 4.1.4 and 4.1.5, the respective values for all the Nordic countries are given as separate estimates for each country (using MLwiN2.10 ANOVA).

\section{Family socio-economic status}

For level, the socio-economic status (using highest parental value of white-collar high-skilled, white-collar low-skilled, blue-collar highskilled or blue-collar low-skilled) was a significant factor explaining $8.9 \%$ of total student-level variation. The estimated model illustrated that 
the means for children from white collar, high status families were the highest, while the means for children from blue collar low status families were the lowest. The differences between white-collar low status and blue-collar and high status were not significant.

For balance, parents' socio-economic status was a significant factor explaining about $2 \%$ of student-level variance. In figures 4.1.4 and 4.1.5, the respective values for all the Nordic countries are given.

\section{First and second generation immigrant students}

For level, immigrant status was a significant factor explaining $6.5 \%$ of total student-level variation. The estimated model showed that if a student was a second generation immigrant, then s/he was below the native level 0.48 , but if $\mathrm{s} / \mathrm{he}$ was a first generation immigrant then $\mathrm{s} /$ he was below the native level -0.72 (the scale uses the value of one (1) for the standard deviation, so this is clearly a lower value).

For balance, immigrant status was a significant factor explaining 1.9\% of the variance. The estimated model for balance showed that the first generation immigrants' mean for balance was negative, and the second generation immigrants' mean for balance was positive. This means that, in the first generation, mathematical and scientific literacy was better than reading literacy, but the relationships changed during one generation such that reading competence was dominant.

Due to the small number of persons with immigrant status in Finland and Iceland, the results for these countries are tentative. However, the general trend was also the same for these countries: students with immigrant backgrounds were not achieving as well as native students. Surprisingly, the competence of students with immigrant backgrounds seemed to follow that of the native students at a fairly constant rate: the higher the competence level of the native students, the higher the competence of immigrant students as well.

\section{Country means of level and balance}

The calculated means for gender, socio-economic status and immigrant status are presented separately for level (figure 4.1.4) and balance (figure 4.1.5). 


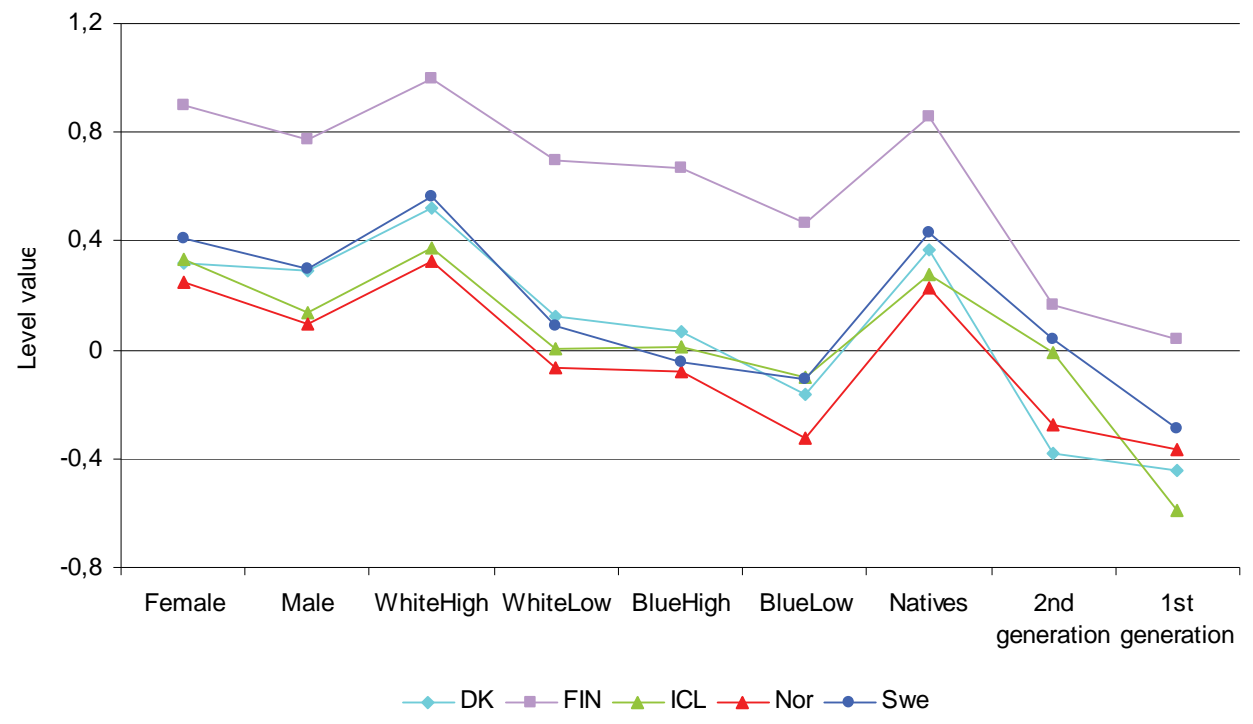

Figure 4.1.4. Means for level of gender (girls-boys), by parents' socio-economic status (white-collar high-skilled, white-collar low-status, blue-collar high-status, blue-collar low-status) and immigrant status (native, $-2^{\text {nd }}$ generation- $1^{\text {st }}$ generation) for Nordic countries (World mean for level is $0, S D=1$ ).

The figure shows, for example, that girls had higher means for level than boys, with the exception of Denmark, where there were no gender differences in level. With regard to socio-economic status, the mean values declined from the white-collar high-skilled to blue-collar low-skilled category. That was also the case for immigrants as the means of native students were significantly higher than those of all immigrant groups, in all Nordic countries.

Figure 4.1.4 indicates that the slopes of equity factors were almost the same in all Nordic countries. This means that equity factor can be thought to produce its effects in the same manner. The major difference is the constantly higher PISA level of Finnish students irrespective of the factor under investigation. Among the other Nordic countries, there are only small differences except for second generation immigrant students. For most groups, Norwegian students most often had lowest level. 


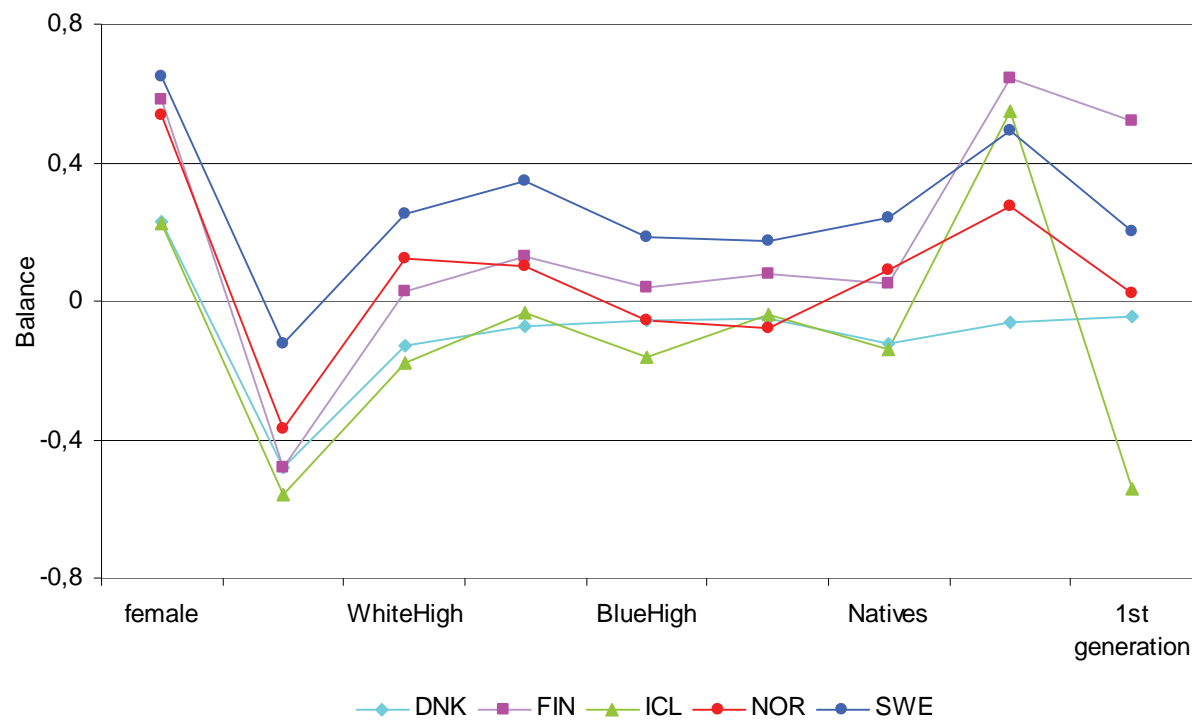

Figure 4.1.5. Means for balance by gender (girls-boys), by parent's socio-economic status (white-collar high-skilled, white-collar low-skilled, blue-collar high-skilled, blue-collar low-skilled) and by immigrant status (natives $-2^{\text {nd }}$ generation- $1^{\text {st }}$ generation) for Nordic countries (World mean of balance is $0, S D=1$ )

The profiles of the average values of balance were similar to each other in the Nordic countries. Additionally, girls were strongly reading dominated, boys math dominated. The positive values for balance implied that the group under scrutiny had generally solved the given PISA items in a way that their scores in reading items were higher than their scores in math or in science items.

\section{Conclusions}

Educational equality has been a goal set up and pursued in Nordic welfare states. The equity factors covered showed that educational equality has been attained fairly well in all the Nordic countries in their comprehensive schools. However, particularly the gender differences for balance point to a potential concern. Some problems in reaching the aim can be seen with regard to immigrants. The level of immigrant students was clearly below that of the native students. In contrast to other groups of 
students, the first generation of immigrants was less balanced in relation to reading and mathematical items.

The profiles of the level of the other Nordic countries were very similar to each other. Finland had a high level with regard to all equality factors. Denmark may have some problems in integrating immigrant children. However, in Denmark the gender differences in level were not significant. The between-school differences were highest in Denmark and Sweden, and lowest in Finland and Iceland.

The contents of figures 4.1.1 \& 4.1.2 and 4.1.4 \& 4.1.5 constitute the educational equity account, where educational outcomes - here in relation to PISA level and balance - are presented as contextualised. The major educational educability contexts - here between-country and betweenschool differences, gender, socio-economic status and immigrant status are only a subset of potential indices. The educational equity account, EEA, can be used for monitoring educational outcomes from the perspective of national and Nordic educational policies or from more general equality principles.

The general conclusion is that, in the Nordic countries, educational equity is at a fairly high level at least as compared to most countries participating in PISA 2006. The major challenge for EEA in terms of level of competence (level) is posed by students with immigrant background while for balance, the challenge is the (relatively) poorer reading skills of boys or mathematical competence of girls. The differences due to socioeconomic factors are also worth monitoring on a regular basis.

\section{References}

Alexander, K.L., Entwistle, D.R. \& Olson, L.S. (2001). Schools, achievement and inequality: a seasonal perspective. Educational Evaluation and Policy Analysis, 23, 2, 171-191.

Hautamäki, J., Harjunen, E., Hautamäki, A., Karjalainen, T., Kupiainen, S., Laaksonen, S., Lavonen, J., Pehkonen, E., Rantanen, P., Scheinin, P. (2008). PISA06 Finland. Analyses, reflections, explanations. Ministry of Education
Publications 2008: 44. Helsinki: Ministry of Education.

Hautamäki, J., Laaksonen, S. \& Scheinin, P. (2008). Level and balance of achievement. (pp. 39-51). In J. Hautamäki et al. (2008).

Hunt, E. \& Wittmann, W. (2008). National intelligence and national prosperity. Intelligence, 36, 1-9.

OECD (2009). PISA 2006. Technical Report. Paris: OECD. 
Wittmann, W.W. (2004). Group differences in intelligence and related measures. In O. Wilhelm. \& R.W.Engle
(Eds.), Handbook of understanding and measuring intelligence. Thousand Oaks, CA: Sage (pp. 223-239). 



\subsection{The influence from individual social background and school social background in the Nordic countries}

Niels Egelund and Flóvin Eidesgaard

\section{Introduction}

Compulsory schooling was introduced in the Nordic countries in the early 1800s providing training for all children, more or less to match the demand for a skilled labour force in an increasingly industrialised society. The length and level of training reached was still highly dependent on social background. The late 1800s saw political goals primarily introduced by the Social Democrats, for more equal distribution of education which in the 1950s and 1960s led to a shift towards a comprehensive school without tracking the compulsory part of the education system. In recent years, the debate on immigration and gender has also led to interest in the effects of ethnicity and gender.

Several studies have focussed on intergenerational educational attainment (Erikson and Jonsson, 1996; Müeller et al., 1989; 1993; Shavit and Blossfeld, 1993) and shown that there are persisting inequalities in educational opportunity across countries over time. This can be seen as a natural result of resources and influence in families differing in education and wealth. But when looking at the Nordic countries with established comprehensive social security systems with the explicit aim of promoting equality of opportunity, there seems to be a paradox as numerous studies show inequality persists in all countries (Breen and Jonsson, 2000; Davies 
et al., 2002; Dryler, 1998; Hansen, 1997; Jonsson, 1993; Jæger and Holm, 2004; Kivinen et al., 2001; Lindbekk, 1998).

The classical theories behind inequality in intergenerational educational attainment contain economic factors (e.g. Duncan \& Brooks-Gunn, 1997; Wagmiller et al. 2006), cultural and social resources (e.g. Bourdieu, 1977; De Graaf et al., 2000) and family structure (e.g. McLanahan \& Sandefur, 1994; Musick \& Mare, 2006). A later theory, the Relative Risk Aversion Theory, has been put forward (Breen \& Goldthorpe; Davies et al., 2002). This theory, in contrast to classical theories, is forward looking and hypothesises that individuals' educational choices are driven by a fundamental desire to avoid downward social mobility by reaching at least the same social class position as their parents, and they are using education as a means of avoidance. The Relative Risk Aversion Theory also explains why some classes have little incentive to pursue higher education, and why class inequalities in educational attainment persist. The theory has been tested in a Danish longitudinal study showing that Relative Risk Aversion affects educational decisions over and above traditional socio-economic factors (Holm \& Jæger, 2008).

While the international reports from the IEA Studies PIRLS (Mullis et al., 2007) and TIMSS (Martin et al., 2008, Mullis et al, 2008) do not provide detailed statistics about the relationships between test results and parent educational background and school level social background variables, PISA has in cycles 2000, 2003 and 2006 made such analyses for each participating country (OECD, 2001, 2004, 2007a, 2007b).

Results from all three PISA cycles have shown that there are educational inequalities in all countries. All Nordic countries have inequality effects below the OECD average, but still profound differences remain between the Nordic countries with Finland and Iceland coming out best, followed by Sweden, Norway and Denmark.

\section{Method and material}

Data used in this study are from PISA 2006 with data from Denmark, Finland, Iceland, Norway, Sweden and the Faroe Islands. Data from the Faroe Islands was collected using test materials from PISA 2006 trans- 
lated to Faroese. Testing was carried out over the same time period as in the international PISA.

As the majority of PISA students are in their compulsory school years there are no vocational track based differences between girls and boys in the student samples.

There are, however, slight country differences in socio-economic background. Socio-economic background in PISA is defined by an index, ESCS, derived by principal component analysis from indicators of parent economic, social and cultural status, and are standardised to have an OECD mean of 0 and a standard deviation of 1 . It can be seen in table 4.2.1 that Iceland has the highest ESCS average, followed by Norway, Denmark, Sweden, Finland and the Faroe Islands. There is, however, high variance between school ESCS. Sweden has the highest between school variation, followed by Denmark, Norway, Finland, Iceland and the Faroe Islands. Regarding the latter, due consideration must be given to the fact that both the number of students and schools are low ( $\mathrm{N}=23)$. Table 4.2.1 shows the subjects and their social background in the current study.

Table 4.2.1. Students in PISA 2006 from the Nordic countries and social and ethnic background (unweighted data)

\begin{tabular}{lrrr}
\hline Country & Student N & ESCS mean & ESCS variance \\
\hline DNK & 4,532 & 0.282 & 1.479 \\
FAO & 764 & 0.119 & 0.126 \\
FIN & 4,714 & 0.214 & 0.392 \\
ISL & 3,789 & 0.582 & 0.242 \\
NOR & 4,692 & 0.353 & 0.981 \\
SWE & 4,443 & 0.261 & 3.713 \\
\hline
\end{tabular}

\section{Results}

It is already known that PISA performance differs in the Nordic countries (OECD, 2007). Table 4.2.2 presents these differences, where Finland scores highest in all subject areas and the Faroe Islands score lowest. 
Table 4.2.2. Results in PISA 2006 in science (combined scale), reading and mathematics

\begin{tabular}{lrrr}
\hline Country & Science & Reading & Mathematics \\
\hline DNK & 496 & 494 & 513 \\
FAO & 417 & 409 & 450 \\
FIN & 563 & 547 & 548 \\
ISL & 491 & 484 & 506 \\
NOR & 487 & 484 & 490 \\
SWE & 503 & 507 & 502 \\
\hline
\end{tabular}

The influence of social background and PISA results has been estimated for each country by means of Hierarchical Linear Models analysis, where both individual social background and school social background can be separated.

In table 4.2.3., looking at Denmark, the first row shows the rise in PISA score where the student is 1.0 point higher on the ESCS scale. Thus 1 ESCS point higher individual background would give the student a 31.3 higher PISA score. The school social effect is the rise in PISA score following a school average ESCS which is 1.0 point higher. Thus a rise in Denmark of 1 ESCS point will give 47.3 PISA points on the combined science scale.

Table 4.2.3. Social background and results in PISA 2006 in science (combined scale) on individual level and on school level.

\begin{tabular}{lrr}
\hline Country & Student social effect & School social effect \\
\hline DNK & $\mathbf{3 1 . 2 6}$ & $\mathbf{4 7 . 2 7}$ \\
FAO & $\mathbf{2 7 . 1 0}$ & 18.54 \\
FIN & $\mathbf{2 7 . 7 3}$ & 5.94 \\
ISL & $\mathbf{2 8 . 9 6}$ & -5.30 \\
NOR & $\mathbf{2 8 . 7 9}$ & 31.49 \\
SWE & $\mathbf{3 0 . 6 3}$ & 32.52 \\
\hline
\end{tabular}

Values in bold are statistically significant at the $5 \%$ level

From table 4.2.3 it can be seen that all six countries have student social effects from ESCS of around 30 PISA points. All values are statistically significant. The Faroe Islands are relatively the lowest with 27.1 and Denmark the highest with 31.26 points. Looking at the influence of school ESCS, there are substantial numerical differences, from 47.3 PISA points in Denmark to 5.94 in Finland and even a negative value of -5.3 in Iceland. However, only the value in Denmark is statistically significant. 
The reason behind this is that the ESCS gradient is relatively stable for all schools while it differs much more in the other countries.

Table 4.2.4. Social background and results in PISA 2006 in reading on individual level and on school level.

\begin{tabular}{lrr}
\hline Country & Student social effect & School social effect \\
\hline DNK & $\mathbf{2 4 . 1 6}$ & $\mathbf{5 4 . 4 9}$ \\
FAO & $\mathbf{2 8 . 9 2}$ & 27.07 \\
FIN & 23.14 & 21.07 \\
ISL & 23.11 & 8.43 \\
NOR & 31.66 & 28.27 \\
SWE & 24.90 & 52.03 \\
\hline
\end{tabular}

Values in bold are statistically significant at the $5 \%$ level

Table 4.2.4 shows the results from reading. In this domain, influence from ESCS on the individual level is between 23.1 and 31.7. Norway has the highest influence, and Finland and Iceland the lowest. Thus influence on the individual level is much higher in reading than in science. All effects are statistically significant. Influence from school ESCS is numerically highest in Denmark and Sweden and lowest in Iceland. Only the result from Denmark is statistically significant.

Table 4.2.5. Social background and results in PISA 2006 in mathematics on individual level and on school level.

\begin{tabular}{lrr}
\hline Country & Student social effect & School social effect \\
\hline DNK & $\mathbf{2 7 . 2 9}$ & $\mathbf{4 8 . 0 6}$ \\
FAO & $\mathbf{2 8 . 6 8}$ & 12.76 \\
FIN & $\mathbf{2 8 . 6 1}$ & 9.22 \\
ISL & $\mathbf{2 8 . 7 6}$ & -0.26 \\
NOR & $\mathbf{2 7 . 1 4}$ & 29.46 \\
SWE & $\mathbf{3 0 . 0 3}$ & 37.30 \\
\hline
\end{tabular}

Values in bold are statistically significant at the $5 \%$ level

For mathematics the results in table 4.5 show an almost similar pattern as in science and reading. Influence on the individual level is between 27.1 and 30.0. All effects are significant. School level effect is highest for Denmark with 48.1 and lowest for Iceland with -0.3 , it is, however, only significant for Denmark 


\section{Discussion}

There are profound differences in the PISA results for the Nordic countries (OECD, 2001; 2004; 2007) and this leads to an interest in looking at the factors behind the differences. The PISA reports have also pointed at different influences of social, gender and ethnic factors in the Nordic countries where the welfare states have a focus on equality in the educational system and thus on avoiding such inequalities.

Previous studies have shown that intergenerational educational attainment persists in countries over time (Breen and Jonsson, 2000; Davies et al., 2002; Dryler, 1998; Hansen, 1997; Jonsson, 1993; Jæger and Holm, 2004; Kivinen et al., 2001; Lindbekk, 1998). Thus it is somewhat surprising that the Nordic countries show such differences. The Relative Risk Aversion Theory (Breen \& Goldthorpe; Davies et al., 2002) with its fundamental desire to avoid downward social mobility would point at country specific differences in avoidance as being probably caused by historical and cultural variations in the role of expectations regarding educational attainment.

The variable ESCS covers both economic factors (Duncan \& BrooksGunn, 1997; Wagmiller et al., 2006) and cultural and social resources (Bourdieu, 1977; De Graaf et al., 2000) and family structure (McLanahan \& Sandefur, 1994; Sandefur, 1994; Musick \& Mare, 2006)

The multi level analysis carried out in the present study shows that the influence of individual social background is more or less the same in all Nordic countries and for all three subject areas covered. For each ESCS point, PISA increases between 23 and 32 points. The differences between the Nordic countries are thus primarily related to school level social differences, peer effects, which are quite different for the countries. Denmark, and to a lesser extent Norway and Sweden have school level gradients which are parallel, while gradients vary for schools in the Faroe Islands, in Finland and Iceland. Again only qualitative studies will be able to provide an understanding of the mechanisms involved. Andersen (2008) has pointed out that Denmark in a qualitative comparison with Finland has a learning climate characterised by a high degree of individualised educational progressivism leading to low expectations for educational achievement in schools with low average social background, and 
Egelund \& Tranæs (2007) found the same in a quantitative comparison of Danish schools.

\section{References}

Andersen, F.Ø. (2008): Nordiske læringsmiljøer. Tydelighed, opmerksomhed og engagement i skolehverdagen? Ph.D. dissertation. Copenhagen: Danish School of Education, University of Aarhus.

Bourdieu, P. (1977): Reproduction in education, society, culture. NY: Wiley and Sons.

Breen, R. \& Goldthorpe, J.H. (1997): Explaining educational differentials. Towards a formal rational action theory. Rationality and Society. 9. 275-305.

Breen, R. \& Johnsson, J.O. (2000): Analyzing educational careers: a multinominal transition model. American Sociological Review. 65. 754-772.

Davies, R., Heinesen, E. \& Holm, A. (2002): The relative risk aversion hypothesis of educational choice. Journal of Population Economics, 15. 683-713.

De Graaf, N.D., de Graaf, P.M. \& Kraykamp. G. (2000): Parental cultural capital and educational attainment in the Netherlands: A refinement of the cultural capital perspective. Sociology of Education, 73, 92-111.

Dryler, H. (1998): Parental role models, gender and educational choice. British Journal of Sociology, 49. 375-398.

Duncan, G.J. \& Brooks-Gunn, J. (1997): Consequences of growing up poor. NY: Russell-Sage Foundation.

Egelund, N. \& Tranæs, T. (Eds.) (2007): PISA Etnisk 2005. Kompetencer hos danske og etniske elever i 9. klasser i Danmark 2005. 2. udgave. Odense: Syddansk Universitetsforlag.

Erikson, R.E. \& Jonsson, J.O. (1996): Can education be equalized? The
Swedish case on comparative perspective. Boulder, CO. Westview Press.

Hansen, M.N. (1997): Social and economic inequality in educational career: do the effects of social background characteristics decline? European Sociological Review. 13. 305-320.

Holm, A. \& Jæger, M. (2008): Does Relative Risk Aversion explain educational inequality? A dynamic choice approach. Research in Social Stratification and Mobility. 26. 199-219.

Jonsson, J.O. (1993): Persisting inequalities in Sweden. In: Shavit, Y. \& Blossfeld. H.-P. (Eds.): Persistent inequality. Changing educational attainment in thirteen countries. Bolder, CO. Westview Press. Pp. 101-132.

Jæger, M.M. \& Holm, A. (2004). Penge, (ud)dannelse, forbindelser eller brains? En test af fire forældreressourcers betydning for unges uddannelsesvalg i Danmark. Dansk Sociologi, 15. 67-84. Kivinen, O. Ahola, S. \& Hedman, J. (2001): Expanding education and improving odds? Participation in higher education in Finland in 1980s and 1990s. Acta Sociologica. 44. 171-181.

Lindbekk, T. (1998): The education backlash hypothesis: The Norwegian experience 1960-92. Acta Sociologica. 41. 151-162.

Martin, M.O., Mullis, I.V.S., \& Foy, P.: (2008). TIMSS 2007 International Science Report: Findings from IEA's Trends in International Mathematics and Science Study at the Fourth and Eighth Grades. Boston, US: TIMSS \& PIRLS International Study Center, Boston College. 
McLanahan, S. \& Sandefur, G. (1994): Growing up with a single parent: What hurts and what helps. Cambridge, MA: Harvard University Press.

Müeller, W., Lüttinger, P. \& Karle, W. (1989): Class and education in industrial nations. International Journal of Sociology. 19. 3-39.

Mullis, I.V.S., Martin, M.O., Kennedy, A.M. \& Foy, P. (2007): PIRLS 2006 International Report.

IEA's Progress in International Reading Literacy Study in Primary Schools in 40 Countries. Boston, US: TIMSS \& PIRLS International Study Center, Lynch School of Education, Boston College.

Mullis, I.V.S., Martin, M.O. \& Foy, P. (2007): TIMSS 2008 International Mathematics Report: Findings from IEA's Trends in International Mathematics and Science Study at the Fourth and Eighth Grades. Boston, US: TIMSS \& PIRLS International Study Center, Lynch School of Education, Boston College.

Musick, K. \& Mare, R.D. (2006): Recent trends in the inheritance of poverty and family structure. Social Science Research. 35. 471-499.

OECD (2001): Knowledge and Skills for Life. First results from PISA 2000. Paris, OECD.

OECD (2004): Learning for Tomorrow's world. First results from PISA 2003. Paris, OECD.

OECD (2007a): PISA 2006. Science Competencies for Tomorrow's World. Volume 1. Analysis. Paris, OECD. OECD (2007b): PISA 2006. Volume 2. Data/Données. Paris, OECD.

Shavit, Y. \& Blossfeld, H.-P. (Eds.) (1993): Persistent inequality. Changing educational attainment in thirteen countries. Bolder, CO. Westview Press.

Skolverket (2003): Läsforståelse hos lever med utlänsk bakgrund. En fordjupad analys av resultaten från PISA 2000 i 10 länder. Rapport 227. Stockholm. Skolverket.

Wagmiller, R.L., Lennon, M.C., Kuang, L., Alberti, P.M. \& Aber, J.L. (2006): The dynamics of economic disadvantage and children's life chances. American Sociological Review, 71. 847-866. 


\title{
4.3. Reading and Socio-Economic Factors: A cross-sectional Nordic study of the 2000, 2003 and 2006 PISA-results
}

\author{
Jarkko Hautamäki \& Airi Hautamäki
}

Reading and socio-economic factors

The focus of this chapter is on the role of socio-economic factors in PISA, particularly, with regard to reading literacy during the three cycles. The aim is to study whether socio-economic factors provide an explanation for between-country and between-school differences.

In the analyses, the dependent variable has been constructed as a mean of plausible values for reading, for 2000, 2003 and 2006. The independent variable is the HISEI score. HISEI is the combined index of the occupational level of the parents, and is an acronym for "highest international social and economic index". Students were asked about their parents' occupation, and employment status: whether their mother and father were in full-time work, worked part-time, were unemployed, or had some other status. These pieces of information were coded by trained coders, using the International Standard Classification of Occupations (ISCO 1988, and Ganzeboom \& al. 1992), which is a socio-economic index of occupational status. The index is available in all three PISA data-files. Its values range from 16 to 90: low values represent a lower socio-economic status and high values represent a higher socio-economic status. It was used as a 
non-categorical variable without any recoding. The methods were based on multilevel modelling, using MlwiN2.10.

HISEI combines information from both parents. The correlation of HISEI to the separate socio-economic indices of mothers and fathers was 0.72 and 0.81 , respectively, in 2000, and 0.71 and 0.77 , respectively, in 2003, and 0.73 and 0.79 , respectively, in 2006. The correlation of HISEI with the mean reading score was $0.26,0.11$, and 0.22 , for 2000, 2003 and 2006, respectively. The correlations of the combined family's HISEI with mothers' and fathers' socio-economic scores were high and stable (as it should be given it was calculated from parents' values), and with reading stable and relatively small, but still statistically significant (which is a contingent outcome). The aim of this chapter is to analyse some aspects of the type and size of the HISEI effect in the Nordic countries.

The approach used takes into account the multilevel nature of data using 3-level models. The levels are countries, schools and students. First, a basic 3-level model is given, and then the HISEI variable is entered (model 2) and, finally, the HISEI* country interaction is included (model 3). All these are analysed in relation to the mean reading score. All the country-level and HISEI* country interactions are presented in relation to the Swedish scores as a point of reference.

The Nordic countries differed both in reading and HISEI score in all three cycles (ANOVA significant for all cycles, for reading and HISEI, no pair-wise comparisons are presented in this connection, but are available on request). Number of pupils, mean reading scores and HISEI scores are presented in table 4.3.1, for three cycles, 2000, 2003 and 2006. The reading scores for Iceland, Norway and Sweden have decreased. For other countries, in particular Finland, but also Denmark, the scores have remained at the same level.

Table 4.3.1. Reading scores and HISEI values for Nordic countries $(2000,2003$, and 2006) (sample sizes, $\mathrm{N}$, are also given)(all figures rounded)

\begin{tabular}{lrrrrrrrrr}
\hline & N00 & READ00 & HISEI00 & N03 & READ03 & HISEI03 & N06 & READ06 & HISEI06 \\
\hline Denmark & 4235 & 498 & 50 & 4218 & 491 & 49 & 4532 & 494 & 49 \\
Finland & 4864 & 548 & 50 & 5796 & 542 & 51 & 4714 & 547 & 49 \\
Iceland & 3372 & 508 & 53 & 3350 & 492 & 54 & 3789 & 485 & 54 \\
Norway & 4147 & 505 & 54 & 4064 & 500 & 55 & 4692 & 484 & 53 \\
Sweden & 4416 & 517 & 51 & 4624 & 513 & 51 & 4443 & 509 & 51 \\
\hline
\end{tabular}


The table should be read with caution, as it is evident that at the country level there is a negative association between the HISEI and reading score. This is due to the fact that the PISA reading score is lower in countries with higher HISEI values. The country level correlations of the standardised reading residual and the mean HISEI for the five Nordic countries were $-0.37,-0.25$ and -0.79 for years 2000, 2003 and 2006, respectively. However, this is only a paradox at the country aggregate level. In schools, in all the Nordic countries, the correlations were $0.44,0.42$ and 0.41 , indicating that the reading scores are higher in relation to the schools' mean HISEI level. Finland created this country-level paradox due to the fact that the reading level of Finland was very high in relation to the HISEI mean score. One interpretation is that the other Nordic countries appear to offer lower educational returns to their well-educated socioeconomically well-established families than Finland.

\section{Country and school variances in reading}

In the multilevel analysis, adding both school and country levels increased the model fit, and country level variances were significant. The use of 3-level modelling was warranted. The student-, school- and country level variances and the mean Nordic reading score (b0ijk) are presented in table 4.3.2 for 2000, 2003 and 2006.

Table 4.3.2. Three-level variance component model of mean reading scores in the Nordic countries $(2000,2003$ and 2006) (all figures rounded)

\begin{tabular}{lrrr}
\hline Model 1 & $\mathbf{2 0 0 0}$ & $\mathbf{2 0 0 3}$ & $\mathbf{2 0 0 6}$ \\
\hline ReadMean (b0ijk) & 514 & 508 & 504 \\
Country & 308 & 327 & 505 \\
School & 915 & 709 & 1249 \\
Student & 7493 & 6623 & 6914 \\
Total & 8716 & 7658 & 8668 \\
\hline
\end{tabular}

Compared to 2000, total 2006 variance was about the same, but both the between-country and between-school differences had increased. When compared to 2003, the total variance for 2006 has increased, and the between-country and between-school differences have increased. The school-level variance component decreased from 2000 to 2003, but increased in 2006. The intra-class correlations of schools, as an index of 
between-school variation, were $0.12,0.10$ and 0.17 in 2000, 2003 and 2006, respectively. With regard to the between-country level, the decrease in the 2006 scores in Iceland and Norway is the main observation, whereas the other countries retained their level. With regard to betweenschool differences, the outcome - increased between-school differences appears be the opposite to the goal of increasing educational equity by means of educational policy.

\section{HISEI included}

When the HISEI was included in the model (table 4.3.3, model 2), the fit increased. Of the total Nordic variance, HISEI explained $11.3 \%$, $9 \%$ and 11.4\% in 2000, 2003 and 2006, respectively. However, there were other changes in variances as well.

Table 4.3.3. Three-level variance component models of reading (in 2000, 2003 and 2006) with the highest international socio-economic index (HISEI)

\begin{tabular}{|c|c|c|c|c|c|c|}
\hline & 2000 & Se & 2003 & Se & 2006 & $\mathrm{Se}$ \\
\hline \multicolumn{7}{|l|}{ Model 2} \\
\hline ReadMean & 444.50 & 8.02 & 447.90 & 8.34 & 442.10 & 10.58 \\
\hline Country & 297.60 & 191.80 & 327.50 & 209.86 & 537.30 & 344.16 \\
\hline School & 558.90 & 42.70 & 493.00 & 36.74 & 930.40 & 58.54 \\
\hline Student & $6,872.40$ & 69.50 & 6147.10 & 60.45 & $6,209.00$ & 61.27 \\
\hline Total & $7,728.90$ & & 6967.60 & & $7,676.70$ & \\
\hline HISEI & 1.42 & 0.04 & 1.20 & 0.04 & 1.28 & 0.04 \\
\hline \multicolumn{7}{|l|}{ Model 3} \\
\hline ReadMean & 444.20 & 11.66 & 447.50 & 11.74 & 441.00 & 14.20 \\
\hline Country & 655.20 & 416.50 & 667.90 & 424.30 & 979.20 & 623.30 \\
\hline School & 547.50 & 42.20 & 474.90 & 35.80 & 915.80 & 57.70 \\
\hline Student & $6,861.20$ & 69.40 & $6,125.80$ & 60.20 & $6,194.60$ & 61.14 \\
\hline Total & $8,063.90$ & & $7,268.60$ & & $8,089.60$ & \\
\hline HISEI & 1.50 & 0.08 & 1.46 & 0.08 & 1.53 & 0.08 \\
\hline *Denmark & 0.11 & 0.12 & -0.21 & 0.11 & -0.33 & 0.11 \\
\hline *Finland & -0.28 & 0.11 & -0.42 & 0.1 & -0.51 & 0.11 \\
\hline *Iceland & -0.45 & 0.12 & -0.84 & 0.11 & -0.47 & 0.11 \\
\hline *Norway & 0.21 & 0.12 & 0.17 & 0.11 & 0.16 & 0.11 \\
\hline Sweden & Ref. & & Ref & & Ref & \\
\hline
\end{tabular}

Model 2 without interaction and model 3 with $\mathrm{HISEl}^{\star}$ Country interaction ( $>0.05$ significant *terms in italics)

On the country level, the variances increased with HISEI included in the model. This means that if the socio-economic differences are taken into 
account, country differences were even larger. This was mainly due to the high level of reading in Finland and partly in Iceland, and the lower reading scores in Norway.

At the school level, HISEI had its largest effects, and school-level variances decreased 39\%, 31\% and 26\% in 2000, 2003 and 2006, respectively.

At the student level, decreases in variances in 2000, 2003 and 2006 were $8.3 \%, 7.2 \%$ and $10.2 \%$, respectively.

In model 3 (table 4.3.3), the interaction of HISEI*Country is included. The reference country was Sweden. The results showed that the HISEI effects in 2000 were larger in Norway and Denmark than in Sweden and more modest in Iceland and Finland. Since 2003 only Norway has had higher effects for HISEI than Sweden, whereas the HISEI effects were smaller than in Sweden, Denmark, Finland and Iceland, in 2003 and 2006.

\section{Reading and HISEI by countries in 2000, 2003 and 2006}

Results presented above warranted a closer look at national differences. All the three cycles were analysed using separate files for each country for each year, i.e., in 2000 there were five national files, one for each country, as well as in 2003 and 2006. The 2-level models are given in tables 4.3.4, 4.3.5 and 4.3.6 without (basic 2-level model) and with HISEI. Also the values of HISEI (with standard errors, se) for all five countries are presented. In addition, the tables include the explained variances (in \%) for school- and student-levels by the HISEI scores. 
Table 4.3.4. Two-level variance component models for reading literacy in 2000 , for all Nordic countries, one without HISEI and the other with HISEI

\begin{tabular}{lllrrrr}
\hline & HISEI (se) & School variance & exp\% & Pupil variance & exp\% \\
\hline \multirow{2}{*}{ Denmark } & basic 2-level model & & $1,479.88$ & & $7,509.92$ & \\
& with HISEI & $1.62(0.09)$ & $6,74.58$ & 54 & $6,766.56$ & 10 \\
\multirow{2}{*}{ Finland } & basic 2-level model & & $5,85.08$ & & $6,515.49$ & 7 \\
& with HISEI & $1.20(0.07)$ & 463.8 & 21 & $6,079.9$ & 7 \\
\multirow{2}{*}{ Iceland } & basic 2-level model & & 684.75 & & $7,217.53$ & \\
& with HISEI & $1.05(0.09)$ & 537.5 & 22 & $6,790.4$ & 6 \\
\multirow{2}{*}{ Norway } & basic 2-level model & & 968.48 & & $9,148.52$ & \\
& with HISEI & $1.73(0.1)$ & 660.53 & 32 & $8,235.58$ & 10 \\
\multirow{2}{*}{ Sweden } & basic 2-level model & & 741.03 & & $7,191.37$ & \\
& with HISEI & $1.52(0.08)$ & 374.39 & 50 & $6,576.02$ & 8.5 \\
\hline
\end{tabular}

Table 4.3.5. Two-level variance component models for reading literacy in 2003 , for all Nordic countries, one without HISEI and the other with HISEI

\begin{tabular}{|c|c|c|c|c|c|c|}
\hline & & HISEI (se) & School variance & exp\% & Pupil variance & $\exp \%$ \\
\hline \multirow[t]{2}{*}{ Denmark } & basic 2-level model & & $1,325.13$ & & $5,361.92$ & \\
\hline & with HISEI & $1.18(0.08)$ & 960.68 & 28 & $5,025.26$ & 6.3 \\
\hline \multirow[t]{2}{*}{ Finland } & basic 2-level model & & 273.77 & & $5,155.76$ & \\
\hline & with HISEI & $1.03(0.06)$ & 209.01 & 24 & $4,838.5$ & 6.2 \\
\hline \multirow[t]{2}{*}{ Iceland } & basic 2 -level model & & 353.56 & & $7,950.81$ & \\
\hline & with HISEI & $0.63(0.1)$ & 284.06 & 20 & $7,640.04$ & 4 \\
\hline \multirow[t]{2}{*}{ Norway } & basic 2-level model & & 783.82 & & $8,264.7$ & \\
\hline & with HISEI & $1.66(0.1)$ & 546.66 & 30 & $7,460.54$ & 9.7 \\
\hline \multirow[t]{2}{*}{ Sweden } & basic 2-level model & & 785.52 & & $7,184.32$ & \\
\hline & with HISEI & $1.48(0.08)$ & 404.36 & 49 & $6,470.74$ & 9.9 \\
\hline
\end{tabular}


Table 4.3.6. Two-level variance component models for reading literacy in 2006, for all Nordic countries, one without HISEI and the other with HISEI

\begin{tabular}{lllrrrr}
\hline & & HISEI (se) & School variance & exp\% & Pupil variance & exp\% \\
\hline \multirow{2}{*}{ Denmark } & basic 2-level model & & $1,467.00$ & & $5,889.00$ & \\
& with HISEI & $1.18(0.07)$ & $1,063.00$ & 28 & $5,403.00$ & 8.3 \\
\multirow{2}{*}{ Finland } & basic 2-level model & & 660.00 & & $5,253.00$ & \\
& with HISEI & $1.01(0.06)$ & 542.00 & 18 & $4,895.00$ & 6.8 \\
\multirow{2}{*}{ Iceland } & basic 2-level model & & $1,166.00$ & & $7,571.00$ & \\
& with HISEl & $1.07(0.09)$ & $1,041.00$ & 11 & $6,952.00$ & 8.2 \\
\multirow{2}{*}{ Norway } & basic 2-level model & & $1,271.00$ & & $8,655.00$ & \\
& with HISEI & $1.71(0.08)$ & $8,36.00$ & 34 & $7,398.00$ & 14.5 \\
\multirow{2}{*}{ Sweden } & basic 2-level model & & $1,565.00$ & & $7,314.00$ & \\
& with HISEl & $1.52(0.08)$ & $1,123.00$ & 28 & $6,437.00$ & 12.0 \\
\hline
\end{tabular}

The socio-economic index explained school variances in 2006 from the lowest level of $11 \%$ (Iceland) to the high level of 34\% (Norway). The explained proportions of student-level variances in 2006 ranged from the lowest value of $6.8 \%$ (Finland) to the highest value of $14.5 \%$ (Norway).

\section{HISEI-coefficients as a summative index}

The values of HISEI 2000, 2003 and 2006 for the Nordic countries differed from each other, as can be seen in table 4.3.7, in which HISEI means including standard errors are presented. The values of the coefficients and their standard errors have been estimated using multilevel modelling, and the coefficient is the effect of HISEI in modelling the mean reading score. The HISEI was higher in Norway and Sweden and lower in Denmark, Finland and Iceland. A high value of HISEI indicated a higher social and economic disparity, which appeared to be the case in Norway and Sweden. The trend, or change by cycle, was that HISEI did not change in Norway and Sweden, and their coefficients were consistently higher than in Iceland or Finland. The coefficients of Denmark decreased from 2000 to 2003, after which it remained the same from 2003 to 2006 . 
Table 4.3.7. HISEI-coefficients by PISA cycles $(2000,2003,2006)$ and by country

\begin{tabular}{lllllll}
\hline & hisei 2000 & Se & hisei 2003 & Se & hisei 2006 & Se \\
\hline Denmark & 1.62 & 0.09 & 1.18 & 0.08 & 1.18 & 0.07 \\
Finland & 1.20 & 0.07 & 1.03 & 0.06 & 1.01 & 0.06 \\
Iceland & 1.05 & 0.09 & 0.63 & 0.10 & 1.07 & 0.09 \\
Norway & 1.73 & 0.10 & 1.66 & 0.10 & 1.71 & 0.08 \\
Sweden & 1.52 & 0.08 & 1.48 & 0.08 & 1.52 & 0.08 \\
\hline
\end{tabular}

Using both the HISEI coefficient and the respective standard errors in a two-step cluster analysis indicated that there were two solutions: either all the Nordic countries belong to the same cluster (the one cluster solution) or Denmark, Finland and Iceland form one cluster, and Norway and Sweden another cluster (the two cluster solution). Using the K-means cluster, one cluster comprised Finland and Iceland, and another Denmark, Norway and Sweden. In essence if we draw a research conclusion, there seems to be one cluster consisting of Finland and Iceland with low HISEI coefficients, and another cluster of Norway and Sweden with high HISEI coefficients. Denmark occupied a middle position. The oscillation of Denmark between the cluster groups in different analyses seems to be due to the relatively high HISEI coefficient in 2000 and the decreased value of the index in 2003 and 2006. It is worth bearing in mind that the higher the HISEI coefficient, the lower the equity balance with regard to this socio-economic indicator.

\section{HISEI coefficients by PISA cycles and by countries}

The estimated HISEI values are the core of the analysis. The HISEI or socio-economic effects are all different from zero, that is, the socioeconomic background of the family still appears to exert an influence on scholastic achievement. This is hardly unexpected, but it is a fact to be looked at more thoroughly and pondered over. In principle, according to the equity model, schools should be one means of evening out socioeconomic differences. However, there are secondary effects connected to the interaction between the family related to the origin of the pupils and the extent to which they are capable of benefiting from their school education. In accordance with the St. Matthew effect (Dencik, 1989; Hau- 
tamäki, 2000), the children during their educational career appear to benefit in an ever-increasing, cyclic-cumulative way from their parents' education and social position. This means that socio-economic factors in the Nordic welfare states also play a role in explaining a part of the variance in schooling. Thus, it is important to keep an eye on HISEI effects. If these effects are growing in the educational system, the outcomes will increase social inequality and constitute a moral problem in egalitarian oriented societies.

In all Nordic countries there were differences between schools in relation to socio-economic factors, i.e., how homogeneous or heterogeneous the schools were in socio-economic composition. In particular, this is the case in Norway and Sweden. In these countries it is important to reconsider educational policy, and evaluate the pros and cons of educational reforms or societal processes that have favoured a diversification of schools, even promoting segregation in terms of socio-economic factors. However, there should also be certain degrees of freedom for suitable tracking and diversification based on the needs and wishes of students.

The independent score is the mean of plausible values. This means that results are not directly comparable to other studies using multivariate modelling, in particular, if the reading scores have been estimated using other solutions. In Finland, Malin (2005) used weighted likelihood estimates when analysing the 2000 reading outcomes. Malin presented slightly different variance components, according to which the total variance was found to be 7,742, as compared to the present variance estimate of 7,100 in Finland. We are not aware of other multilevel studies of PISA data in other Nordic countries. This difference in results should be taken as a warning against jumping to hasty conclusions. In order to have a well-founded opinion, several independent studies using different estimates are needed (see other articles in this book).

The role of international studies such as PISA is to provide an option to look at national processes and outcomes, for example, to have access to data on the basis of which educational outcomes in relation to educational polices in the Nordic countries can be compared. If educational outcomes are not in accordance with the original blue-print of schooling in Nordic countries, PISA data may point out how to proceed in changing educational policies. 


\section{References}

Ganzeboom, H.B., De Graaf, P., \& Treiman, D.J. (1992). A standard international socio-economic index of occupational status. Social Science Research, 21, 1, 1-56.

Dencik, L. (1989). Growing-up in the post-modern age: On the child's situation in the modern family, on the position of the family in the modern welfare state. Acta Sociologica, 32, 155-180.

Hautamäki, A. (2000). The matrix of relationships in the late modern family in the Nordic countries: A haven in a heartless world, a disturbed nest or a secure base? In A. Hautamäki (Ed.), Emergent trends in early childhood education - towards an ecological and psychohistorical analysis of quality. University of Helsinki, Department of Teacher Education, 216.

Malin, A. (2005). School differences and inequalities in educational outcomes. PISA 2000 results of reading literacy in Finland. Research Reports 15. Jyväskylä: Institute for Educational Research.

(name: 090415ReadHisei000306.doc - revised 16.4.2009)

\section{Appendix}

\section{Excel modelling of the HISEI effect}

The outcomes have been calculated for each of the Nordic countries in Excel using the 2006 hisei coefficients and the starting level of reading in different Nordic countries, for hisei values of $1,20,40,60,80$, and 90 to show that these coefficients have powerful effects. In Norway and Sweden there is a bigger difference between students with the highest and lowest hisei values than in Finland or Iceland. 


\section{Summary and comments}

Tomas Matti, Kerstin Mattsson, Kristian Ramstedt \& Anita Wester

The Nordic countries are situated in the north-western corner of Europe and consist of Denmark, Finland, Iceland, Norway and Sweden. The Faroe Islands and Greenland, both of which are autonomous under Denmark, as well as Åland, which belongs to Finland, are also parts of the Nordic countries. The two last mentioned territories will not be covered in this report.

The Nordic countries are seen as a territory with common roots for more than a thousand years. One connecting factor is the linguistic community for all the countries, with the exception of Finland. It is however, important to remember that Swedish is an official language in Finland, spoken by 6 percent of the population. Over the years the Nordic countries have been involved in several wars against each other, but have also formed unions with varying constellations. Nowadays their relations are characterized by agreement and collaboration. One example is the Nordic Council constituted in 1952 which is an agency for cooperation between the Nordic parliaments. A second example is the common Nordic labour market which was established in 1954, and a third is the Nordic Council of Ministers, an agency for cooperation between the Nordic governments, constituted in 1971.

The countries are similar in many ways, but also different, and this provides a good basis for examining how the results from PISA vary between the countries, and if these variations can be explained by differences in attitudes, instructional practice, organization of education, or other factors relevant to educational outcomes.

Why do Finnish students outperform students in other Nordic countries? Could one explanation be that the teaching profession is still popu- 
lar in Finland? How important is engagement in reading and reading ability? Are the instruments used in PISA valid for measuring the competences and knowledge needed today and in the future? These are examples of questions asked, discussed and at least to some extent answered in this anthology, which focuses on the results in science in PISA 2006.

According to Lysne (2006), the Nordic countries have on the whole followed parallel lines of development regarding educational issues, even though their reforms and changes have not been introduced at the same time in all countries. The general pattern seems to be that Sweden has been the leading country in the implementation of educational reforms and is about 5 to 10 years ahead of the other Nordic countries.

The compensatory role of education with the aim of levelling out social differences and giving all students the same opportunities for learning is an important feature of the policy for increased equity and equality in the Nordic countries. This is reflected in the introduction of a coherent nine-year compulsory school system that took place during the 60s and the 70s in all countries, except the Faroes where 9 years schooling became compulsory in 1997. In addition, the view of education as socialisation, shaping, and preparing the student for higher education, for professional life and becoming an active member in society is common to the Nordic countries.

The degree of centralization of the educational systems varies in the Nordic countries. Denmark and Iceland are now moving from a decentralized to a more centralized system while the opposite has been true for Sweden and Finland in the 90s. Norway has had the most centralized system with a high degree of national control but is now becoming more decentralized in line with the other Nordic countries. In the Faroe Islands teachers' salaries are paid centrally while costs of premises and teaching materials are paid by the municipalities themselves.

The number of independent schools is low in all Nordic countries - with the highest frequency in Denmark 12 percent) and Sweden (9 percent).

Thus, in many domains the changes and reforms in education have developed parallel in the Nordic countries. But there are areas with differences, such as the use of grades, type of grading scales, use of national tests and the presence of exams.

In Finland and Sweden there are no formal exams and no centrally constructed tests for a final school certificate which is the case in the 
other Nordic countries. National tests with the aim of supporting grading are mainly used in Sweden, while in Denmark, Norway and the Faroe Islands the national tests are more focused on evaluation at different levels. In Finland there are no national tests for all students, but a sample of students take a test every year. The basis for grading and the grading scales also varies among the Nordic countries. The number of levels in the grading system is different - in Sweden 4 levels are used, in Norway 6 levels, in Finland and Denmark 7 levels, in Iceland and the Faroe Islands 10 levels. Finland differs from the other countries by using a grading scale which has not been changed in the last century.

The Nordic countries differ from many other countries by not grading students until the last years of compulsory schooling.

PISA has been carried out three times so far - in 2000, 2003 and 2006. In 2000 reading literacy was the main domain with mathematics and science as minor domains, in 2003 the main domain was mathematics and in 2006 it was science.

Finland outperforms the other Nordic countries - and all other countries - in the three domains in all three measurements. The results in Sweden, Norway and Denmark have varied around the OECD-average over the years. The Faroe Islands participated only in PISA 2006 with low scores in all three domains.

In Denmark and Finland the results are quite stable over time, while the Swedish, Norwegian and Icelandic results have to some extent declined throughout the years in all three subjects.

The results from IEA's studies TIMSS 1995, 2003 and 2007, and PIRLS 2001 and 2006 also show partly similar patterns.

Sweden and Norway both participated in IEA's TIMSS study among 14 year olds in 1995, 2003 and 2007 and the downward trend in the results in both mathematics and science is very similar for the two countries.

In PIRLS, an IEA study on reading comprehension among $4^{\text {th }}$ year pupils, show a downward trend in results for Sweden between 2001 and 2006, while the results in Norway and Iceland are quite stable, remaining at a low level in the two measurements.

Thus, it seems that there is no clear connection between early grading, national tests, the use of exams, and the existence of a modern grading system and success in PISA. 
A comparison of the science curricula in the Nordic countries in chapter 2.1 showed that the national ambitions for science education seem to be similar, at least on a general level. The curricula are also generally compatible with the competences described in the PISA 2006 framework. On a more concrete level there are, however, differences between how specific the national curricula and syllabi are and how integrated the different subjects are in the science field. In general one could argue that the Finnish steering documents and practices are the most subject oriented, while the other countries seem to be more inclined to integrate. There are also differences between Finland and the rest in other respects as well. The Finnish curriculum puts more emphasis on the number of hours spent on science education than the rest. Finnish teachers are more specialists in their subjects than teachers in the other Nordic countries and they need a Master's degree. So even though ambitions in the Nordic countries are similar on a superficial level there are interesting differences that should be an issue for deeper analyses.

In comparison with the OECD in general, the Nordic countries do not use between-class streaming to the same degree. Instead, within-class streaming is used to a varying extent. The between-school variation is the lowest among the OECD countries.

The supply of science teachers is good according to principals in Finland and Sweden, but less satisfactory in the other countries.

A vast majority of students spend a maximum 2 hours per day on school homework in all the Nordic countries.

In Finland students' mean scores are the highest of all participating countries. Finnish students are roughly between one and a half to two years ahead of the other Nordic countries! This is remarkable, and as we ask ourselves the reason for this gap, we also ask what consequences this gap could have. What does Finland being at the leading edge mean for Finland? Does it affect, for example, the labour market in any way? Any studies on that question would possibly be difficult to carry out but the question is nevertheless interesting.

When comparing each question on the PISA 2006-test, the Nordic countries are clustered and stand out from all other countries. This indicates that the Nordic countries show similarities in their strengths and weaknesses on single items. The Scandinavian countries, Norway, Denmark and Sweden have particularly high inter-correlations, whilst Iceland 
and Finland have slightly less in common in this respect. Comparing with countries outside the Nordic countries, it is shown that the Germanic countries have the highest correlation with the Nordic countries and thereafter the Anglo-Saxon countries. This way of looking at results is interesting in itself, but we want to ask if this could have any impact on educational policies?

If we speculate a little, we could say that this is a result of a more or less common history. The similarity has historical roots. If results in schools are hard to change, this finding may support the idea that when looking for changes in the educational system, the area to start examining is possibly those countries where there are similarities.

When it comes to computer based tests in Iceland, Denmark and South Korea, boys did better than girls. The question then asked was; why? In the article about computer based tests, the authors reason that it could be because the tests themselves were easier to do on computers than as paper based tests, and that this benefits the boys. Girls seem to do better when the test is harder and the texts are longer. This finding focuses on how to construct tests, and what they actually measure. Questions like this are always important, and we could ask if the PISA-tests in general have benefited girls more than boys?

The question about interest in reading and its implications for the result on tests about reading capacity has shown interesting results. Students with relatively high socio-economic backgrounds but weak interest in reading do much worse on tests than students with great interest in reading combined with relatively low socio-economic background. Interest in reading beats socio-economic background! This is interesting, not least because socio-economic background is usually a good predictor of test outcomes. It would be interesting to know if those students with low socio-economic background and good results on the test continue to higher education more than predicted, or if the educational level of their parents is a stronger variable.

In Norway, especially, boys had weak results in reading in year 2000 and they showed a weak interest in reading. To get better results, Norway wanted to increase interest in reading. They succeeded in raising interest in reading in the PISA-test 2006, but it still seems too early to say how the increase in reading interest will affect the test results. Maybe the PISA 
tests in 2009 and 2012 will give better answers to that question, when they have reached the age to be tested in PISA.

Since the middle of the 20th century when the idea of a comprehensive nine year school for all took form in the Nordic countries, one of the basic ideas has been that school should compensate for poor home conditions. In Sweden many studies into the so called "reserve of talent" were carried out. Researchers were able to show, for example based on results from military service tests, that many young men from families with no tradition of academic studies reached high scores on the intelligence tests that were used. The basic idea was that if society offered all young people equal opportunities to study, then the talented would take advantage of the opportunity, and a double win situation would occur. The individual could develop her/his potential to get a better position and better life, and society would get a better educated work force.

Unfortunately it soon became obvious that it wasn't that easy. Individual talent and opportunities provided by society were not sufficient to bring talented young people from groups with, what was later called, low socio-economic status to apply for further studies in upper secondary school, and later on to higher education. White collar students in comprehensive school used the opportunities to a much higher degree than blue collar students. The so called "social inheritance", lack of social and cultural capital turned out to be much more important and influential than the early reformists had ever imagined. The school as a tool to compensate for poor contextual factors turned out not to be very effective.

However, the ambition remains, and all the Nordic school systems emphasise equity and fairness, and aim at providing equal opportunities for all students and to compensate for different socio-economic and other circumstances. In chapter 4 some studies examining the current situation in the Nordic countries are presented. In chapter 4.1 the concepts level and balance are used. Level is a composite measure of the three literacies and balance is a measure whether a country has reached better results in reading than in mathematics and science (a positive value) or the opposite.

Finland has as in other measures the highest value on level, and outscores by far the other four Nordic countries. On the balance measure Finland and Norway have a value close to zero, which indicates small differences between results in reading and results in math and science. The difference in level, on the other hand, is big. Sweden has a strong 
positive value on balance indicating a much stronger ability in reading literacy than in mathematical and science literacy. Iceland and Denmark on the other hand have negative values indicating the opposite relationship. The study also shows that female results on balance not surprisingly are highly positive while male results are stronger in math and science.

In chapter 4.2 results are analysed in relation to ESCS, a measure of parent's financial, cultural and social status. Iceland and Norway have the highest values (at least this was the case when the study was conducted), followed by Denmark, Sweden, Finland and the Faroe Islands. The result of the analysis shows that Sweden has the highest between school variance followed by Denmark and Norway. What could be noticed is that the overall impact of socio-economic background is about the same in all the Nordic countries. The differences between the countries are then mainly due to different socio-economic conditions on school level rather than on student level. Other effects such as peer effects can also be influential on school level.

Chapter 4.3 provides results from the reading literacy assessment related to different socio-economic factors aggregated in HISEI, an index based on student answers about their parents' occupation. In this respect it is related to the ESCS measure used in chapter 2. This study also points out significant differences between student groups with different socioeconomic backgrounds. Even though it is a well known fact that the Nordic countries compared to other countries have generally had relatively low differences, this is a matter of concern. In Sweden and Denmark the socio-economic gradient is around the OECD-average, in Norway it is slightly below, and in Finland and Iceland it is significantly below the OECD-average, implying that the student's socio-economic background has less influence on PISA performance. What might be of concern from what is shown here and from other sources is that the importance of socio-economic factors, and thus also of ethnicity, seems to persist to some extent. The general vision of equity and a school that is able to compensate for lack of socio-economic resources still seems to be far away. And what perhaps is even more disturbing is that in some countries the trends seem in fact to be going in the opposite direction. 